CALL TIMING INTERACTIONS, AGGRESSIVE BEHAVIOR, AND THE ROLE OF ACOUSTIC CUES IN CHORUS FORMATION IN TREEFROGS

A Dissertation
presented to
the Faculty of the Graduate School
at the University of Missouri-Columbia

In Partial Fulfillment

of the Requirements for the Degree

Doctor in Philosophy

by
CARLOS C. MARTÍNEZ-RIVERA

Dr. H. Carl Gerhardt, Dissertation Supervisor

July 2008 
C Copyright by Carlos César Martínez Rivera 2008

All Rights Reserved 
The undersigned, appointed by the Dean of the Graduate School, have examined the dissertation entitled

\section{CALL TIMING INTERACTIONS, AGGRESSIVE BEHAVIOR, AND THE ROLE OF ACOUSTIC CUES IN CHORUS FORMATION IN TREEFROGS}

Presented by Carlos C. Martínez Rivera

A candidate for the degree of Doctor of Philosophy

And hereby certify that in their opinion it is worthy of acceptance

Professor H. Carl Gerhardt, Chair

Professor Reginald B. Cocroft

Professor Mark R. Ryan

Professor Johannes Schul

Professor Raymond D. Semlitsch 
Treading through a Louisiana bayou full of treefrogs and gators on a warm summer night on 2004, I couldn't help but think about the words that Mario said to me earlier that day as I won my first (and only) pool game against him. He said: "Yo no sé porqué siempre te ha gustado bregar con sapos y jodiendas, pero me gusta que vengas pa'cá los veranos". Mario works for the Army Corps Engineers in Vicksburg, Mississippi and he is also my cousin; I had been using his home as my field house for the previous three summers while working on bird-voiced treefrogs. Unfortunately, that same year I moved my sites to Tennessee and South Carolina. Latter I went off chasing Canyon Treefrogs far west into the Grand Canyon in the Hualapai Nation and Zion National Park, Utah. We barely see each other anymore and we certainly don't talk much nowadays; we're buried way too deep in things more important than pool, beer, and music (if there should ever be such a thing). But what he said to me before I went off to the field that night, which roughly translate to: "I don't know why you've always liked playing with frogs and stuff, but it's good to have you around every summer", still rings in my head today as loud as a bird-voiced treefrog. I hope to keep playing with frogs and stuff for as long as I can, even if I don't get a chance to spend as much time with my family and friends as I would like to.

For some of us, biology becomes a way of life. In the process, there are many stages and milestones where someone was there to make your life more fascinating (or complicated) and pushes you over the threshold into a new stage. I remember that as s a high-school student, I would make my dad drive all the way from San Juan to Mayagüez (on a school day, of course) so that Dr. Juan A. Rivero could identify the amphisbaenians that Miguel and I found in an old coffee plantation in the mountains of Lares, Puerto 
Rico. Later as an undergrad, Fernando Bird, Gary Breckon, and Duane Kolterman, all patiently and eagerly took me under their wing as I constantly pestered them with every imaginable question about Coquí frogs, Mona Island Iguanas and rainforest ferns. There were also the never ending discussions with Spanish professor Alberto Martínez about who was a better songwriter, Silvio or Milanés? During those early years, the Asociación de Estudiantes de Biología served as refuge for our kind where Alberto, Omar, Iván, and Vecky just to mention a few, worked our way each year to scrape up a trip to Mona Island with Gupi and Icky. It was also the time where Antonio Soto and I met our respective fates and started to think of Puerto Rico as a closing chapter, ready to start a new life on the other side of the pond. I remember telling Carl on my first visit to Columbia that I wanted to apply all the gray treefrog knowledge to the Coquís back home, of course I knew next to nothing about behavioral ecology then. But with time came that infamous OTS trip to Costa Rica, "el parteaguas" (the crossroad) as Ruth precisely called it, and upon my return Mike Smith and Yikweon became more than lab mates, they became friends, buddies, brothers, mentors that guided me through the harshest of times both professionally and personally. Then a brief, albeit intense, period of fun and games (and plenty of beers) on McNally's and Walnut 414 with Chris, Harvey, Dani, Jakey and Demian. During the final stage of my life as a graduate student, the eve of a new beginning, a different start and a passion for traveling combined with a thirst for more and more that almost drowned me in a Ph. D. that lasted the better part of 7 years (almost a $1 / 4$ of my life!) But here it is, a finalized product that documents only a mere fraction of my many adventures with frogs and stuff in a quest to ask why they behave the way they do and what benefits, if any, they get from doing the things they do. 
Oh, and one last thing, a very special thanks to Noah Gordon who helped cover my labs through most of my travels.

\section{Dedico este trabajo:}

... a la mama gallina

... a Evelyn y a César, a Carlos y a Keryl, a Evie Marie y a los Freds, a Normita, Grace y Christian, a mama Flora, a titi Miriam, a Mario Jorge y Crystal, a Lucero y al resto de mi familia.

... y a mis otros hermanos (as) Maridalia Arzuaga, Miguel Irrizary, Yikweon Jang, Alberto González Negrón, Omar Monsegur, Michael J. Smith y Ricardo Valentín.

... a Carl, mi padre en Missouri. 


\section{Interesting quotes:}

"If we can discover the meaning in the trilling of a frog, perhaps we may understand why it is for us not merely noise but a song of poetry and emotion."

\section{Adrian Forsyth}

"If we get the frogs wedded, the Varuna, the god of the oceans, will bless us with rains,"

Beni Prasad, a farmer in the village of Khapa, India.

"Le deben al silencio, la voz los ruiseñores"

(Songbirds are forever indebt to silence for the marvel of their voice)

Silvio Rodríguez

“... cada cantor es una buena noticia, porque cada cantor es un soldado menos"

(... every singer is good news, for each signer is one less soldier)

Facundo Cabral 


\section{ACKNOWLEDGEMENTS}

This dissertation was possible thanks to the help and technical (and moral) support of Carl Gerhardt, S. Adams, Maridalia Arzuaga, Johnette Blair, Amanda Bockhorst, Miltiza Bonet, Jessica Borroughs, Adam Boyette, Leroy Brown, Amandy Carranza, Rex Cocroft, Chris Conner, Choncho, Richard Daniels, Drew Dittmer, Michelle Drew, Nila Emerich, Dayna Glanz, Noah Gordon, Jennifer Hamel, Julie Harding, Joshua Hartley, Gerlinde Höbel, Daniel Hocking, Tim Holtsford, Sara Humfeld, Yikweon Jang, Bob Jones, Geroge K., Katy Klymus, Tyeece Little, Alan Marshall, Vincent Marshall, César Martínez, Zapic Martínez, Amy Miles, Danielle Miller, Courtney Nicholas, Meredith Peebles, Evelyn Rivera, Saraí Rivera, Rafael Rodríguez, Mark Ryan, María Belén San Martin, Danielle Sattman, Santiago Schalamuk, Johannes Schul, Josh Schwartz, Michael Smith, Ray Semlitsch, Jacob Soule, María de los Angeles de la Torre Cuadros, María Alejandra Troncoso Joffre, Kristy Wharton, Mitch Tucker, Si Yol Yi.

Funding was provided by a competitive grant for Graduate Assistance in Areas of National Needs from the U.S. Department of Education, a Doctoral Dissertation Improvement Grant from the National Science Foundation, multiple Research Assistantships provided by H. Carl Gerhardt, multiple Teaching Assistantships provided by the Division of Biological Sciences (thanks Ace) and a Scholarship for Excellence in Advance Studies from the Department of Education of the city of Mayagüez, Puerto Rico (thanks Nila for signing the same piece paper over and over every semester for the past 8 semesters!). 


\section{TABLE OF CONTENTS}

ACKNOWLEDGEMENTS ....................................................ii

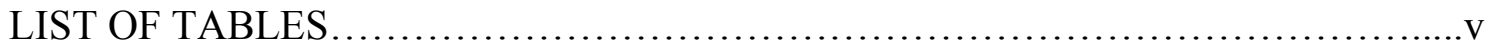

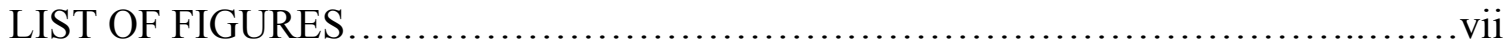

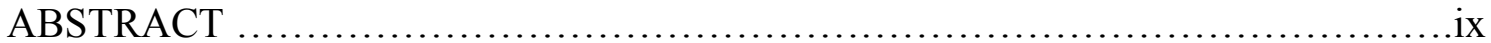

Chapter 1: Introduction.......................................................

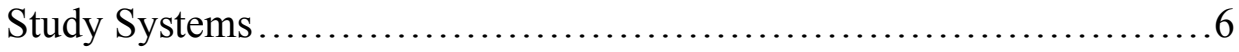

Literature Cited.....................................................

Chapter 2: Advertisement-call modification, male competition and female preference in the bird-voiced treefrog Hyla avivoca

Abstract.................................................................... 11

Introduction............................................................. 12

Methods............................................................... 15

Results............................................................25

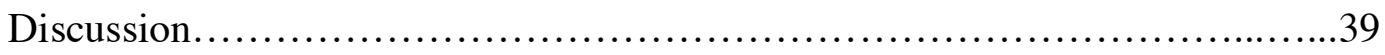

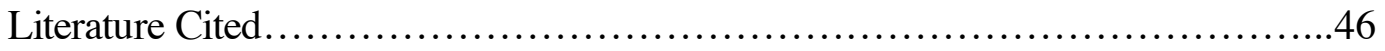


Chapter 3: Agonistic interactions in treefrogs I: Chorus organization, aggressive calling, and fighting

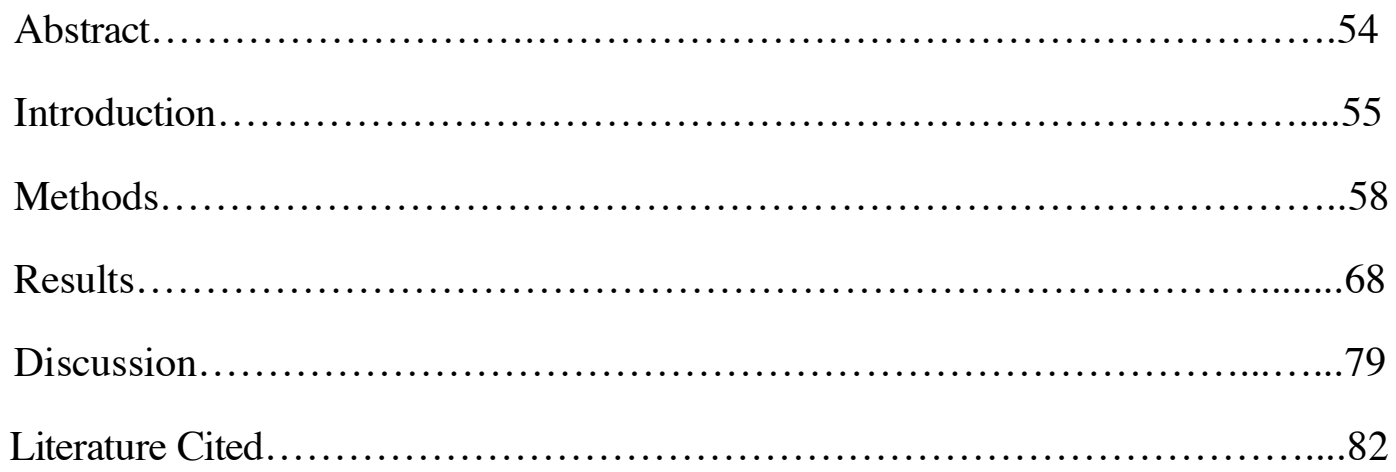

Chapter 4: Agonistic interactions in treefrogs II: Evolution and behavioral relevance of aggressive calling and fighting

Abstract..........................................................92

Introduction......................................................93

Methods.......................................................... 94

Results.........................................................101

Discussion...................................................... 112

Literature Cited ........................................................... 116 
Chapter 5: Role of acoustic signals in chorus formation in treefrogs

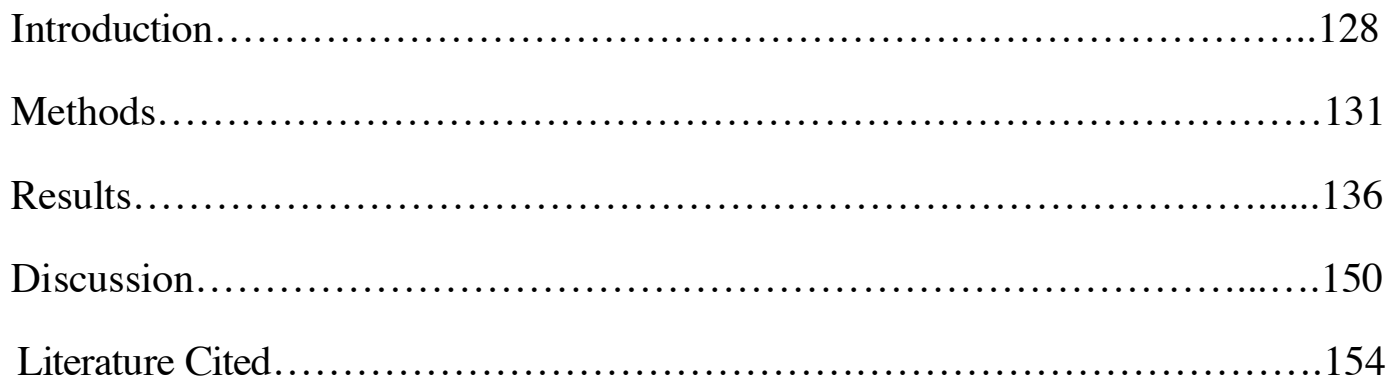

Chapter 6: General Discussion........................................... 160

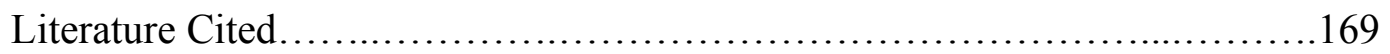

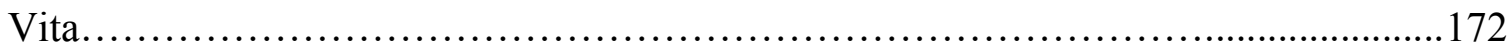




\section{LIST OF TABLES}

\section{Chapter 2}

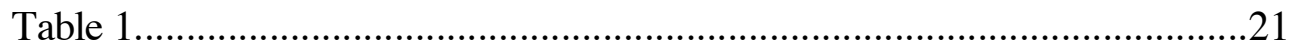

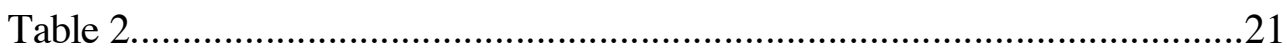

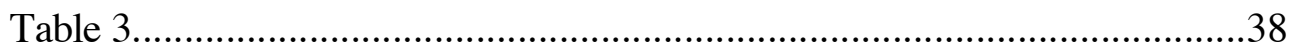

Chapter 3

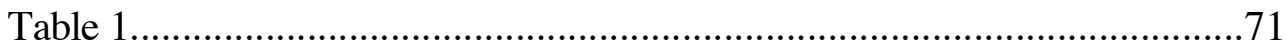

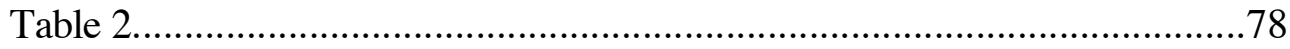

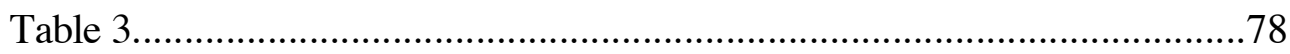

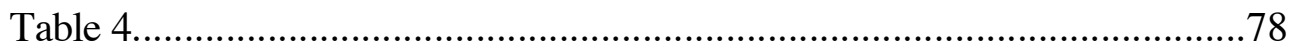

\section{Chapter 5}

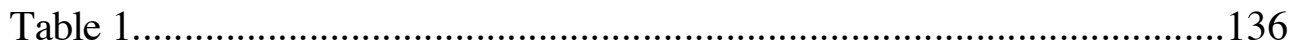

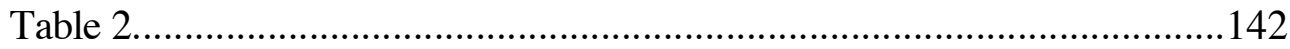

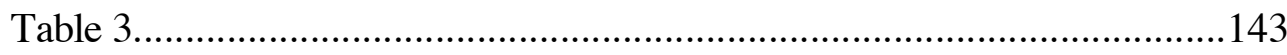

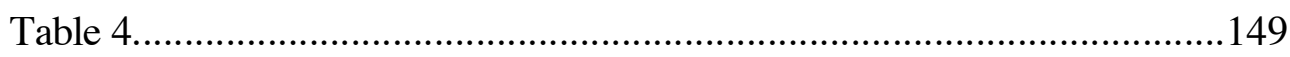




\section{LIST OF FIGURES}

\section{Chapter 2}

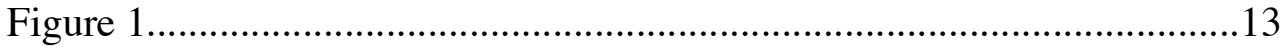

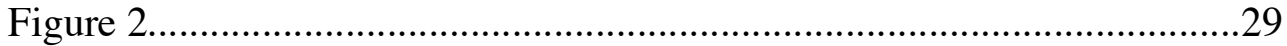

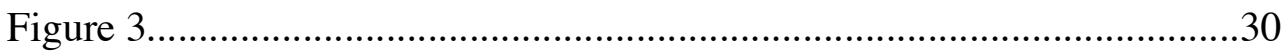

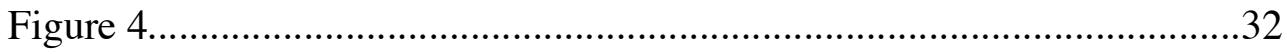

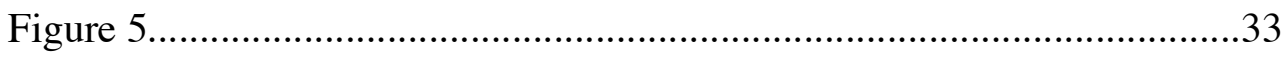

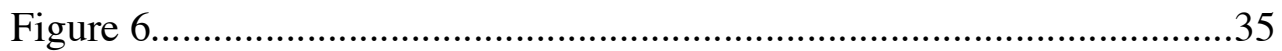

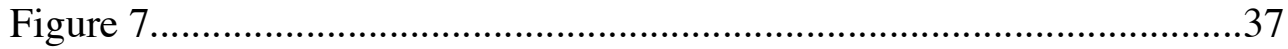

Chapter 3

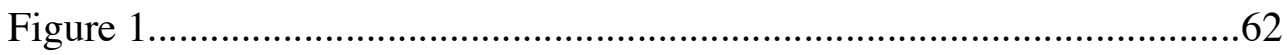

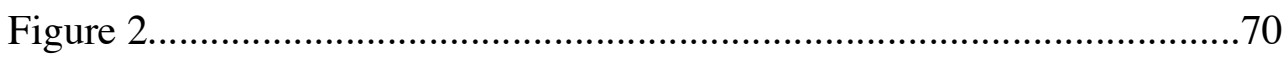

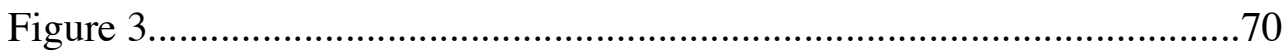

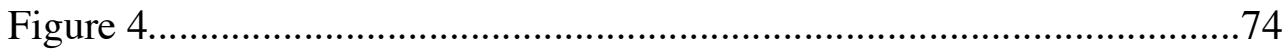

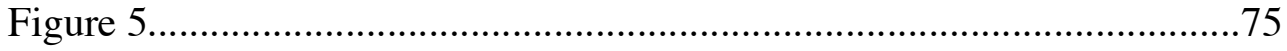

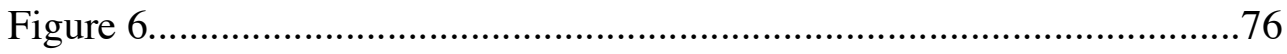

\section{Chapter 4}

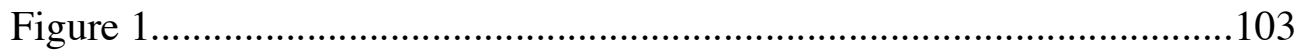

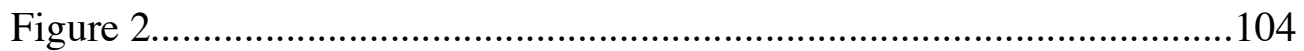

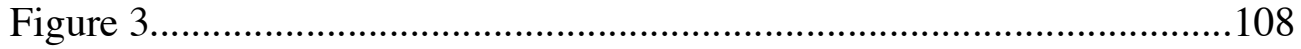

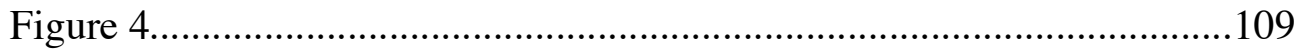

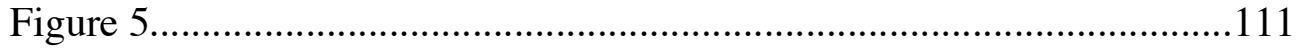


Chapter 5

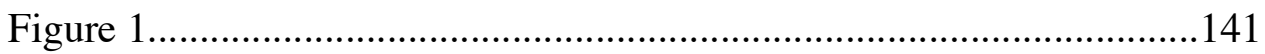

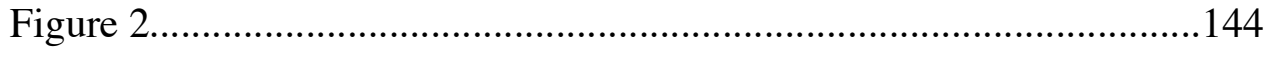

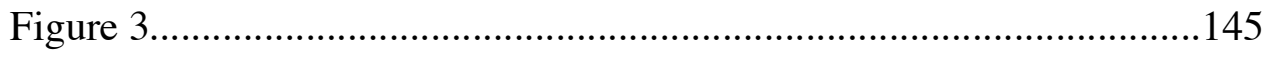

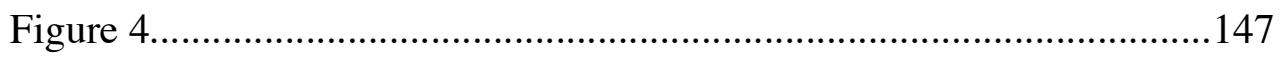




\title{
CALL TIMING INTERACTIONS, AGGRESSIVE BEHAVIOR, AND THE ROLE OF ACOUSTIC CUES IN CHORUS FORMATION IN TREEFROGS
}

\author{
Carlos C. Martínez Rivera
}

Dr. H. Carl Gerhardt, Dissertation Supervisor

\begin{abstract}
I studied calling patterns and aggressive behavior of the Bird voiced treefrog, Hyla avivoca, to assess how dynamic call characters influences males and the factors influencing the onset of choruses and settling patterns of males in a chorus. Choruses are dynamic, socially complex communication networks that function as focal points for sexual selection. Frogs calling in groups produced longer calls, overlapped calls, and engaged in aggressive calling and fights. During call overlap, males increased duration of the silent interval between pulses so that these interdigitated. Males resort to aggression during the early hours of chorus formation, before females arrival, and engage in fights without showing signs they evaluate the opponent's ability. Females preferred long, nonoverlapped calls to overlapped calls and overlapped calls with pulse interdigitatio. Females do not respond to aggressive calls alone, but approached combinations of advertisement and aggressive calls. I also studied the role of acoustic signals on chorus formation and location and found that males may benefit from settling next to attractive males and that calls influences the behavior of males by attracting individuals to the established chorusing area, and to new areas within the breeding area in some species.
\end{abstract}




\section{Chapter 1}

\section{Introduction}

Visiting a wetland or rainforest at night during the breeding season of frogs guarantees an impressive experience of choruses of hundreds or even thousands of frogs of many species calling in an effort to attract a mate. Choruses of frogs and insects are dynamic, socially complex networks, which vary in duration, species composition, density, and in the spatial arrangements of calling individuals (Bradbury and Vehrencamp 1998). Choruses are also focal points for sexual selection (Blair 1958; Gerhardt and Huber 2002) where signalers interact with other individuals for calling sites, and potential mates must locate and choose signalers mainly based on the acoustic properties of the signals.

A first step in understanding evolutionary processes such as the dynamics of acoustic communication and sexual displays in a chorus is to study sexual selection and mate choice (Andersson 1994). In most animals, one of the sexes, usually males, performs a display in an effort to attract and mate with the other sex. The choosing sex, generally females, affects the evolution of communication systems by selecting a displaying male with a specific set of characteristics. Hence, those males selected are favored in the population along with their genes. However, there are various physical and biological factors shaping the outcome of displaying males. A lek is an aggregation of males displaying in arenas in an effort to attract females and mate (Höglund and Alatalo 1995). 
Leks are an example where not only female preference has shaped the evolution of the display, but other forces, like predation and male-male competition, have certainly played a role (Höglund and Alatalo 1995). Males of species that display from leks offer only sperm to their mates, and it is assumed that female choice has driven most of the evolution of this particular mating behavior (Höglund and Alatalo 1995). Empirical evidence shows that females of most species where males display from leks choose males with certain display traits when given the opportunity (Bourne 1992; 1993; Sullivan 1982a; Grafe 1997; Friedl and Klump 2005). Moreover, it has been shown that for some anurans, the preference exerted by females results in more successful and competitive offspring that perform better in their initial stages of development (Welch 1999). Several hypotheses have been proposed for the evolution of leklike choruses in anuran amphibians, namely (1) forming choruses near oviposition sites (hotspot model), (2) attraction of females to sub-groups within a chorus (hotshot model) (3) attracting more females by the collective male display of the chorus, (chorus attraction) and (4) predator avoidance due to safety in number (selfish herd hypothesis, reviewed in Hamilton 1971; predator satiation effect, Ims 1990).

Anuran choruses can be considered leks in species where the immediate locality of the chorus and the individual display territories have no immediate, direct value to females other than the displaying males themselves (see Höglund and Alatalo 1995 for a general review of leks and lekking behavior). Some examples of anuran choruses that have been classified as leks include: Bufo 
woodhousei (Sullivan 1982), Ololygon (Scinax) rubra (Bourne 1992), and Hyla arborea (Friedl and Klump 2005). However, most anurans breed in or near bodies of water, where females will carry the males in order to lay and fertilize the eggs; this type of aggregation is best explained as a resource-based lek (Alexander 1975). Certainly, males that are successful in displaying and competing for the attention of females mate and pass their genes to the next generation (Andersson 1994), and such behavior could easily explain how certain traits are being selected in a population. However, researchers have seldom shown to what extent other pressures, such as male-male competition and predation risks, have played a role on the evolution of lek-like choruses in many anurans (Gerhardt and Huber 2002). Thus, anuran choruses are useful tools for studying conflicts among conspecific males and the role of acoustic signals in shaping the evolution of the chorus as a lek system.

The focus of this dissertation is to understand how sexual selection and the interactions among signalers in a chorus serve as evolutionary mechanisms associated with signaling and sexual display in animals. More specifically, I studied acoustic communication and chorus formation in anurans as a way to investigate how the calling environment and female preferences have shaped the evolution of calling behavior.

This dissertation contains four main data chapters. First, I investigated the advertisement call modifications that arise when animals call together from aggregations and the role of females in influencing the evolution of the calling behavior of males. Males calling from a chorus act as both senders and receivers 
and are influenced by other males calling in the aggregation (Mc Greagor and Peake 2000, Brumm 2006), thus males should interact with other senders in an effort to maintain the attractiveness of their calls to females. Females in turn potentially choose among calling males based on multiple characters (Castellano and Rosso 2007) and will influence the behavior of males on an evolutionary time scale (reviewed in Gerhardt and Huber 2002). I observed and recorded the calling patterns of the bird-voiced treefrog Hyla avivoca, and performed playback tests on calling males to assess how the dynamic characters of calls vary during interactions among groups of males in a chorus. I also performed playback experiments with females to assess what calling patterns observed among interacting males might allow them to increase the attractiveness of their calls.

Second, I investigated the process of chorus formation and the role of aggressive calls in male calling patterns and fights. Interactions among signaling animals should be high during chorus formation, as males arrive to the chorus site and gather to call. I observed the behavior of the bird-voiced treefrog during chorus formation and used acoustic playbacks to test if males engage in ritualized agonistic interactions mainly during the period of chorus formation.

Third, I studied the aggressive behavior of the bird-voiced treefrogs to determine if males incur a potential loss of fitness while engaging in agonistic interactions by reducing their attractiveness to females. Previous studies suggest that males engaged in aggressive behaviors might not be as attractive to females as males that produce only advertisement calls (Brenowitz and Rose 1999; add at least one more reference). However, if aggressive calls are unattractive to 
females, why have so many species evolved aggressive calls, which are acoustically distinct signals used mainly in male-male interactions? I tested female responsiveness to aggressive calls and assessed how their preferences might affect the evolution of calling strategies employed by interacting males that produce both aggressive and advertisement calls.

Lastly, in the fourth data chapter, I tested the hypothesis that acoustic signals influence the onset and location of chorus formation. Acoustic signals, by virtue of their efficient propagation, may serve as long-range cues with information about the location and timing of a breeding aggregation (see Swanson et al. 2007 and Bee 2007). I also tested the hypothesis that males can assess the quality of neighbors and consequently settle preferentially near a neighbor that produces attractive calls rather than settling near a male that produces unattractive calls. These questions were tested in choruses of the bird-voiced treefrog (Hyla avivoca) and the canyon treefrog $(H$. arenicolor $)$ and were framed in the context of the evolution of aggregative calling behavior (i.e. a frog chorus) in order to shed light into the origins and evolutionary advantages of lekking behavior in anurans.

In the following chapters of this dissertation, I will demonstrate precisely what are some of the conflicts in which males engage while displaying from a chorus and how females have helped shape the evolution of male calling behavior. I will also investigate the role of acoustic signals in the spacing of males within an aggregation and in influencing the onset of chorus formation. 


\section{STUDY SYSTEMS}

The bird-voiced treefrog is a small frog that can be found in forested floodplains and swamps near large rivers and in bald cypress-tupelo swamp areas in the southeastern United States. Within this habitat, bird-voiced treefrogs breed from April to August in permanent or semi-permanent swamps, where males call at various heights from overhanging vegetation or tree trunks directly above water (Dundee and Rossman 1989). Males usually form small, dispersed choruses (sometimes of a few hundred) that spread through a vast area within the shoreline of a lake or swamp with an average male-male distance of about $2.4(+/-0.9)$ meters (Martinez-Rivera, unpublished data). I observed and recorded calling males and collected gravid females from five sites throughout the species range in Louisiana, Mississippi and Tennessee (Appendix 1). The sites in Louisiana and Mississippi are oxbow lakes formed from large rivers, which are the typical habitat for the species. The Tennessee population occurs along Reelfoot Lake, a 'recent' lake formed from intense geological activity in 1811-1812 (Kelson 1996).

I also studied the chorusing behavior of the canyon treefrog, $H$.

arenicolor, which is somewhat related to $H$. avivoca within the subfamily Hylinae (Barber 1999; Duellman 2001; Faivovich et al. 2004; Halloway et al. 2005). The main habitat of $H$. arenicolor is composed of very xeric, dry scrubland and rocky outcrops and canyons close to bodies of water, especially fast flowing creeks and streams in the Southwestern US and Northern Mexico. Canyon tree frogs often bask during the day under full sunlight near the chorusing areas close to streams (Stebbins 2003). 
Males of both species produce a stereotyped pulsed call repeated at regular intervals from small lek-like aggregations where male clump in smaller groups within the larger breeding site. Males increase call length but reduce call rate in response to a greater number of calling neighbors (pers. obs.; this study). Females of both species show similar preference patterns for the gross temporal parameters of the calls of conspecific males, preferring higher call rates and call length (Chapter 2 for H. avivoca; H. arenicolor: pers. obs., Gerhardt et al. in prep). This pattern of calling appears to be more energetically costly compared to producing short calls at long time interval in a close relative, $H$. versicolor (Wells et al. 1998). The species differ in the shape and location of their choruses, and in the inter-male interactions that arise in the chorus, providing an excellent setting for comparing male reproductive behavior under different ecological environments in related species.

\section{Literature Cited}

Alexander RD. 1975. Natural selection and specialized chorusing behavior in acoustical insects. In: Insects, science and society, ed D. Pimentel, 35-77, NY Acad. Press. New York, NY

Andersson M. 1994. Sexual Selection. Princeton Univ. Press. Princeton, NJ

Barber PH. 1999. Phylogography of the canyon treefrog Hyla arenicolor (Cope) based on mitochondrial DNA sequence data. Mol Ecol 8:547-62 
Brumm H. 2006. Signalling through acoustic windows: nightingales avoid interspecific competition by short-term adjustment of song timing. J Comp Physiol 192:1279-1285

Bee MA. 2007. Selective phonotaxis by male wood frogs (Rana sylvatica) to the sound of a chorus. Behav Ecol Sociobiol 61:955-966

Blair WF. 1955. Mating call and stage of speciation in the Microhyla olivacea-M. carolinensis complex. Evolution. 9:469-80

Bourne GR. 1993. Proximate costs and benefits of mate acquisition at leks of the frog Ololygon rubra. Anim Behav 45:1051-1056

Bradbury J, Vehrencamp S. 1998. Principles of animal communication. Sunderland, MA: Sinauer

Brenowitz EA, Rose G. 1997. Plasticity of aggressive thresholds in Hyla regilla. Discrete accommodation to encounter calls. Anim Behav. 53:353-61

Castellano S, Rosso A. 2007. Female preferences for multiple attributes in the acoustic signals of the Italian treefrog, Hyla intermedia. Behav Ecol Sociobiol 61:1293-1302 
Dundee HA, Rossman DA. 1996. The Amphibians and Reptiles of Louisiana. 1996 Paperback Ed. Louisiana State University Press. P. 87-89

Duellman WE. 2001. Hylid frogs of Middle America. St. Louis, MO. Society for the Study of Amphibians and Reptiles.

Friedl TWP, Klump GM. 2005. Sexual selection in the lek-breeding European treefrog: body size, chorus attendance, random mating and good genes. Anim Behav 70, 1141-1154

Gerhardt HC, Huber F. 2002. Acoustic communication in insects and anurans. The University of Chicago Press, Chicago

Grafe UT. 1997. Costs and benefits of mate choice in the lek-breeding reed frog, Hyperolius marmoratus Anim. Behav. 53:1103-1117

Hamilton WD. 1971. Geometry for the Selfish Herd J. Theor. Biol. 31: 295-311

Höglund J, Alatalo RV. 1995. Leks. Princeton: Princeton University Press

Ims RA. 1990. On the Adaptive Value of Reproductive Synchrony as a PredatorSwamping Strategy. Am Nat. 136: 485-498 
McGregor PK, Peake TM. 2000. Communication networks: social environments for receiving and signaling behaviour. Acta Ethol. 2: 71-81

Stebbins RC. 2003. Western Reptiles and Amphibians, Third Edition. HoughtonMifflin, Boston

Sullivan BK. 1982. Sexual selection in Woodhouse's toad (Bufo woodhousei) I. Chorus organization. Anim Behav 30: 680-686

Swanson EM, Tekmen SM, Bee MA. 2007. Do female frogs exploit inadvertent social information to locate breeding aggregations? Can J Zool 85:921-932

Welch AM, Semlitsch RD, Gerhardt HC. 1998. Call duration as an indicator of genetic quality in male gray treefrogs. Science. $280: 1928-30$ 


\title{
Chapter 2.
}

\section{Advertisement-call modification, male competition and female preference in the bird-voiced treefrog Hyla avivoca}

\begin{abstract}
Senders and receivers influence dynamic characteristics of the signals used for mate attraction over different time scales. On a moment-to-moment basis, interactions among senders competing for a mate influence dynamic characteristics, whereas the preferences of receivers of the opposite gender exert an influence over evolutionary time. I studied the calling patterns of Hyla avivoca to assess how dynamic characters of calls vary during male interactions in a chorus. I used playbacks to assess how changes in dynamic call properties are likely to affect male mating success. Frogs calling in pairs, groups, or in response to playbacks produced longer calls than isolated males. During call overlap, males often increased the duration of the silent interval (gaps) between the pulses of their calls so that the pulses of the two calls interdigitated, resulting in increased variability of pulse rate, a traditionally static acoustic property. Non-overlapped calls had low variability in pulse rate with species-typical values. Females preferred long to short and average-length calls, and non-overlapped calls to overlapped calls. Females preferred pairs of overlapped calls in which the proportion of overlap was low and overlapped calls in which pulses interdigitated. The patterns of vocal competition reflect the preferences of conspecific females, which have influenced the evolution of the calling behavior of $H$. avivoca.
\end{abstract}




\section{Introduction}

The evolution of communication systems is complicated because senders and receivers are sources of mutual selection (Andersson 1994; Kamo et al. 2002; Vehrencamp 2000). In a reproductive context, senders compete with others to attract members of the opposite gender (Bradbury and Vehrencamp 1998; Gerhardt and Huber 2002; Wells and Schwartz 2006) and alter signal properties during these interactions in ways that directly or indirectly increase their chances of mating (Greenfield 1994; Gerhardt and Huber 2002). The indirect effects of such interactions include the expulsion of other males from a resource required by females or from the immediate area of a signaler, which may increase the chances of the signaler being detected by females (see examples in Bee and Gerhardt 2001; Bourne et al. 2001; Marshall et al. 2003; Narins et al. 2003). Direct effects, which are the focus of this study, are alterations occurring during vocal interactions that increase the attractiveness of the signal to females (e.g. Klump and Gerhardt 1987; Gerhardt, et al. 1996; Hill 1998; Schwartz et al. 2002).

Vocal communication in the bird-voiced treefrog Hyla avivoca, serves as an excellent system to study patterns of call modification and the behavioral advantages of such changes. Males engage in vocal and physical interactions within the chorus and vary the temporal properties of their pulsed calls (Fig 1) allowing us to identify the call properties that change during vocal responses and the timing of advertisement calls. Additionally, gravid females readily respond to playbacks of synthetic calls allowing us to test hypotheses about the effects of female choice on advertisement call modifications and male competition. 
a.

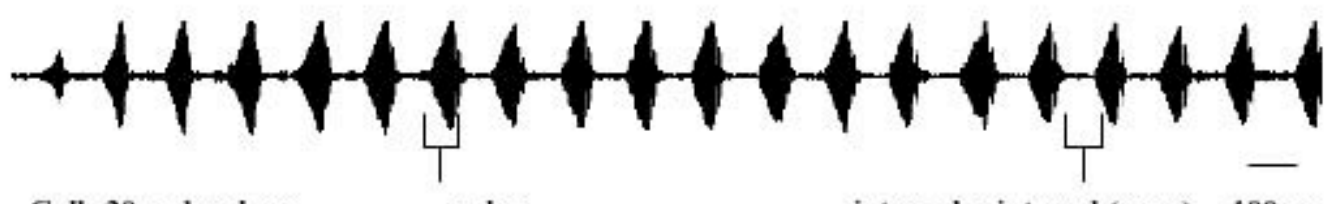

Call: 20-pulses long

pulse

interpulse interval (gaps) $100 \mathrm{~ms}$

b.
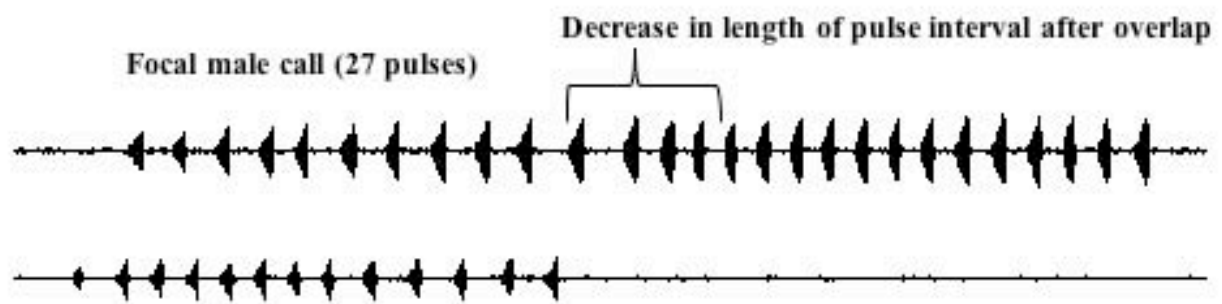

Neighbor call (13 pulses)

c.

$1 \mathrm{sec}$

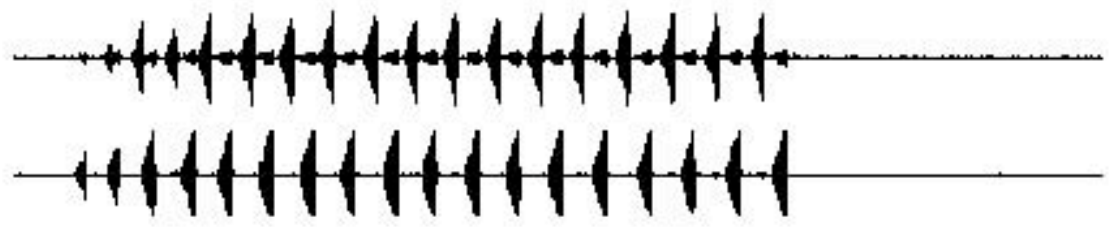

d.

$1 \mathrm{sec}$

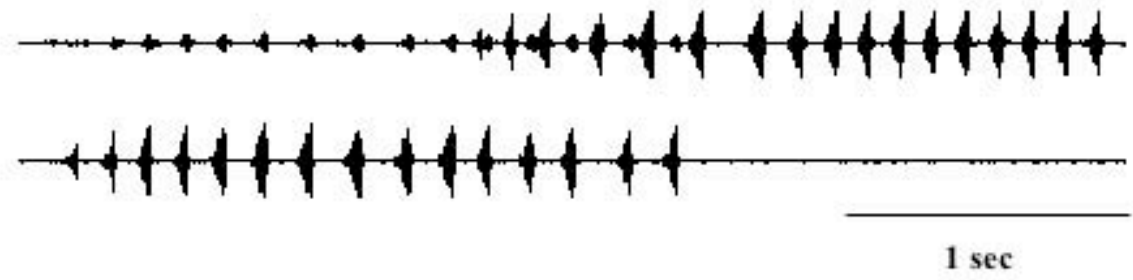

Figure 1. a. Oscillogram of a call of $H$. avivoca in isolation. b. Oscillograms of two overlapped calls showing an example of an extended duration call by the following male. Notice how interpulse interval returns to normal rate after neighbor stops calling. c. Call matching. d. Call interruption. Calls recorded at $22^{\circ} \mathrm{C}$. 
I focused on modifications in advertisement calls such as changes in call duration and call rate, and the patterns of call overlap and alternation that arise in the presence of neighbors (e.g., Wells and Taigen 1986; Schwartz et al. 2002). I then tested how such changes are likely to affect a male's chances of attracting a female. I will show that males calling in isolation had shorter calls and lower call rates compared to males calling in groups and that females preferred longer calls produced at higher rates.

A common phenomenon in calling frogs is that call overlap, which is often discriminated against by females, becomes unavoidable when calling from a chorus (Schwartz 1987). What is unique among North American species is that males of H. avivoca interdigitate pulses within overlapped calls. Pulse interdigitation occurs when males overlapping their calls time the production of such calls so that the pulses within the calls completely alternate (sound file available on electronic version). In H. avivoca, this requires an increase in length of the intervals between pulses and consequently a significant decrease in pulse rate. Such fine-scale timing of pulses does not occur in either of the gray treefrogs (Hyla versicolor and $H$. chrysoscelis), which are closely related to $H$. avivoca.

Interdigitation of call notes has been reported in the Kuvangu running frog Kassina kuvangensis (Grafe 2003) and in the small-headed and hourglass treefrogs, Hyla microcephala and H. ebraccata (Schwartz 1987; 1993). In these species, however, both the patterns and time scale of interdigitation differ from the phenomenon I found in H. avivoca. In $H$. avivoca, pairs of males alternate the smallest acoustic unit of the advertisement call, the pulse, and they do so by 
increasing the interpulse silent interval in the range of 10-40 ms. In $H$.

microcephala and H. ebraccata, pairs of males alternate pulsed introductory and secondary notes but do not alternate the pulses that make up these two kinds of notes (Schwartz 1987; 1993). The magnitude of change of inter-note intervals is of the order of $50 \mathrm{~ms}$ or more (Schwartz 1987, his Figure 1A; pers. comm.). Male K. kuvangensis alternate pulsed calls within overlapped call groups, and the silent intervals between these calls are all greater than $100 \mathrm{~ms}$ (Grafe 2003).

A fine-scale change in the length of pulse interval (=pulse rate) within an advertisement call is unusual and potentially poses a dilemma. Pulse rate in anuran signals is usually a static property (sensu Gerhardt 1991) that shows little within-bout variation and is often essential for species recognition (Gerhardt and Huber 2002). I will show, however, that pulse rate still qualifies as a static property in non-overlapped calls of $H$. avivoca and that females prefer overlapping calls with pulse interdigitation to overlapping calls lacking this timing pattern. Thus, signals with lower-than-average pulse rates are still treated as conspecific calls.

\section{Methods}

\section{Recordings of natural male calling.}

I recorded isolated males and groups of interacting males for three consecutive breeding seasons (June to August 2002 and April to July 2003 and 2004) using a TasCam DAP1 Digital Audio Tape Recorder and Audio-Technica ATR-55 Line Cardioid Condenser Microphones. The sound pressure level (dB SPL re $20 \mu \mathrm{Pa}$, fast root-mean-square [RMS]) was measured at 50, 100, and 150 
cm using a CEL-254 digital impulse sound level meter (Bedford, UK). The SPL

of the calls of nearest neighbors was measured for a sub-sample of males $(\mathrm{N}=30)$ by placing the microphone of the SPL meter directly above a randomly selected focal male in the chorus and reading the average sound output when many the other frogs were calling. I also measured the physical distance of these calling males to the focal male. These measurements allowed us to estimate the average SPL of close neighbors in order to set appropriate intensity levels in the playbacks used for males. Deep-body temperature was taken using Schultheis quick-reading thermometers.

Recording sessions included bouts of at least 20 calls for each individual. I recorded males under three different calling regimes: (1) Solitary recordings calling males that had no calling neighbor within a 5-metre radius; the overall chorus noise was $68 \mathrm{~dB}$ SPL or less at the location of the frog. (2) Pair recordings - pairs of males calling (about $2 \mathrm{~m}$ apart from each other) in choruses of low to moderate density (up to 30 males in a chorus). I focused on pairs of calling males that were each other's closest neighbors, recorded each onto a separate channel of a two-channel stereo recorder, and haphazardly chose one of the two as our focal male for analysis (see below). (3) Groups recordings - males calling from highdensity choruses that had over 20 calling males, where the median inter-male distance was less than $1 \mathrm{~m}$ between closest neighbors. I haphazardly chose one male from a group as a focal male and recorded its calls directly onto one channel of the stereo recorder; another microphone recorded the calls of the adjacent males (usually two) onto the other channel. After each recording, I placed the SPL 
meter directly on top of the focal male to measure the SPL of the calls of the nearest neighbors to assess their relative intensities.

\section{Playback experiments with males.}

Recorded calls were digitized and analyzed using Raven 1.2.1 software (Cornell Laboratories 2003-2005) to obtain the values of an average call (Fig. 1; Table 1). I used SoundEdit 2.0.7 Software (Shockwave Macromedia 1990-1996) on an iBook (Apple Computer Inc., Cupertino, CA, USA) to generate a standard call that consisted of a sequence of synthetic pulses. Calls recorded from males calling at different temperatures were used to create the stimuli used at those temperatures. For example, to create a 23 -pulse call at $16^{\circ} \mathrm{C}$, I created a $2.4 \mathrm{kHz}$ tone of $80 \mathrm{msec}$ and inserted a silent gap of $120 \mathrm{msec}$. I then shaped the envelope of the pulse to approximate that of a typical pulse of an advertisement call of $H$. avivoca. The pulse and silent gap were then repeatedly copied and pasted to create a 23-pulse call. After the 23-pulse call was created, I inserted a $10 \mathrm{sec}$ silent interval. All of our synthetic stimuli were created using this method, and the temporal components of the calls were adjusted to correlate with the parameters of the specific body temperature of the frogs being tested (Table 2). I created additional stimuli by varying the values of pulse duration, interpulse intervals, number of pulses and intervals between calls. Each synthetic call was played back from one of as many as four output channels; phase (timing) relationships of different synthetic calls and their relative intensities were also varied depending on the design of a particular experiment. 
I broadcast synthetic calls using a playback system consisting of a MacIntosh iBook computer connected to a custom-built 2-dB step attenuator that equalized the sound output, which was then amplified using a Virtual Reality Sound Laboratories 200 -watt $\mathrm{VR}^{3}$ car amplifier if needed. The attenuatoramplifier system allowed us to adjust the playback levels broadcasted from a 4" x 10" midrange horn speaker (Parts Express W-46-02-104) mounted on a Velbon 5000 tripod. I adjusted the SPL for the speaker output away from the experimental males prior to each test using a CEL-254 SPL meter. For most tests, I set the fast RMS level of the sound source at $80 \mathrm{~dB}$ SPL at a distance of $2 \mathrm{~m}$, which simulates the intensity of the calls of a neighbor at that distance. Playing back a stimulus to a focal male at any higher intensity elicited aggressive responses from the focal male or from neighboring males. The aggressive responses of males are discussed elsewhere (Martínez-Rivera in preparation).

I performed four different playback tests on solitary males and used 18 different males for each of the first three tests: (1) Standard-call test. I presented males with a 20 -call stimulus of the standard call (4.6 min. total duration; Table 2) at $80 \mathrm{~dB}$ SPL. (2) Longer-than-average call test. I broadcast a playback that contained sequences of five longer-than-average calls presented in random order (27, 30, 30, 27, 30 pulses) at $80 \mathrm{~dB}$ SPL (7 min total duration). (3) Distantneighbor test. I used a 20-call stimulus of the standard 23-pulse call at $74 \mathrm{~dB}$ SPL at $2 \mathrm{~m}$, which simulates a male calling at a distance of about 3.4 meters ( $5 \mathrm{~min}$ total duration). (4) Multiple-male test. For this test, I presented 10 males with a pair of stimuli emitted from a two-speaker playback system (7 min total duration) 
using a stereo audio file that contained a simulated interaction between two males (Fig. 2). The values of call duration and the timing relationship of the two stimuli (see below) were based on data collected over the first two years of study. The arrangement of speakers $\left(120^{\circ}\right.$ of angular separations) mimicked the positions of males calling under low-density conditions (Martinez-Rivera unpublished). One speaker was placed at $1.3 \mathrm{~m}$ from the focal male and the other speaker at $0.8 \mathrm{~m}$; both speakers were pointed at the focal male and formed a roughly $160^{\circ}$ angle with the focal male (Fig. 2). No male was used twice on the same test. 


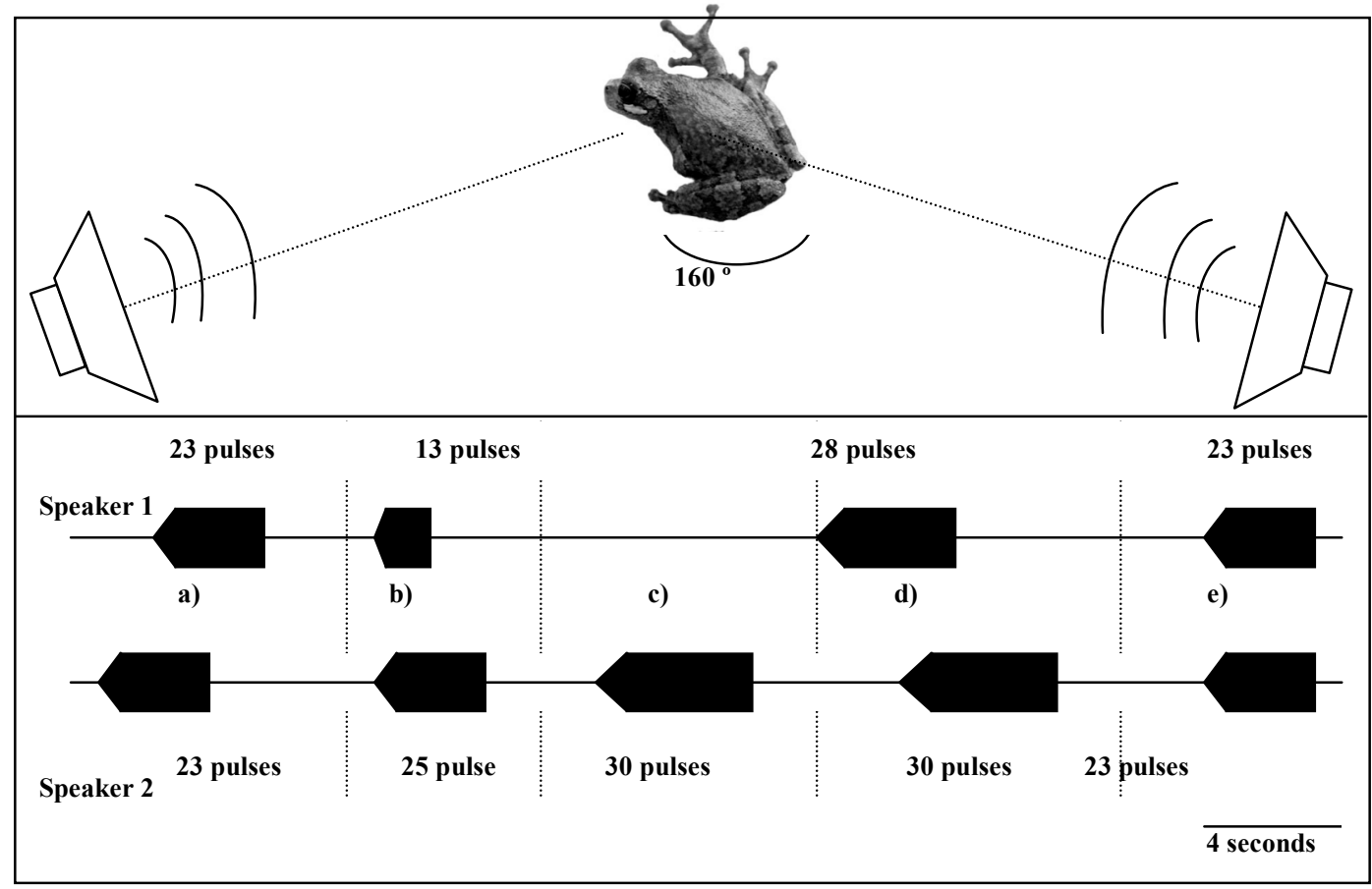

b.
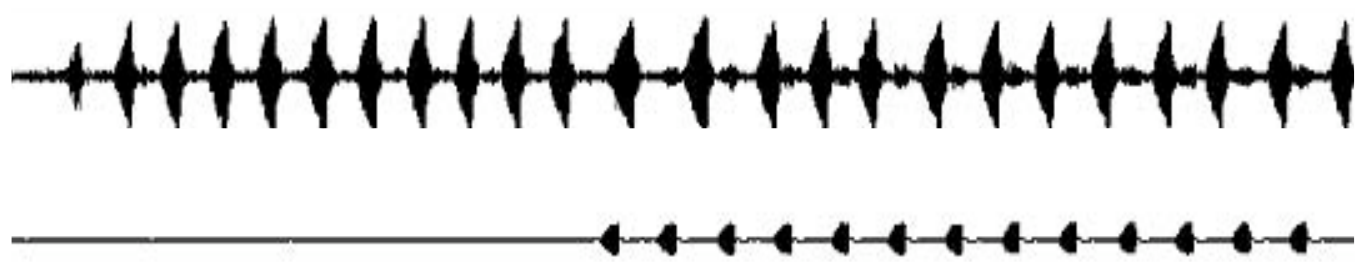

1 second

Figure 2. a. Top panel - diagram of the playback setting used for the multineighbor male test. Bottom panel - stimuli used in our tests: a) Call alternation, b) complete call overlap, c) long calls, d) call jamming, and e) endurance rivalry. Overlapped calls have complete pulse interdigitation not shown in diagram. b. Oscillogram of a male interdigitating an overlapped call with a playback. A clear call (top panel) is interrupted on the $11^{\text {th }}$ pulse by a 13 pulse long playback (bottom panel). As a result, the focal male extends the length of the interpulse interval of its call avoiding interference from the playback and produces a longer call of 24 pulses. Note how the interpulse interval increases as the call progresses, lowering pulse rate. The first four intervals, (before call overlap) are about $60 \mathrm{~ms}$ long, the last five (during call overlap) are about $110 \mathrm{~ms}$. Playback is about $2 \mathrm{~s}$ in duration. 


\section{Playback set up for experiments with females.}

I broadcast synthetic calls generated with commercial software (Canary and SoundEdit) on a portable computer (iBook) using a playback system similar to the one described above for male playback experiments. I used Analog-Digital Systems 200 speakers (Boston, MA, USA) instead of horn speakers. The sound pressure level of each stimulus was adjusted to $86 \mathrm{~dB}$ SPL (fast RMS) midway between the speakers, which were separated by two meters and placed at opposite ends of the arena. Amplectant pairs were collected and placed in individual containers for at least two hours prior to being tested in the field. At this time, the gravid females were separated from their amplectant males; some females were tested on the night of capture, while others were tested on the following night. The latter females were held in their individual containers inside a cooler with ice and salty water to maintain a constant temperature of about $4^{\circ} \mathrm{C}$, which inhibits oviposition and allows for testing of females on following nights. Females were acclimatized to the appropriate ambient temperature prior to testing.

All females were tested in the field at least $800 \mathrm{~m}$ away from the nearest frog chorus using a portable testing arena that consisted of six wooden frames measuring $1 \mathrm{~m}$ long by $0.50 \mathrm{~m}$ high covered with black cloth to minimize wind and light exposure to females. The arena measured $1 \mathrm{~m} \times 2 \mathrm{~m} \times 0.5 \mathrm{~m}$ with an open top and was placed on a flat surface (i.e. porous cement floor). A small holding container made/acoustically transparent hardware cloth placed up-side down was used as a release box to retain each female at the release point midway between the speakers (unless otherwise stated). After broadcasting five calls from 
each speaker, I removed the release box with a pulley system and left the female in the arena free to make a choice between stimuli for up to 10 minutes. A response was recorded as positive when a female approached to within $10 \mathrm{~cm}$ of a speaker and showed the appropriate phonotactic behavior (Rheinlaender et al. 1979).

Females were tested only once per stimulus pair, and there was a time-out of 5 minutes between tests. The alternative stimuli were switched between speakers on every test to eliminate the chance of a side bias in the portable arena or from an outside source, (i.e. light, grade, ambient noise, etc.) which might make females approach or avoid a particular side preferentially. I recalibrated the sound pressure level of the speakers every time I alternated the direction of the source of the stimuli or changed the stimuli. Most females were released at the site of capture within two days of being collected.

I used synthetic signals that were generated as described above to test the selectivity of female phonotaxis with respect to different calling patterns. Given a choice between a typical pre-recorded call of 23 pulses and a synthetic call of the same length, thirteen females chose the natural call and twelve the synthetic call.

I conducted all playbacks at ambient temperatures ranging from $20^{\circ} \mathrm{C}$ to $26^{\circ} \mathrm{C}$ and used stimuli with values of call properties that were close $\left( \pm 2{ }^{\circ} \mathrm{C}\right)$ to those produced by males at the test temperature.

\section{Female playback experiments.}

(1) Effects of call duration - I gave females a choice between the standard 23-pulse call and alternatives of various duration. For convenience, I grouped our 
stimuli as: (a) shorter-than-average calls of 10,12 and 18 pulses; (b) calls that were plus/minus one standard deviation of the 23-pulse average call (a 21 and 24pulse call), and (c) longer-than-average calls of 25, 27 and 30 pulses. I kept call rate (calls per minute) constant so that the alternative stimuli always alternated. The temporal parameters of stimuli fell within species-typical ranges of variation (Table 2).

(2) Effects of call overlap - I gave females a choice between the standard 23-pulse call and a stimulus where every other call had a simulated overlap. The simulated overlapped call used for our stimulus was created by inserting a pulse of $50 \%$ of the relative amplitude of the previous pulse and a $5 \mathrm{msec}$ silence gap to each pulse interval to obtain a simulated overlapped call consisting of a slightly longer call with 46 pulses; 23 pulses at full amplitude, each alternated by a pulse of 50\% amplitude (Fig. 5). This stimulus thus simulated the pattern of pulse interdigitation typically observed in the overlapped calls of close neighbors where pulses are $180^{\circ} /$ phase (see Results). The speaker with the alternative stimulus broadcast a loop consisting of a 23-pulse call followed by two sets overlapping calls. I then performed five more tests in which I kept the intensity of the stimulus with the overlapped calls constant $(86 \mathrm{~dB})$ and varied the intensity of the 23-pulse call ( $84 \mathrm{~dB}, 78 \mathrm{~dB}, 72 \mathrm{~dB}, 66 \mathrm{~dB}$, and $60 \mathrm{~dB}$ ). The SPL (fast RMS) of the overlapped-call alternative was set to $86 \mathrm{~dB}$ SPL using a non-overlapped call prior to each test. This resulted in a slightly higher (about $87 \mathrm{~dB}$ ) overall SPL for the overlapped calls in that stimulus, and the SPL of higher-amplitude overlapping call was $86 \mathrm{~dB}$ and that of the lower-amplitude call about $80 \mathrm{~dB}$. 
(3) Effects of timing during call overlap - A. Gross temporal pattern-I used a four-speaker playback system to simulate two pairs of interacting males. The speakers in each pair were placed adjacent to each other and each pair was then placed in a separate corner of the arena to form a $120^{\circ}$ angle of separation with reference to the female release point (Fig. 6B). This spatial arrangement is an approximation of those commonly observed in groups of calling males. I then varied the timing of calls from the two pairs of speakers. In one test, calls from one pair of speakers always alternated and calls from the other pair overlapped completely in two/every three repetitions. Call rate was adjusted to avoid call overlap between the two sets of speakers. In three additional tests, calls from one pair of speakers always overlapped completely in two/every three calls and was considered the standard stimulus-pair. In the alternative stimulus-pairs, two/three calls also overlapped, but the amount of overlap for each alternative pair was $75 \%, 50 \%$, or $25 \%$ respectively (Fig. $6 \mathrm{~B}$ ). B. Fine-scale temporal pattern.

Females had a choice between a standard stimulus, in which the overlapping calls were timed so that pulse interdigitation was complete ( $0 \%$ pulse overlap) and two alternatives, one in which the alternative stimulus had no pulse interdigitation (100\% pulse overlap) and a second alternative with less pulse interdigitation $(30 \%$ pulse overlap) (Fig. 7).

\section{Data analysis}

I digitized and analyzed at least 20 calls per male using Raven 1.2.1 software (Cornell Laboratories 2003-2005); all recordings were made at 22.4 $27.6^{\circ} \mathrm{C}$. I measured call length, pulse rate, call rate, call duty-cycle, and the 
duration of call overlap, counted the number of pulses per call and counted the number of overlapping calls. A call was considered overlapped if at least three pulses were completely overlapped by a neighbor. I determined the duration of call overlap of individual $i$ by individual $j$ by subtracting the starting time of individual $j$ from the ending time of individual $i$ (Brush and Narins 1989) and analyzed treatment effects using a Friedman test for related samples. A One Factor Analysis of Variance for repeated measures with a multi-comparison significance level at $95 \%$ was used to analyze the male playback tests because I measured call parameters of the same male before, during and after treatment. I used StatView SE+Graphics software for our analyses (Abacus Concepts 1988).

The results of the female-preference test were analyzed in terms of preference functions. I computed $95 \%$-exact confidence limits (binomial distribution) on the proportion of females choosing one of the alternatives. If the results of a two-tailed binomial test were significant $(P<0.05)$, I show only the lower or upper confidence limit. The Animal Care and Use Committee of the University of Missouri approved our experimental procedures.

\section{Results}

\section{Calling patterns during natural interactions.}

Summary statistics for the measurements of the temporal properties of calls are given in Table 1. Because call rate between pairs of interacting males and groups of interacting males were not significantly different, $\left(F_{1,25}=0.036, P\right.$ $=0.855$, Table 1) I combined the two categories into a new category (interacting males) for the rest of our analyses. Mean call rate among interacting males was 
significantly higher than that of males calling in isolation $\left(F_{1,25}=9.821, P=\right.$

0.044 , Table 1). Interacting males had higher pulse number $\left(F_{1,26}=9.96, P<0.01\right)$ and call rate $\left(F_{1,26}=12.667, P=0.0015\right.$, Table 1$)$ than solitary males.

\section{Call overlap.}

Males calling in pairs overlapped $3.9(+/-1.3) /$ every 10 calls on average, whereas males calling in groups overlapped $6.5(+/-0.9)$ calls/every 10 on average $\left(F_{1,15}=15.4, P=0.0057\right)$. Increased call overlap in groups was due to the increased number of calling males in the aggregation and not to changes in the calling patterns of individual males in the group. Call overlap occurred in three ways: 1. Simultaneous initiation of calls - Males began call at the same time, one male produces a longer call (Fig. 1b). 2. Call matching - Both males produced simultaneous calls of similar lengths (duration and pulse number), causing the calls to overlap by $100 \%$ (Fig. 1c). 3. Extended duration calls by following male The follower male added pulses to match or exceed the number of pulses of the leader male, with the leader stopped abruptly, producing a short call (Fig. 1b and 1d). This kind of interaction was most common in groups of calling males and could be characterized as a call interruption. The average pulse number of matched calls was lower than that of alternating calls and extended calls (see below) in the same interacting pair [call matching $=17.5(+/-2.4)$; alternating calls $=22.6(+/-3.1)$; extended calls $=23.6+/-3.6) n=15$ calls, Friedman test; $\chi^{2}=$ $15.63, \mathrm{df}=2 ; P<0.001]$. Calls that were stopped abruptly by an overlapping male were shorter than calls produced in other interactions and were not tested for statistical differences $(\mathrm{n}=27$ calls; $7.8+/-3.2$ pulses $)$. 
Table 1. Mean values (SD) of the gross-temporal call parameters of Hyla avivoca under three different calling densities.

\begin{tabular}{ccccccc}
\hline \multicolumn{7}{c}{ Mean values for temporal parameters (standard deviation) } \\
\hline Type of & Call & Call interval & Calls per & Pulse & Pulse & Pulse \\
aggregatio & duration in & in seconds & minute & number & duration & interval \\
$\mathrm{n}$ & seconds & & & & $(\mathrm{msec})$ & $(\mathrm{msec})$ \\
\hline Solitary & $2.27(0.21)$ & $8.3(1.32)$ & $4.89(0.91)$ & 17.9 & 52.3 & 62.63 \\
$(\mathrm{n}=26)$ & & & & $(1.6)$ & $(0.21)$ & $(2.67)$ \\
Pair & $2.98(0.33)^{*}$ & $6.8(2.51)^{*}$ & $5.73(1.1)^{*}$ & 23.6 & 51.8 & 74.65 \\
$(\mathrm{n}=15)$ & & & & $(2.53)^{*}$ & $(0.36)$ & $(6.34)^{*}$ \\
Group & $2.93(0.41)^{*}$ & $6.9(3.42)^{*}$ & $6.01(0.7)^{*}$ & 23 & 52.1 & 73.29 \\
$(\mathrm{n}=8)$ & & & & $(3.14)^{*}$ & $(0.32)$ & $(5.23)^{*}$ \\
\hline
\end{tabular}

*Denotes a significance of $\mathrm{P}<0.05$ for a One-factor Repeated Measures ANOVA.

Table 2. Temporal structure of the standard synthetic advertisement call created for playback experiments on male and female $H$. avivoca.

\begin{tabular}{ccccccc}
\hline Temperature & $\begin{array}{c}\text { Pulse } \\
\text { number }\end{array}$ & $\begin{array}{c}\text { Call } \\
\text { duration }\end{array}$ & $\begin{array}{c}\text { Pulse } \\
\text { duration }\end{array}$ & $\begin{array}{c}\text { Pulse } \\
\text { interval }\end{array}$ & $\begin{array}{c}\text { Call } \\
\text { interval }\end{array}$ & $\begin{array}{c}\text { Calls per } \\
\text { minute }\end{array}$ \\
\hline $16^{\circ} \mathrm{C}$ & 23 & $4.7 \mathrm{sec}$ & $70 \mathrm{msec}$ & $140 \mathrm{msec}$ & $10 \mathrm{sec}$ & 4 \\
$20^{\circ} \mathrm{C}$ & 23 & $3.6 \mathrm{sec}$ & $60 \mathrm{msec}$ & $100 \mathrm{msec}$ & $8.1 \mathrm{sec}$ & 5 \\
$24^{\circ} \mathrm{C}$ & 23 & $3.1 \mathrm{sec}$ & $48 \mathrm{msec}$ & $90 \mathrm{msec}$ & $6.8 \mathrm{sec}$ & 6 \\
\hline
\end{tabular}




\section{Pulse interdigitation.}

Males often increased the silent interval between pulses during call overlap such that close neighbors interdigitated the pulses of such calls even when overlap occurred during less than $10 \%$ of a call (i.e. 3 pulses). Furthermore, pulse interdigitation occurred at a scale of 10 milliseconds (Fig. 1) and resulted in a within-call reduction in pulse rate. Pulse interdigitation occurred in $62 \%$ of call overlaps when neighbors were about 3.5 meters apart (neighbor SPL of at least 80 $\mathrm{dB}$ ) and in $90 \%$ of overlaps when neighbors call $2 \mathrm{~m}$ apart or closer (neighbor SPL of $86 \mathrm{~dB}$ or more). Males were able to interdigitate pulses with more than one neighbor and with two speakers during the same call when these two alternated with each other but overlapped with the call produced by the focal male.

\section{Male Response to Playback Experiments.}

All males responded to our playbacks by engaging in at least one of the following behaviors: increased call production, increased number of pulses (call duration), increased call overlap, and pulse interdigitation with increased pulse intervals during call overlap (see Fig. $2 \mathrm{~b}$ for an example). I compared the results of our male responses to its base-line calling behavior and observed the behavior of calling males after the stimuli ended. Our data are summarized in Figure 3 and Table 3. Males increased call length and call rate and engaged in call overlap with playbacks of calls of average length and playbacks of long calls. In the third test (distant neighbor), males increased call production but not necessarily call length. In the fourth test (multiple-male test), males responded to multiple speakers by increasing interpulse intervals and alternating pulses with both speakers during 
call overlap (Fig. 2b). However, after initially increasing call rate during the first minutes of being stimulated by a playback, males typically dropped their call rate to pre-stimulus levels within about 6.3 min of playback (Friedman test, $X^{2}=$ 27.25, $P=0.001$; Fig. 3). 
a.

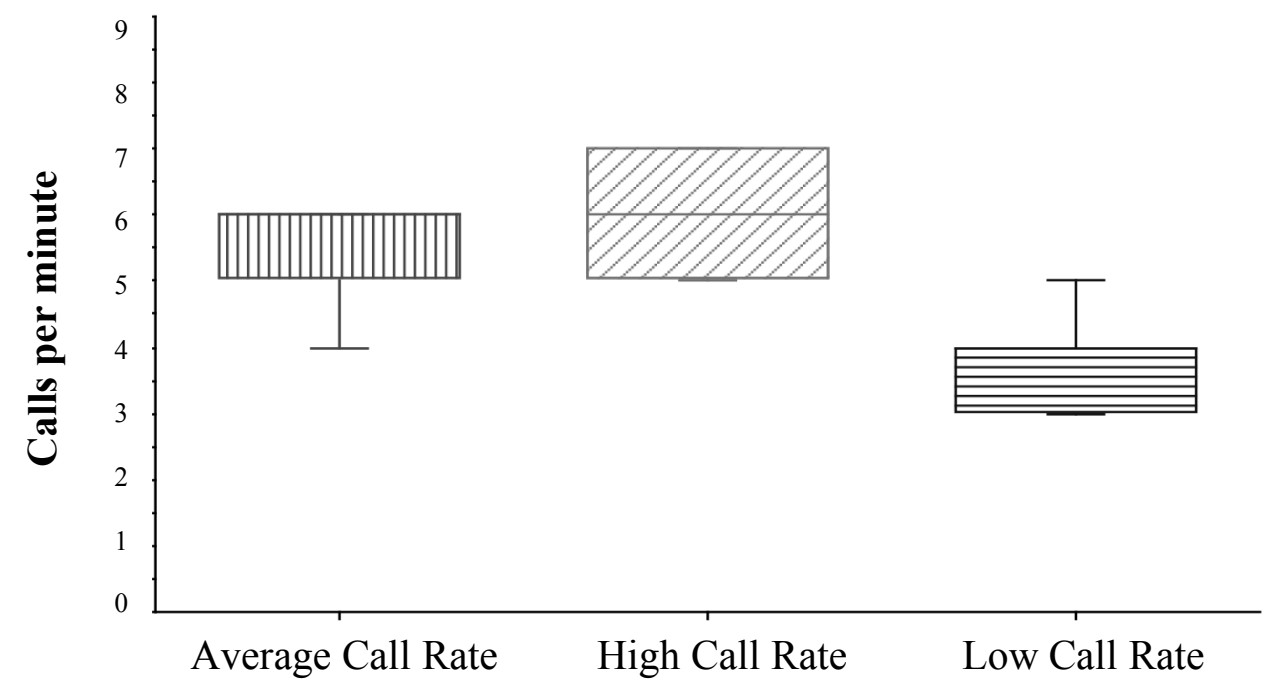

b.

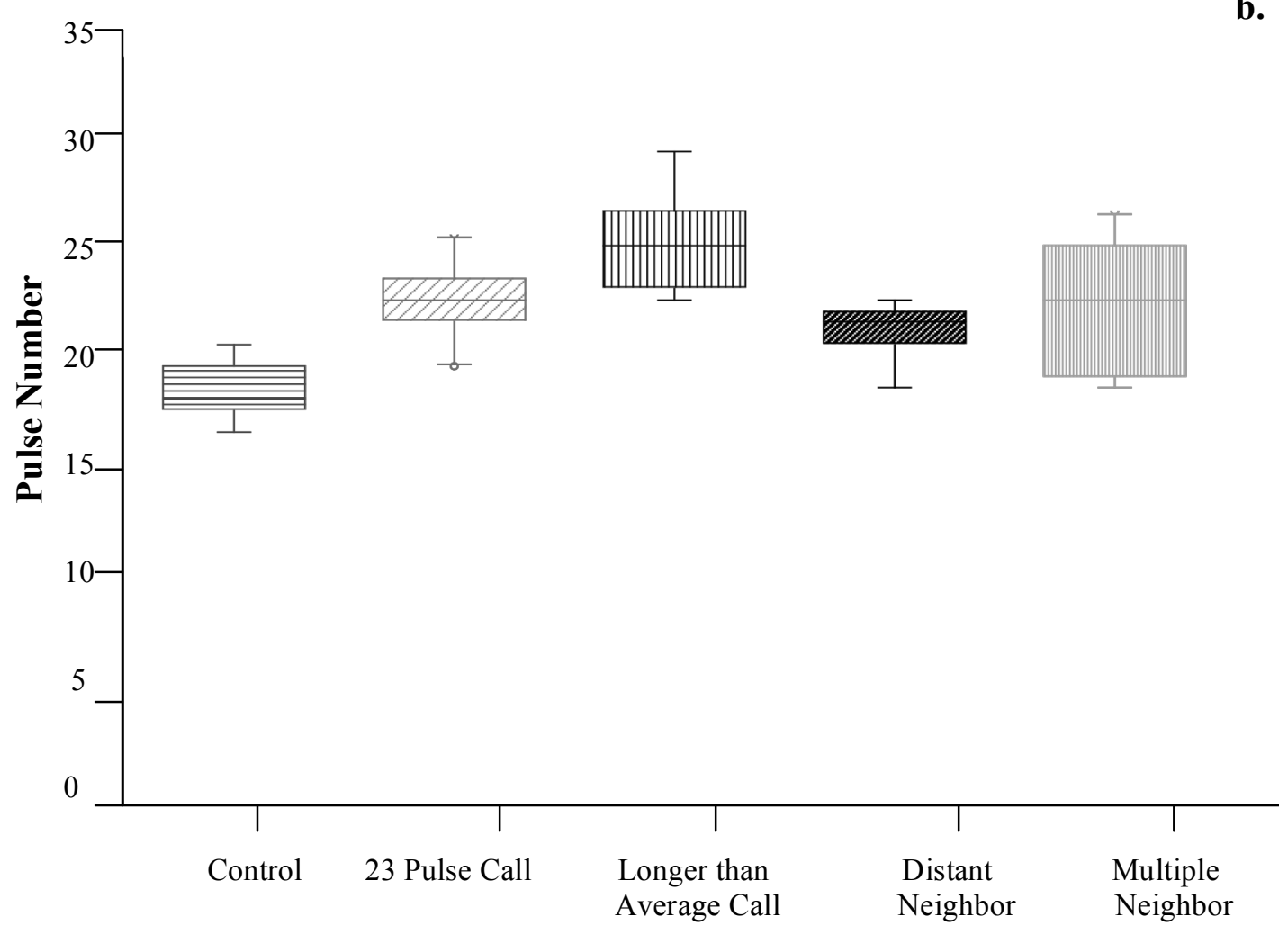

Figure 3. a. Box plot showing the average number of calls produced in a minute of continuous calling before playback stimulation, highest number of continuous calls produced during a minute of playback stimulation and, lowest number of continuous calls produced during a minute of playback stimulation. b. Average pulse number per call given by frogs under different playback regimes. All males increase call length in response to playbacks. Bars indicate standard errors. 


\section{Female preferences.}

(1) Effects of call duration - All females preferred the standard 23-pulse call to calls of shorter length vis-à-vis 10- and 12-pulse calls, and vis-à-vis 18pulse calls. There was no preference in tests of the average 23-pulse call against 21-pulse calls $(P=0.12)$ and 24-pulse calls $(P=0.16)$. Females preferred longer alternatives with 25 or more pulses per call to the standard 23-pulse call (Fig. 4).

(2) Effects of call overlap - Females strongly preferred the non-overlapped standard call even when its SPL was as much as $14 \mathrm{~dB}$ less than that of the stimulus in which every other call was overlapped (Fig. 5). This preference was abolished when the SPL of the standard call was reduced in intensity by $20 \mathrm{~dB}$ or more relative to the alternative with overlapped calls.

(3) Effects of timing during call overlap - A. Gross temporal patternsfemales preferred a pair of alternating calls to a pair of overlapped calls in the four-speaker trials $(P=0.005$; Fig. 6$)$ and preferred calls with a partial overlap of $25 \%$ to a pair of alternative calls. However, females showed no preference when the degree of overlap was $75 \%(P=0.024)$ or $50 \%(P=0.09)$ (Fig. 6). B. Finescale temporal pattern- females showed a significant preference for overlapped calls with interdigitated pulses over a set of overlapped calls in which pulses completely $(P=0.05)$ or partially overlapped $(P=0.008)$ (Fig. 7). 


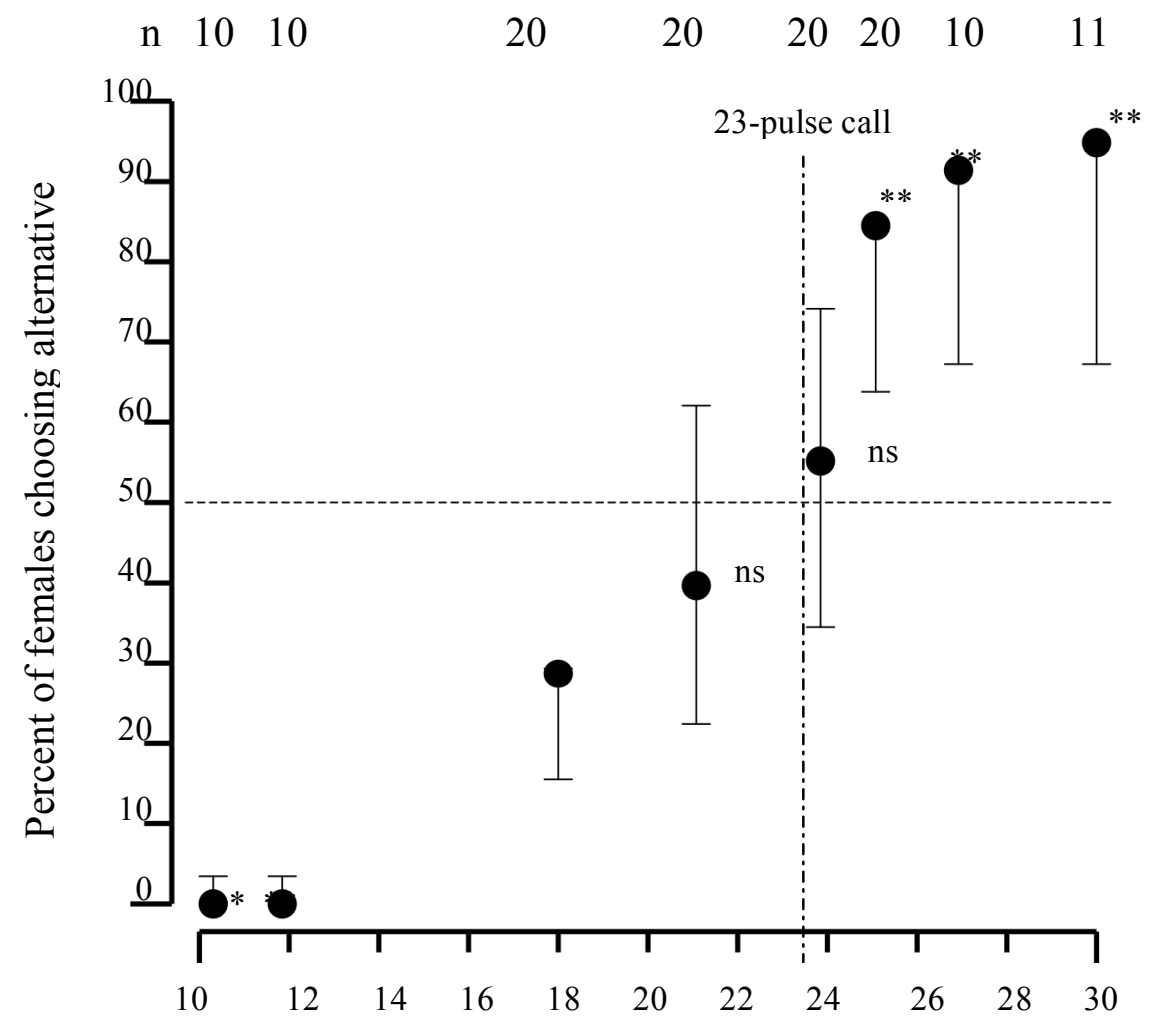

Number of pulses of alternative stimulus

$* P<0.05 ; * * P=0.001$

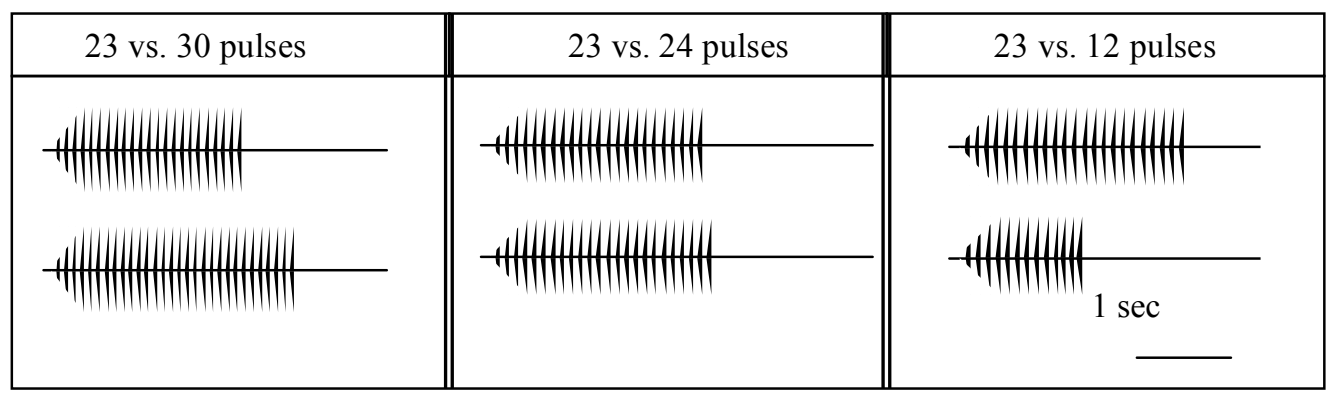

Figure 4. Proportions of females choosing calls of varying length against the standard 23-pulse call. Error bars are 95\% credible intervals; a single bar denotes a significant $(\mathrm{p}<0.05)$ preference in a two-tailed binomial test. 
Female preference for alternating calls

a.
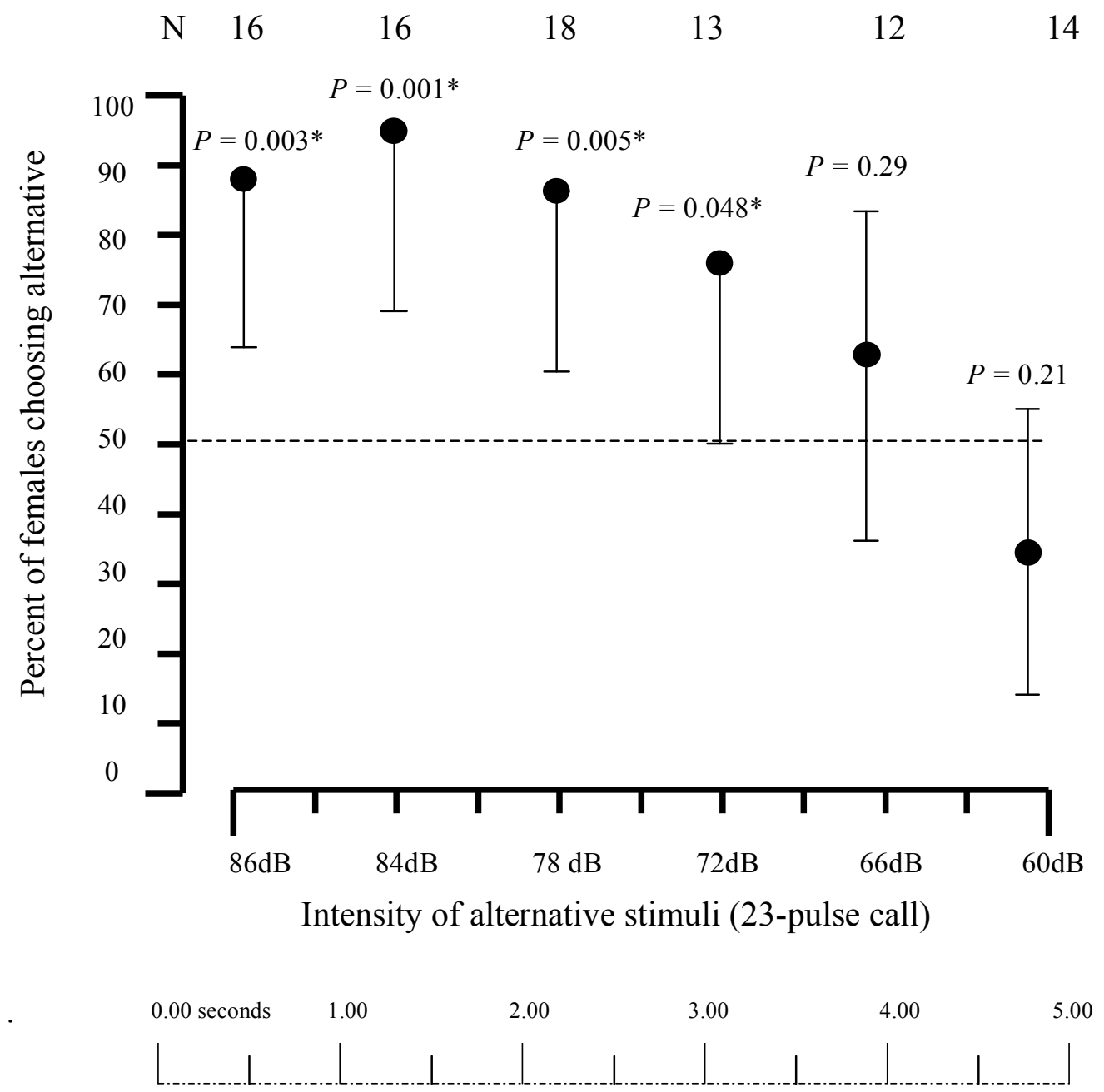

b.

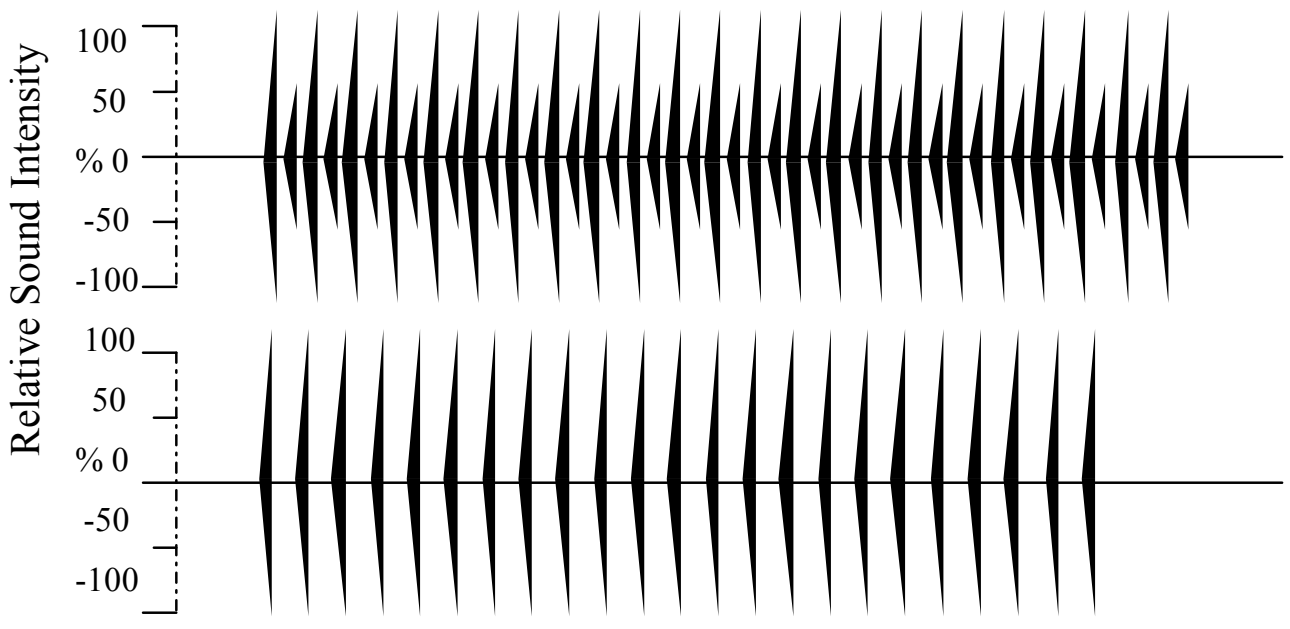


Figure 5. a. Recognition and preference of call overlap. Error bars are 95\% credible intervals; a single error bar denotes a significant $(\mathrm{p}<0.05)$ preference in a two-tailed binomial test. b. Oscillograms of the stimuli used on this test. Top panel shows two simulated 23-pulsed call in overlap, bottom panel shows the 23pulse stimulus. The overlapped call broadcast at an intensity of $86 \mathrm{~dB}$ at $1 \mathrm{~m}$ in all tests, the intensity of the single call in each test was broadcast at one of the following intensities: $84 \mathrm{~dB}, 78 \mathrm{~dB}, 72 \mathrm{~dB}, 66 \mathrm{~dB}$, or $60 \mathrm{~dB}$ at $1 \mathrm{~m}$. * Significant at $\mathrm{P}<0.05$ for a Two-tailed binomial test. 


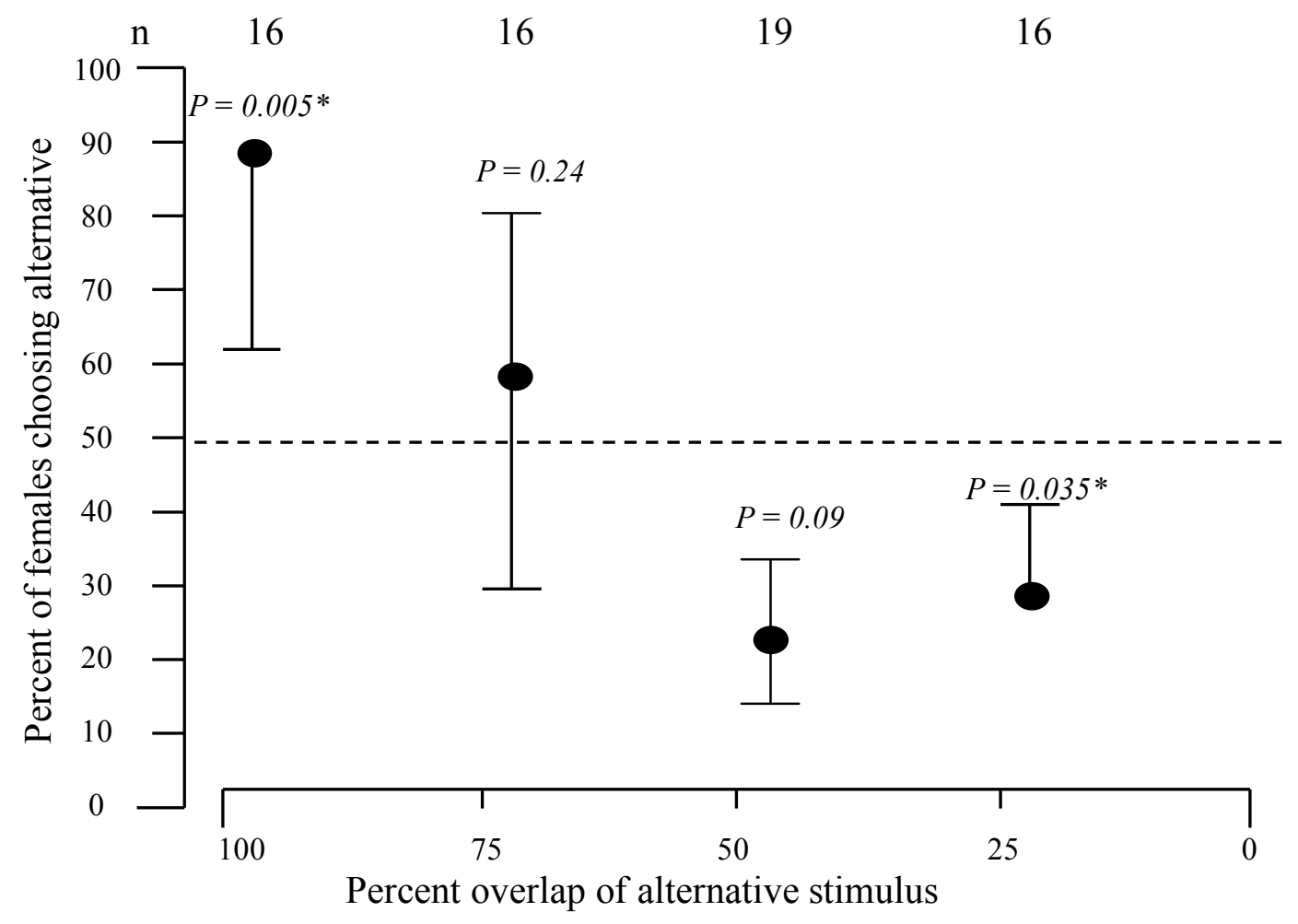

b.

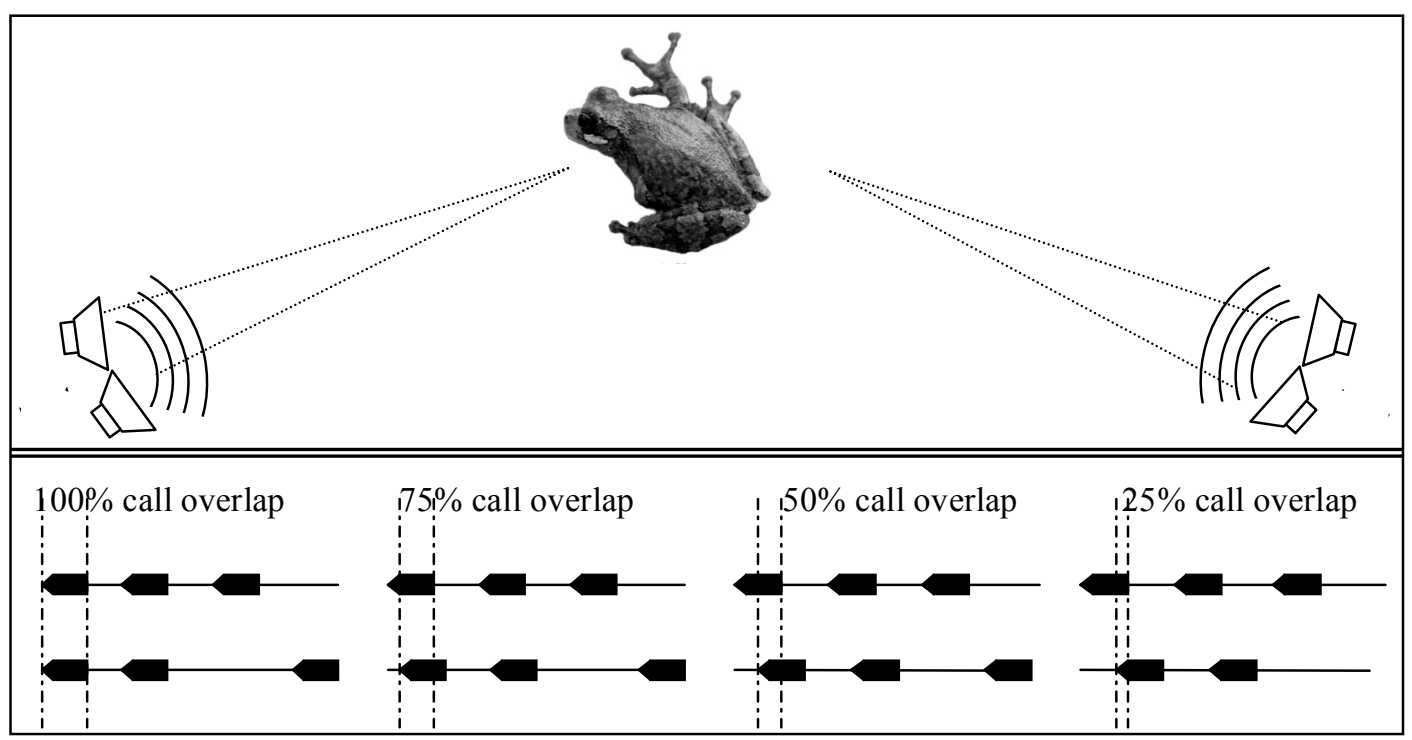


Figure 6. a. Female preference for overlapped calls with different degrees of call overlap. Error bars are 95\% credible intervals; a single error bar denotes a significant $(\mathrm{p}<0.05)$ preference in a two-tailed binomial test. b. Top panel Cartoon of the four-speaker playback system used. Bottom panel - Schematic representation of the oscillograms used in our playback. Calls from one pair of speakers always alternated, calls from the other pair overlapped in two/every three repetitions; the amount of call overlap varied according to the test $(100 \%, 75 \%$, $50 \%$, or $25 \%$ overlap). Call rate not drawn to scale, was such as to avoid call overlap between the two sets of speakers. *Significant at $P<0.05$ for a Twotailed binomial test. 


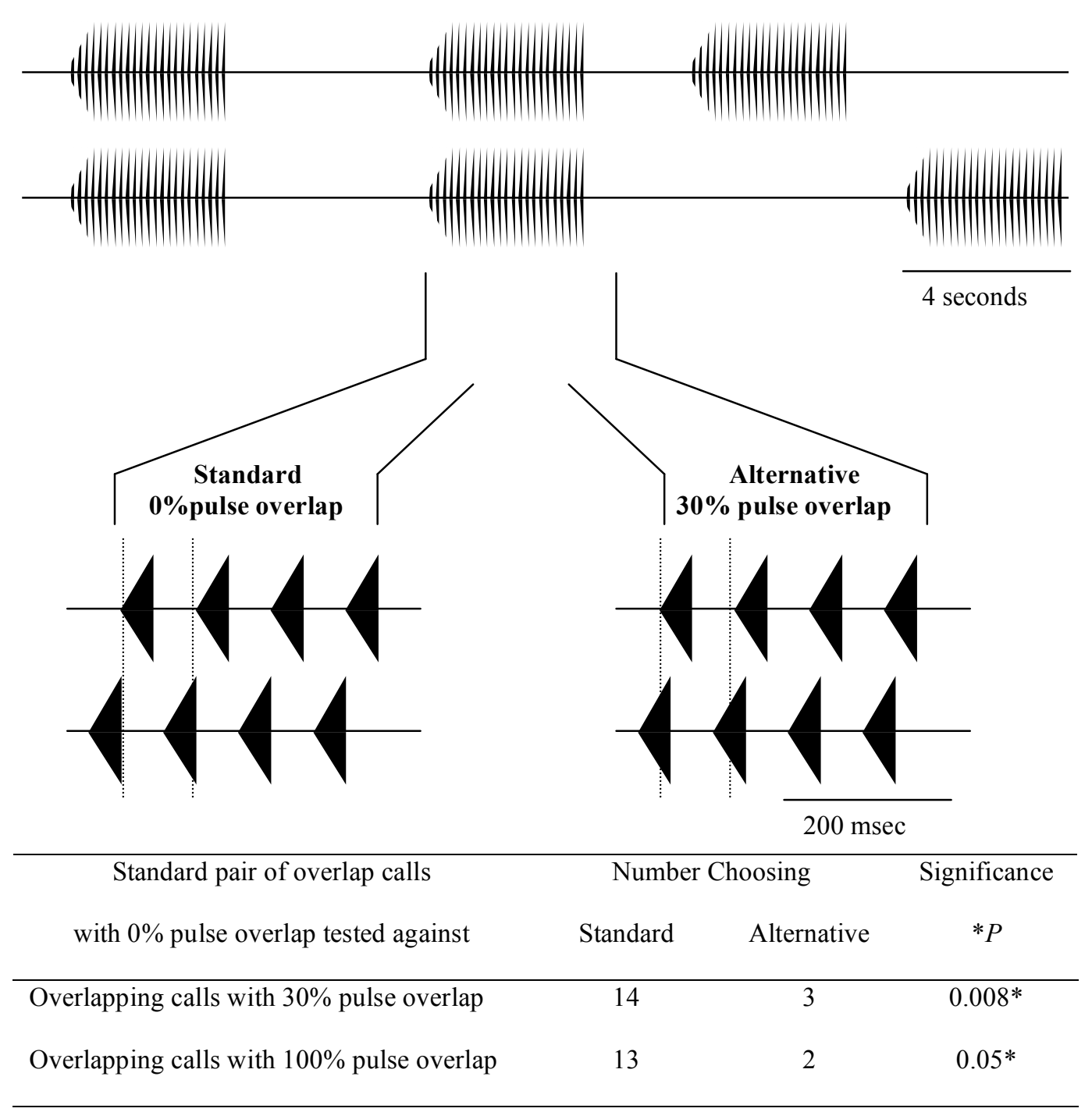

Figure 7. Representation of the stimuli used to test the effects of fine-scale temporal patterns during call overlap. In both stimuli two/every three calls overlapped. The calls of the standard stimulus were timed so that complete pulse interdigitation occurred ( $0 \%$ pulse overlap; bottom left), the alternative stimuli had overlapping calls timed so that either $30 \%$ (bottom right) or $100 \%$ pulse overlap (not shown) occurred. * Significant at $P<0.05$ for a Two-tailed binomial test. 
Table 3. Mean response (SD) of calling males to the playback used in our different tests.

\begin{tabular}{|c|c|c|c|c|c|c|c|c|c|}
\hline \multirow{3}{*}{ 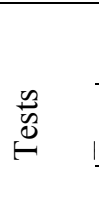 } & \multicolumn{6}{|c|}{ Variation in temporal structures of calls } & \multirow{2}{*}{\multicolumn{3}{|c|}{$\begin{array}{c}\text { Call production } \\
\text { Average calls per minute }\end{array}$}} \\
\hline & \multicolumn{3}{|c|}{ Call length in seconds } & \multicolumn{3}{|c|}{ Average number of pulses } & & & \\
\hline & Before & During & After & Before & During & After & Before & During & After \\
\hline 总 & $\begin{array}{l}2.32 \\
(0.27)\end{array}$ & $\begin{array}{c}2.93 \\
(0.18)^{*}\end{array}$ & $\begin{array}{c}2.87 \\
(0.76)^{*}\end{array}$ & $\begin{array}{l}18.9 \\
(1.7)\end{array}$ & $\begin{array}{l}22.2 \\
(1.5)^{*}\end{array}$ & $\begin{array}{l}23.2 \\
(2.7)^{*}\end{array}$ & $\begin{array}{l}4.8 \\
(0.7)\end{array}$ & $\begin{array}{l}5.9 \\
(1)^{*}\end{array}$ & $\begin{array}{c}5.6 \\
(0.8)^{*}\end{array}$ \\
\hline 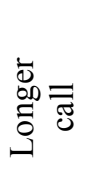 & $(0.25)$ & $(0.28)^{*}$ & $(1.26)^{*}$ & $(2.1)$ & $(2.6)^{*}$ & $(1.9)^{*}$ & $(0.6)$ & $\begin{array}{c}6.2 \\
(1.2)^{*}\end{array}$ & $(1.1)$ \\
\hline 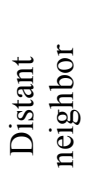 & 2.43 & $\begin{array}{c}2.93 \\
(0.29)^{*}\end{array}$ & $(1.44)^{*}$ & 18.6 & 21.5 & 23.7 & 4.8 & $\begin{array}{c}5.4 \\
(1.3)^{*}\end{array}$ & 4.4 \\
\hline 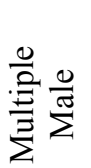 & $\begin{array}{l}2.08 \\
(0.67)\end{array}$ & $\begin{array}{c}3.02 \\
(0.27)^{*}\end{array}$ & $\begin{array}{c}2.94 \\
(0.93)^{*}\end{array}$ & $\begin{array}{l}18.2 \\
(1.3)\end{array}$ & $\begin{array}{c}23 \\
(3.1)^{*}\end{array}$ & $(1.9)^{*}$ & $(0.5)$ & $\begin{array}{c}5.8 \\
(0.3)^{*}\end{array}$ & $\begin{array}{c}5.6 \\
(1.2)^{*}\end{array}$ \\
\hline
\end{tabular}

*Denotes a significance of $\mathrm{P}<0.05$ for a One-factor Repeated Measures ANOVA for the differences observed on the measured temporal parameters between different times during the tests rather than between tests. 


\section{Discussion}

The high levels of noise in a chorus limit the effectiveness of the signals produced by senders (Gerhardt and Klump 1988; Wollerman and Wiley 2001). Thus, it is in the best evolutionary interest of senders to maintain strategies that increase their chances of being detected and chosen by a female (Narins 1992; Greenfield 1994; Hill 1998). Conversely, it is in the best interest of receivers to detect and orient towards the signaler that produces the best (clear) signal (reviewed in Wiley 2006). Receivers (females) that are selective towards advertisement calls would reduce the chances of costly mismatings (H. versicolor and H. chrysoscelis Gerhardt 2005a; Marshall et al. 2006; Hyla cinerea and H. gratiosa; Höbel and Gerhardt 2003) and reduce the probability of mating with lower-quality conspecific males (Spea bombifrons and S. multiplicata Pfennig and Simovich 2002; reviewed in Pfennig 1998; H. versicolor Welch et al. 1998). Noise reduces the effectiveness of sound localization (Schwartz and Gerhardt 1989) and might increase possible costs associated with mate assessment, since females would require more time to locate a calling mate (reviewed in Gerhardt and Huber 2002).

Dynamic properties of acoustic signals of insects and anurans (Gerhardt 1991) are especially variable within calling bouts and can be related to on-going social interactions between rival males (Greenfield 1994; Gerhardt and Huber 2002). In this study, I have described how different calling situations alter patterns of advertisement calling in the bird-voiced treefrog. I have also shown how several of these changes affect the relative attractiveness of signals to females. I 
now discuss relationships between calling patterns and female preferences and the implications for their co-evolution.

\section{Increased call duration during male-male interactions.}

Males calling in groups or in response to playbacks produced longer calls by adding more pulses to their calls. The response of female $H$. avivoca to orient towards longer calls suggest an open-ended preference within the biological maxima of the calling behavior observed in the populations studied, a preference pattern that is typical for dynamic call properties (Gerhardt and Huber 2002). As stated above, the production of longer calls in chorusing situations should benefit the male by increasing his detectability to females in noisy choruses (Schwartz et al. 2002; but see Passmore and Telford 1981). However, females preferred long to short calls in the relatively quiet testing situations I used for our playback experiments. Thus, males would be expected to increase mating success by producing longer calls whenever they are calling near other males even if call detectability remains high. The fact that males increased duration and call rate only when stimulated vocally and reverted to producing fewer calls of normal duration after such a challenge, also suggests that the production of long calls is probably energetically more costly than producing short advertisement calls (see

Schwartz et al. 1995) and could be reliable indicators of male reproductive fitness. Thus, the production of long calls and female preferences for such signals may have parallels with the gray treefrog $(H$. versicolor $)$ system in which call duration may be an honest indicator of genetic as well as physical fitness (Welch et al. 1998). In order to test this hypothesis, breeding experiments with $H$. avivoca, that 
compare the fitness and attractiveness of the offspring of long and short callers would be needed.

\section{Call Overlap: a conflict of calling strategies.}

Males of $H$. avivoca increased call production and call length in the presence of calling neighbors and during playback experiments. This change invariably resulted in increased call overlap. Even though pairs of calling males overlapped calls often, they still produced clear calls $58 \%$ of the time. Males calling in dense groups overlapped calls with more than one neighbor, and produced clear calls only about $35 \%$ of the time. Such overlap would be expected to counter-balance the attractive effect of increasing call duration because females preferred clear calls even when their intensity was as much as $14 \mathrm{~dB}$ lower than a set of calls that overlapped only $50 \%$ of the time. The results are generally consistent with other studies of chorus-breeding frogs showing that females discriminate against overlapped calls (Passmore and Telford 1981; Schwartz 1987, Gerhardt and Klump 1988; Wollerman and Wiley 2001). However, one exceptional result was a preference for a pair of calls with $25 \%$ overlap rather than a pair of alternating calls. By broadcasting calls from adjacent speaker in our experiment, I might have created a stimulus that was perceived by females as a single longer-than- average call, which female anurans usually prefer (Gerhardt and Huber 2002.

\section{Pulse interdigitation: a partial solution?}

I have shown in this study that many of the calls of close neighbors inevitably overlapped during male-male interactions and that male $H$. avivoca 
actively interdigitated the pulses of overlapped calls even in calls with partial overlap (Fig.1). Perhaps the most significant of our results is the demonstration that females preferred overlapped signals with interdigitated pulses to overlapped signals where pulses partially overlapped (Fig. 7). This result could be considered unexpected in that the pulse rate, which is usually a species-specific, relatively invariant property, was lowered within each overlapped call in order to achieve pulse interdigitation. Furthermore, if the overlapped signals were perceived as a summed signal, then the perceived pulse rate would be significantly higher (i.e. double) than that of a non-overlapped call.

Interdigitation of call notes has been reported in other anuran species, but these patterns are not strictly comparable. In K. kuvangensis call groups are repeated in short succession followed by a period of silence; when males call synchronously they alternate the calls within the overlapped call groups (Grafe 2003). Note alternation in H. microcephala can involve both the introductory component (a buzz-like pulsed note) and the shorter secondary notes (clicks) of two neighbors (Schwartz and Wells 1985). The introductory note contains more of the species-identifying properties of the call and can attract females in the absence of secondary notes (Schwartz 1987). Males add secondary click-notes in increasing numbers as male-male interactions in the chorus intensify (Schwartz and Wells 1985; reviewed in Schwartz 1993).

The effects of note interdigitation on female choice have been tested in $H$. microcephala. As in H. avivoca, alternating (interdigitating) notes were preferred to out-of-phase overlapping calls (Schwartz 1987; 1993). Even though males of 
H. versicolor do not show pulse-interval adjustments, a recent experimental study found that, unlike $H$. avivoca, pulse interdigitation of overlapping calls was less attractive to females than partial pulse overlap (Schwartz and Marshall 2006). This species difference probably reflects the fact that two overlapping calls of $H$. versicolor with pulse interdigitation would result in a signal with a pulse timing that resembles that of the call of H. chrysoscelis, a genetically incompatible species that often breeds at the same time and place as $H$. versicolor. By comparison, the pulse rate of an interdigitated pair of calls of H. avivoca is significantly different from that of any other sympatric species.

\section{Interdigitation of pulses: an exceptional pattern?}

Interdigitation resulted in increased duration of silent gaps between pulses and hence sharp drops in pulse rate. Males are also able to return to the normal, faster pulse rate within the call once an overlapping call stops (Fig. 1). Such within-call variation in pulse rate is an exception to the pattern observed in many other anurans. The within-male coefficient of variation (CV) in pulse rate is typically $4 \%$ or less (review in Gerhardt and Huber 2002), and in H. versicolor, a close relative of $H$. avivoca the mean was $1.5 \%$ (range: $0.2-5.0 \%$; Gerhardt 1991). By contrast, the mean within-bout coefficient of variation for pulse rate in Hyla avivoca during call overlap, is about $9 \%$ (range $3.8-10.9 \%$ ) ( $\mathrm{n}=30$ males; this study). Because they responded to pairs of interdigitating calls in which the pulse rate of the calls of both signals were lower than average or in which the pulse rate of the composite signal was higher than average, females of H. avivoca may not be relying on pulse rate per se for mate recognition. Indeed, females of 
H. versicolor are selective for signals with a minimum pulse duration and maximum silent interval rather than the species typical pulse rate (Schul and Bush 2002). Preliminary results of experiments suggest that females of $H$. avivoca use similar criteria (Martinez-Rivera and Gerhardt, unpubl. data).

Even if females of H. avivoca rely on pulse rate for species identification, there would almost certainly be sufficient numbers of clear calls (35\% in groups and $58 \%$ between pairs of males) from which the unaltered rate could be assessed. Moreover, the mean CV for the pulse rate of calls produced by solitary males is about $2 \%$ (range $1.3-3.4 \%, n=32$ ), well within the usual range of variation for static properties (Gerhardt and Huber 2002). Finally, the elevated mean CV for pulse rate in overlapped calls was still considerably lower than the mean CVs for classically dynamic properties such as call rate (mean CV 18.3\%, range 12-25\%, $\mathrm{n}=32$ ) and pulse number (mean $\mathrm{CV}-25.3 \%$, range $13-31 \%, \mathrm{n}=32$ ) in males of H. avivoca calling in isolation. Indeed, a more biologically relevant perspective concerning the static-dynamic continuum emphasizes that within each species there are acoustic properties of relatively low and high within-bout variability rather than attempting to define an arbitrary and universal cutoff value of the mean CV for categorizing a property as static or dynamic (Gerhardt and Huber 2002; see also Shaw and Herilihy 2000).

\section{Future Studies.}

Pairs of vocally interacting males showed four common patterns: synchronizing calls, matching call duration, increasing duration beyond the end of an overlap, and call interruptions. More research is need to evaluate the conditions 
in which each pattern is more likely to occur, and female-preference tests need to be conducted to assess which, if any, of these patterns females may favor. In such studies and in further investigations of pulse interdigitation, the angular separation of speakers should also be varied. Schwartz and Gerhardt (1995) and Marshall et al. (2006) show that when the angular separation of speakers was reduced, females of $H$. versicolor often failed to choose an alternative that was preferred when the angular separation was $90^{\circ}$ or more. Thus, angular separation is likely to affect the choices of H. avivoca in tests in which a longer (i.e. more attractive) call is overlapped by a shorter call. For example, two overlapping calls of different length might be treated as a single longer call when presented from abutting or closely spaced speakers (or calling males) but not when there is greater angular separation.

In general, the calling patterns of $H$. avivoca, as in other frogs and insects become increasingly complex as group size increases. Uncovering complex patterns of interaction is a difficult challenge and will almost certainly require some new approaches and analytical techniques such as communication-network theory (McGregor and Peake 2000). In this approach, any member (signaler or receiver) of the network (i.e. chorus) can gain information from an interaction among other senders and influence its future behavior accordingly (McGregor and Dabelsteen 1996). For example, Siamese fighting fish (Betta splendens) exposed to a fighting event used the information about who won the fight to gauge the abilities of the opponent in future encounters and modified their behavior in the initial stages of agonistic interactions to avoid costly fights with the previous 
winner (Oliveira et al. 1998). Likewise, female black-capped chickadees eavesdropped on male-male vocal interactions and used this information to choose males with which they engaged in extra pair copulations (Mennill et al. 2002). Males and females of $H$. avivoca might also gain information by attending to vocal interactions and would be expected to alter their responses to a rival depending on his prior behavior. For example, females were attracted to a pair of speakers broadcasting a simulated interaction of only advertisement calls and not to a pair of speaker broadcasting a simulated interaction that contained both advertisement and aggressive calls (Martinez-Rivera, in prep.). Furthermore, females were not reliably attracted to playbacks of aggressive calls when there was no other stimulus (Martinez-Rivera, unpubl. data). Hence, females probably avoid a male (or groups of calling males) engaged in aggressive behavior.

\section{Literature Cited}

Andersson M. 1994. Sexual Selection. Princeton Univ. Press. Princeton, NJ

Bee MA, Gerhardt HC. 2001. Habituation as a mechanism of reduced aggression between neighboring territorial male bullfrogs, Rana catesbeiana. J Comp Psych $115: 68-82$

Bourne GR, Collins AC, Hoder AM, McCarthy CL. 2001. Vocal communication and reproductive behavior of the frog Colostethus bebeei in Guyana. J Herpetol $35: 272-81$ 
Bradbury J, Vehrencamp S. 1998. Principles of animal communication. Sunderland, MA: Sinauer

Brush JS, Narins PM. 1989. Chorus dynamics of a Neotropical amphibian assemblage: comparison of computer simulation and natural behavior. Anim Behav 37: 33-44

Gerhardt HC. 1991. Female mate choice in treefrogs: static and dynamic acoustic criteria. Anim Behav 42:615-35

_. 2001. Acoustic communication in two groups of closely related treefrogs. In: Slater PJB, Rosenblatt JS, Snowdon CT, Roper TJ (ed) Advances in the Study of Behavior. pp. 99-167. NY Academic Press

_. 2005a. Advertisement-call preferences in diploid-tetraploid treefrogs (Hyla chrysoscelis and Hyla versicolor): implications for mate choice and the evolution of communication systems. Evolution 59:395-408

_. 2005b. Acoustic spectral preferences in two cryptic species of grey treefrogs: implications for mate choice and sensory mechanisms. Anim Behav 70:39-49 
Gerhardt HC, Huber F. 2002. Acoustic Communication in Insects and Frogs: Common Problems and Diverse Solutions. Chicago: University of Chicago Press

Gerhardt HC, Klump GM. 1988. Masking of acoustic signals by the chorus background noise in the green tree frog: a limitation on mate choice. Anim Behav $36: 1247-49$

Gerhardt HC, Dyson ML, Tanner SD. 1996. Dynamic properties of the advertisement calls of gray treefrogs: patterns of variability and female choice. Behav Ecol 7:7- 18

Grafe TU. 2003. Synchronized interdigitated calling in the Kuvangu running frog, Kassina kuvangensis. Anim Behav 66:127-36

Greenfield MD. 1994. Synchronous and alternating choruses in insects and anurans: Common mechanisms and diverse functions. Am Zool 34:605-15

Hill PSM. 1998. Environmental and social influences on calling effort in the prairie mole cricket (Gryllotalpa major) Behav Ecol 9 (1): 101-108

Höbel G, Gerhardt, HC. 2003. reproductive character displacement in the acoustic Communication system of green tree frogs (Hyla cinerea). Evolution, 57:894-90 
Kamo M, Ghirlanda S, Enquist M. 2002. The evolution of signal form: effects of learned versus inherited recognition. Proc R Soc Lond B; 269 (1502):1765-71

Klump, G.M. and Gerhardt H.C. 1987. Use of non-arbitrary acoustic criteria in mate choice by female gray tree frogs. Nature (London) 326:286-288

Marshall VT, Humfeld SC, Bee MA. 2003. Plasticity of aggressive signaling and its evolution in male spring peepers Pseudacris crucifer. Anim Behav 65:1223-34

Marshall VT, Schwartz JJ, Gerhardt HC. 2006. Effects of heterospecific call overlap on the phonotactic behaviour of grey treefrogs. Anim Behav 72 (2): 449459

McGregor PK, Dabelsteen T. 1996. Communication networks. In: Kroodsma DE, Miller EH (eds) Ecology and evolution of acoustic communication in birds. Cornell Univ. Press

McGregor P K, Peake TM. 2000. Communication networks: social environments for receiving and signalling behaviour. Acta Ethologica 2, 71-81

Mennill DJ, Ratcliffe LM, Boag PT. 2002. Female eavesdropping on male song contest in songbirds. Science 296:873 
Narins PM. 1992. Evolution of anuran chorus behavior: Neural and Behavioral constrain. Am Nat 139:S90-S104

Narins PM, Hödl W, Grabul DS. 2003. Bimodal signal requisite for agonistic behavior in a dart-poison frog, Epipedobates femoralis. PNAS 100:577-80

Oliveira RF, McGregor PK, Latruffe C. 1998. Know thine enemy: fighting fish gather information from observing conspecific interactions. Proc R Soc Lond B 265:1045-1049

Passmore NI, Telford SR. 1981. The effect of chorus organization on mate localization in the painted reed frog (Hyperolius marmoratus). Behav Ecol Sociobiol. 9: 291-293

Pfennig K. 1998. The evolution of mate choice and the potential for conflicts between species and mate-quality recognition. Proc R Soc Lond B 265:17431748

Pfennig K, Simovich MA. 2002. Differential selection to avoid hybridization in two toad species. Evolution 56(9): 1840-1848

Rheinlaender J, Gerhardt HC, Yager D, Capranica RR. 1979. Accuracy of phonotaxis in the green treefrog (Hyla cinerea). J Com Physiol 133:247-55 
Schul J, Bush SL. 2002. Non-parallel coevolution of sender and receiver in the acoustic communication system of treefrogs. Proc R Soc. Lond. B 269:1847-1852

Schwartz JJ. 1987. The function of call alternation in anuran amphibians: a test of three hypotheses. Evolution 41:461-471

Schwartz JJ. 1993. Male calling behavior, female discrimination and acoustic interference in the Neotropical treefrog Hyla microcephala under realistic acoustic conditions. Behav Ecol Sociobiol. 32: 401-414

Schwartz JJ, Gerhardt HC. 1995. Directionality of the auditory system and call pattern recognition during acoustic interference in the gray treefrog, Hyla versicolor. Auditory Neurosci. 1: 195-206

Schwartz JJ, Wells KD. 1985. Intra-and interespecific vocal behavior of the neotropical treefrog Hyla microcephala. Copeia 1985:27-38

Schwartz JJ, Marshall VT. 2006. Forms of Call Overlap and Their Impact on Advertisement Call Attractiveness to Females of the Gray Treefrog, Hyla versicolor. Bioacoustics 16:39-56

Schwartz JJ, Ressel S, Bevier C. 1995. Carbohydrate and calling: Depletion of muscle glycogen and the chorusing dynamics of the Neotropical frog Hyla 
microcephala. Behav Ecol Sociobiol 37:125-35

Schwartz JJ, Buchanan BW, Gerhardt HC. 2002. Acoustic interactions among male gray treefrogs, Hyla versicolor, in a chorus setting. Behav Ecol Sociobiol 53:9-19

Shaw KL, Herhlihy D. 2000. Acoustic preference functions and song variability in the Hawaiian cricket Laupaula cerasina. Proc Royal Soc London B 267: 577584

Vehrencamp SL. 2000. Handicap index and conventional signal elements of bird songs. In: Espmark Y, Amundsen T, Rosenquist G (ed) Animal signals: signaling and signal design in animal communication. Tapir Academic Press, Trodheim, Norway pp 277-300

Welch AM, Semlitsch RD, Gerhardt HC. 1998. Call duration as an indicator of genetic quality in male gray treefrogs. Science 280:1928-30

Wells KD, Schwartz JJ. 2006. The behavioral ecology of anuran communication. In: Narins PM, Feng AS, Fay RR, Popper AN (ed) Hearing and sound communication in amphibians. V 28. Springer, Berlin Heidelberg NY. pp 44-86 
Wells KD, Taigen TL. 1986. The effect of social interactions on calling energetics in the gray treefrog (Hyla versicolor). Behav Ecol Sociobiol 19:9-18

Wiley RH. 2006. Signal detection and animal communication. Advances in the Study of Behavior. 36: 217-47

Wollerman L, Wiley RH. 2001. Background noise from a natural chorus alters female discrimination of male calls in a Neotropical frog. Anim Behav 63:15-22 


\title{
Chapter 3.
}

\section{Agonistic interactions in treefrogs I:}

\section{Chorus organization, aggressive calling, and fighting}

\begin{abstract}
Animals that form choruses and advertise to prospective mates must compete for a physical and acoustic space from which to display. Competition among signaling animals in the chorus often escalates into ritualized agonistic interactions and fights. I observed the behavior of the bird-voiced treefrog Hyla avivoca during chorus formation and tested the hypothesis that aggressive behaviors, such as aggressive calling and fighting, are more likely to occur during the early stages of chorus formation. I also tested the hypothesis that arriving males are more likely to settle near males giving advertisement calls than males giving aggressive calls. Aggressive calls were common early at night prior to female arrival. Contrary to expectations, males were as likely to settle next to a speaker broadcasting aggressive calls or a speaker broadcasting advertisement calls. Males were more likely to give aggressive calls when calling from dense, loud aggregations than when calling from dispersed choruses. Fights occurred after an exchange of bouts of fast-rate aggressive calls. However, there was no evidence that males assess the fighting abilities of potential rivals in natural aggressive encounters: no morphological or call variable predicted the winner of a fight. Aggressive behavior is discussed in light of the adaptive significance of male-male interactions, rival assessment and chorus organization.
\end{abstract}




\section{Introduction}

Male-male interactions during mating rituals arise as males try to increase their chances of attracting a mate (Alcock 2005). These interactions can directly or indirectly benefit males (Greenfield 1994; Gerhardt and Huber 2002). Interactions that result in greater signal attractiveness will benefit males directly by increasing the chances of being chosen by a female (e.g. Klump and Gerhardt 1988; Gerhardt et al. 1987; Hill 1998; Schwartz et al. 2002). Males might benefit indirectly by reducing competition within the chorus because of interactions that exclude rival males from a resource required by females or from the immediate displaying arena (Narins et al. 2003). In the previous chapter, I demonstrated that some modifications of the advertisement call should directly increased male mating success in the bird-voiced treefrog Hyla avivoca, by increasing call attractiveness. I now focus on indirect benefits of male-male interactions that arise from agonistic encounters in chorusing males, such as aggressive calling and fighting.

Frog choruses are breeding aggregations that are inherently male biased (Sullivan 1982a; Murphy 2003). Males typically travel to a particular chorus site and start to call before females arrive (Duellman and Trueb 1986; Murphy 1999); choruses of calling male frogs can be considered lek-like aggregations. Males in a lek advertise and display to females, which do not receive any direct benefit from their mates other than sperm (Bourne 1992; 1993; Sullivan 1982a; Grafe 1997; Friedl and Klump 2005; see Gerhardt and Huber 2002 for discussion of distinction between lekking and non-lekking frogs). As more males join the 
mêlée, the available calling sites as well as the acoustic space needed to transmit clear calls become saturated, limiting the production of clear signals and reducing attractiveness and detectability of individual calls (Wollerman and Wiley 2001; Gerhardt and Klump 1988). Male-male competition over these limited resources ensues quickly and often escalates into agonistic interactions and territorial disputes (Wells 1978; Huntingford and Turner 1987).

Frogs calling from a chorus typically maintain a minimum distance between males, presumably to reduce interference from other callers and to increase male mating success (Gerhardt and Huber 2002). Male distance is typically regulated by a species-specific amplitude of the calls of neighbors; when this amplitude is exceeded, aggressive behavior may ensue (Brenowitz 1989; reviewed in Gerhardt and Huber 2002). Males may modify the advertisement call, which also attracts females, to maintain male spacing (Telford 1985). Males however, may also employ a distinct aggressive or encounter call when advertisement-call modifications fail to repel a rival (Halliday and Adler 1987). If these signals fail to increase male spacing, males may engage in physical interactions in an effort to evict a rival signaler from the immediate calling area (Wells 1978). Because fights are potentially costly, however, male spacing is likely to be mediated by signals produced by males (Hammerstein and Reichert 1988; Shackleton et al. 2005).

Agonistic interactions are defined here as competitive interactions in which males produce an acoustically distinct call (aggressive calls, territorial calls, release calls: Wells 1977; 1978; Halliday and Adler 1987), engage in 
aggressive behaviors such as approaching or searching for a rival male, or initiate and engage in physical combat (Wells 1978; Kluge 1981). Males in agonistic interactions might reduce their chances of being selected by a potential mate because aggressive calls differ acoustically from advertisement calls and are usually less attractive to females than are advertisement calls (Gerhardt and Huber 2002). Males engaging in aggressive interactions prior to fighting are presumably prepared to fight and may be accurately displaying their fighting abilities (Burmeister et al. 2002) or resource holding potential (RHP; Parker 1974). Under this assumption, males engaged in aggressive interaction can assess the fighting abilities of potential rivals as measured by their RHP. In the behavioral context of displaying anurans, the RHP serves as a correlate to determine a male's willingness to defend a resource needed by mates (Dawkins and Krebs 1978).

Calling is energetically costly (Wells and Taigen 1986), and in anurans that call from lek-like choruses, advertisement call production is the main determinant of male mating success (Sullivan 1982 a b; Bourne 1992; 1993; Gerhardt 2005); faster advertisement call rates, for example, typically translate to increased relative attractiveness among males (Gerhardt and Huber 2002). So, males that change calling strategy to incorporate aggressive calls during agonistic interactions might reduce the production of attractive advertisement calls and might incur additional loss of metabolic energy if aggressive calls are more costly energetically than advertisement calls, reducing the potential for future behavior including costly displays and fights (Thorpe et al.1995). 
I sought to understand the role of aggressive calls in agonistic interactions and their effect on the settling patterns of callers in the chorus by observing frogs in the field from the onset of nightly chorusing activity. I tested three main hypotheses: (1) males should restrict aggressive calling and fighting to the early stages of chorusing when females arrive males are producing more advertisement calls; (2) males are more likely to settle near a speaker broadcasting advertisement calls than a speaker broadcasting aggressive calls; and (3) that the social context of an interaction affects the aggressiveness of an agonistic response.

\section{Methods}

\section{Arrival time, settling patterns and calling behavior.}

The bird-voiced treefrog, $H$. avivoca, usually calls from dispersed choruses spread along the shoreline of lakes, swamps and in flooded forests of the Southeastern United States (Dundee and Rossman 1989). However, males often form smaller aggregations along coves, ditches, and swamps near large rivers and may cluster in small groups within larger choruses (Chapter 2). In addition, birdvoiced treefrogs commonly call, albeit sporadically, from the canopy during hours of evening twilight, before descending to call in or around suitable breeding habitat at the chorus site (average height $1.4 \pm .8 \mathrm{~m}$ ). I refer to this as the prechorus calling activity period (Chapters 4 and 5). Chorusing is defined as the time when males are calling at the breeding assemblage, close to water. I observed the chorusing behavior of bird-voiced treefrogs in 18 small choruses throughout the species range (see Appendix 1 for localities) from April to July in 2003 and 2004. Each chorus was sampled on two consecutive days to gather separate data on 
arrival time and settling pattern on one day, and to observe the calling behavior of males arriving at the chorus site the other day. I determined sampling day with a number generator from Research Randomizer (www.Randomizer.org; C19972008, Urbaniak and Plous) to reduce confounding events from external sources, such as temperature or weather conditions. I selected small, isolated choruses (maximum of 14 males estimated on the day prior to conducting the study at each site) in order to follow the behavior of individual males accurately.

\section{Arrival times and settling patterns.}

I observed the chorusing behavior of $H$. avivoca for 120 minutes starting at sunset. Projected times for sunset were obtained from the US Naval Observatory database (http://aa.usno.navy.mil/data/docs/RS OneYear.php). I scored times of male and female arrival as the individuals were first heard or seen, mapped their initial position within the chorus site, and noted the location of males within the chorus every ten minutes for the 120 minutes sampling period. These data were used to: (1) identify the time of initiation of daily chorus activity (onset of chorus formation), (2) determine the movements and settling patterns of males throughout the chorus, and (3) determine if the number of males in the aggregation predicted the time of female arrival and number of females present.

\section{Calling behavior.}

In a separate set of observations, I registered the position of males calling in the chorus and recorded the number of aggressive calls and advertisement calls produced by up to four frogs for a three-minute period every ten minutes for 120 minutes starting at sunset. I counted males by ear and sight when males were 
calling at chorus level, and used two Bioear 10 parabolic acoustic receivers (Information Unlimited - Amhrest, NH) from the ground to accurately localize and detect the calls from individual males calling from the canopy during the prechorus calling period. I defined three sequential periods based on calling activity and number of males present at the chorus site: (1) pre-chorus calling activity, when males call from the canopy and there are no males at the chorus site; (2) chorus formation, which began when the first male was observed calling from the chorus site; (3) chorusing, which refers to chorus activity after the chorus formation period, when $90 \%$ of males were present at the chorus site. The first male observed to descend and start calling at the chorus site was considered the founder of the chorus. I defined the end of chorus formation as the time when $90 \%$ of the total males observed that night were already settled and calling.

Tracking the calls of individual bird-voiced treefrogs is possible in small groups, males emit advertisement calls about 5.8 calls per minute (Chapter 2) and once mapped at the chorus site, it is possible to locate and identify the calls produced by an individual frog. Using calls as a correlate of male density in anuran surveys (USGS 2004) is a common tool that has yield mixed results when working with large, multi-species choruses (Accurate estimates: Crouch and Patton 2002; Stevens and Paszkowski 2004; de Solla 2006. Non-accurate estimates: de Solla 2005), but are appropriate for small, single-species choruses.

\section{Aggressive calling, fights and playback experiments.}

I studied the aggressive behavior of bird-voiced treefrogs from May to August in 2003 and 2005 at two larger chorus sites in Mississippi (MS). One 
chorus at Lake Perry State Park, MS was a medium sized aggregation with an average of about $38( \pm 6.9)$ males per night. The other chorus was a nearby site with over 200 males calling from the shore of an oxbow lake near the Leaf River. I recorded aggressive calls, observed aggressive interactions, and conducted acoustic playback experiments to assess the effectiveness of aggressive calls in mediating male-male spacing within the chorus and to determine the rules of aggressive behavior in males.

\section{Recordings of aggressive calls.}

I selectively sought males that were producing aggressive calls and recorded at least 5 minutes of calling activity with a TasCam DAP1 Digital Audio Tape Recorder and Audio-Technica ATR-55 Line Cardioid Condenser Microphones. I used a CEL-254 digital impulse sound level meter (Bedford, UK) to obtain the Sound Pressure Level (SPL in decibels [dB] re $20 \mu \mathrm{Pa}$, fast rootmean-square [RMS]) of the nearest neighbors of all focal males. The SPL meter was placed directly above the focal male after each recording session to read the intensity levels of the calls of up to six of the nearest neighbors. I also measured the physical distance of these calling neighbors to the focal male and obtained deep-body temperature of the focal male using a Schultheis quick-reading thermometer after each recording. Males were assigned to two categories based on the number and proximity of calling neighbors: (1) high-density chorus (more than 3 males per $2 \mathrm{~m}^{2}$ ); and (2) low-density chorus (less than 3 males per $2 \mathrm{~m}^{2}$ ). Each male was toe-clipped with a unique code for individual identification and to avoid recording the same male twice. 


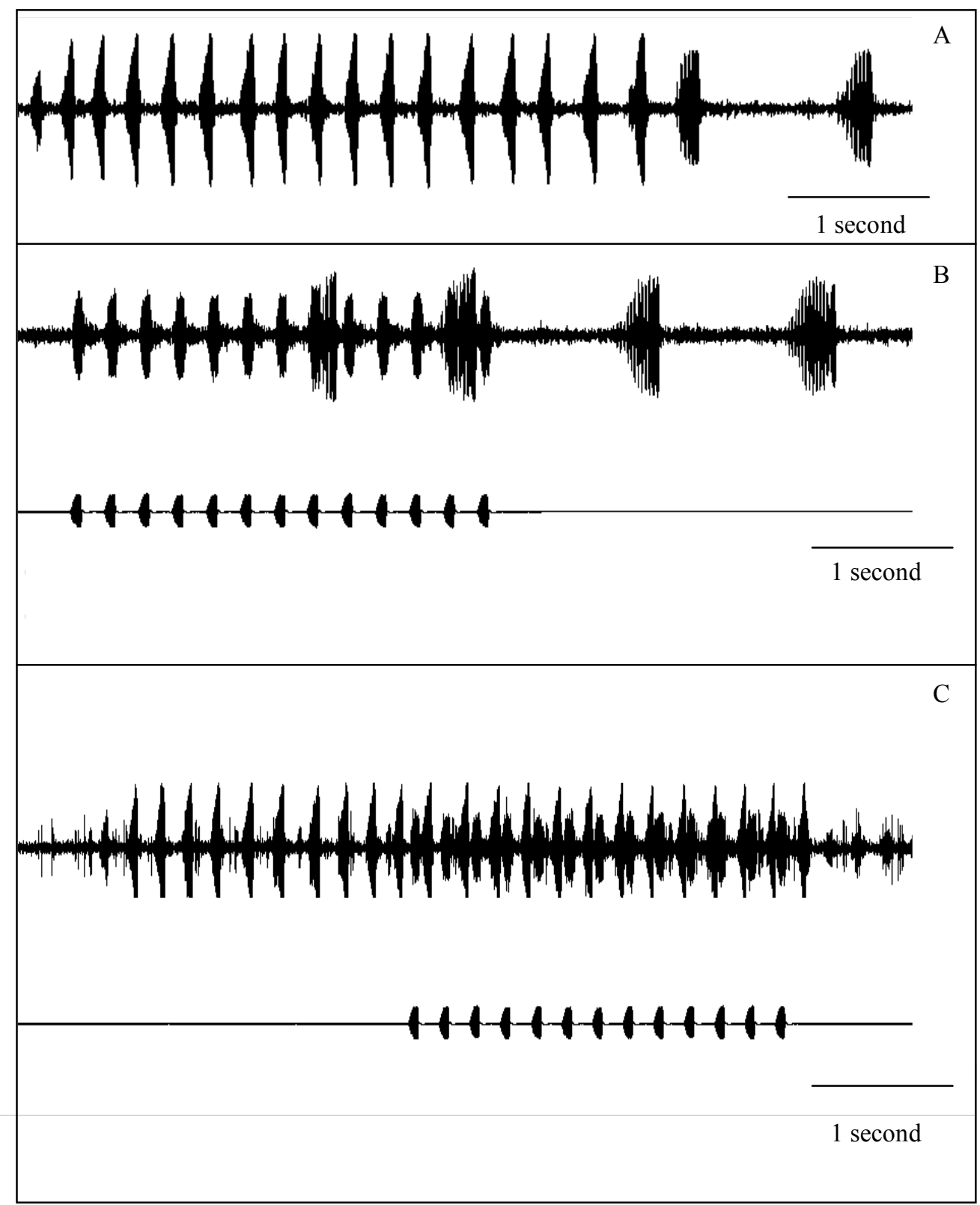

Figure 1. Sonograms of advertisement and aggressive calls of Hyla avivoca. A. Pulsed advertisement call followed by two aggressive calls. B. Top panel shows the response of a male to a playback of advertisement call by interrupting the playback with aggressive calls; botom panel shows the advertisement call plaback. C. Advertisement call (top panel) of $H$. avivoca, a playback of advertisement call (both panels) interrupts the call. The male increases call length and overlaps its pulses with the playback. Calls of Acris gryllus on background . Both playbacks broadcast at $82 \mathrm{~dB}$ SPL at a distance of 2 meters. 
Recordings were digitized and analyzed with Raven 1.2.1 software (Cornell Laboratories 2003-2005); all recordings were made at $22.4-27.6^{\circ} \mathrm{C}$ (Figure 1). I analyzed at least 20 aggressive calls per male as well as any advertisement calls produced by the focal male. I then measured call length and call repetition rate (= call rate) for each call type and counted the number of calls. Results were analyzed with a One Factor Analysis of Variance for repeated measures with a multi-comparison significance level at 5\% to compare calling activity of males under the different density conditions. I used StatView SE+Graphics (Abacus Concepts 1988) and JMP IN 5.1 (SAS Institute Inc. 19892003) software to obtain statistical analyses.

\section{Observations of Fights.}

Agonistic interactions that led to fights were observed throughout the study at all sites. When possible, I identified the challenging male as the male that initiated fighting and identified one male as the winner if the other retreated, ceased calling, or was expelled from his calling site. At the end of every fight, I measured snout-to-vent length (SVL) and tibia-fibula length (TFL) to the nearest $0.1 \mathrm{~mm}$ using a dial caliper and measured the mass of contestants to the nearest $0.1 \mathrm{~g}$ using a Pesola spring balance. The data were used to calculate residual indexes of body condition (Jakob et al. 1996) to determine if the winner of a fight could be predicted by size or condition regardless of tenancy of the calling site.

\section{Playback experiments.}

Two different playback tests were performed on calling males using synthetic sounds. Sound files of advertisement and aggressive calls were 
generated using SoundEdit 2.0.7 Software (Shockwave Macromedia 1990-1996)

on a MacIntosh PowerBook G4 (Apple Computer Inc., Cupertino, CA, USA)

following the steps described in Chapter 2. Modifications of a pure tone of 2.4

$\mathrm{kHz}$ were used to create a synthetic aggressive call. Envelope shape and pulse structure of aggressive calls vary greatly between and among males, but always consisted of an amplitude-modulated note of about $120 \mathrm{~ms}$ with four to six pulses of varied length. The synthetic aggressive call created had values of temporal properties matching those of an average aggressive call of five pulses (for examples of synthetic aggressive calls see the call diagrams on Fig. 4 A Chapter 4). The call consisted of five rhomboid shaped pure tones of $2.4 \mathrm{kHz}$. The initial pulse was 34 milliseconds and $80 \%$ relative amplitude. I then pasted three smaller rhomboid pulses of 18 milliseconds of $70 \%$ relative amplitude and pasted another pulse of 34 milliseconds with $80 \%$ relative amplitude, identical to the first pulse.

I broadcast a loop of synthetic aggressive calls to 10 males and a loop of natural aggressive calls to a different set of 10 males at $82 \mathrm{~dB} \mathrm{SPL}$ at $1 \mathrm{~m}$ to test the effectiveness of the synthetic aggressive call in eliciting a response. This intensity is the average value obtained for the calls of males calling at a distance of $1 \mathrm{~m}$ (this study; Gerhardt 1975). All 20 males reacted with aggressive calls to the playback; hence, I used synthetic aggressive calls for all tests.

\section{Playback Experiment 1 - Effect of advertisement and aggressive calls on chorus formation and male spacing: I used a GS 10 (T-Sound) omnidirectional speaker (TIC corporation) strapped to a tree to broadcast synthetic calls simulating an early neighbor during the period of chorus formation. The speaker}


was connected to a Virtual Reality Sound Laboratories 200-watt VR ${ }^{3}$ car amplifier to control the gain of the stimulus that was output from a MacIntosh PowerBook computer. I set the SPL to $86 \mathrm{~dB}$ at a distance of $0.5 \mathrm{~m}$ using a CEL254 SPL meter. The intensity adjustment was done away from the chorus prior to each test. A mute omnidirectional speaker was placed 10 meters from the active speaker at an ecologically similar site (i.e. similar canopy cover, water depth, distance to shore, overall perch availability) within the chorus and served as visual control for each trial. Speakers were placed in the afternoon before any chorus activity at known chorus site. Playbacks started after civil twilight, when natural light is not sufficient to distinguish terrestrial objects (Forsythe et al. 1995). Projected times for end of civil twilight were found at the US Naval Observatory database (http://aa.usno.navy.mil/data/docs/RS_OneYear.php).

In 15 trials, I broadcast a 20-minute playback of an average 23-pulse advertisement call at a rate of five calls per minute. In 15 different trials, I broadcast a 20-minute playback of a bout of four aggressive calls at a rate of 0.5 calls per sec $(200 \mathrm{msec}$ call and $1.8 \mathrm{sec}$ interval; $8 \mathrm{sec}$ total duration for the call bout); the bout was repeated every 40 seconds. I used a number generator (see above) to determine which stimulus was to be used each night.

I recorded the arrival times of each male that settled within a $3 \mathrm{~m}^{2}$ radius of both speakers and the position of males every five minutes until the end of the 20minute playback. At the end of the playback I recorded intermale distance and distance to speaker for all males. 


\section{Playback Experiment 2 - Male response to advertisement and aggressive}

calls: The playback system consisted of a PowerBook G4 (Apple Computers)

connected to a 200-watt $\mathrm{VR}^{3}$ car amplifier (Virtual Reality Sound Laboratories)

broadcasting calls from a 4" x 10" midrange horn speaker (Parts Express W-46-

02-104) mounted on a Velbon 5000 tripod. I used a CEL-254 SPL meter to adjust

the intensity for the speaker output at a location away from the experimental

males prior to each test.

I performed aggressive-response tests for advertisement and aggressive calls on 96 males calling under three different intensities for a fully factorial design. Of these, 48 males were presented with a 10-call playback loop of a 23pulse advertisement call (average length of the calls produced by males calling with neighbors) repeated every five seconds. The intensities for the playbacks were: $88 \mathrm{~dB}$ SPL, $82 \mathrm{~dB}$ SPL and $76 \mathrm{~dB}$ SPL at a distance of about $1 \mathrm{~m}$ from the focal male. The other 48 males were presented with a series of four aggressive calls repeated at a rate of 0.5 calls per sec $(200 \mathrm{msec}$ long call and $1.8 \mathrm{sec}$ long interval $\sim 8 \mathrm{sec}$ total duration) repeated every 40 seconds. I broadcast playbacks at the same intensities ( $88 \mathrm{~dB}$ SPL, $82 \mathrm{~dB}$ SPL and $76 \mathrm{~dB}$ SPL). Males were tested only once and were assigned to one of three different intensity levels, 16 males to each intensity levels per call type.

The vocal responses of the 96 males were recorded with a TasCam DAP1 Digital Audio Tape Recorder using Audio-Technica ATR-55 Line Cardioid Condenser Microphones. Deep-body temperature was obtained using a Schultheis quick-reading thermometer. I recorded at least five calls before, during, and after 
the playback. Whenever possible, 20 calls were digitized and analyzed for each male using Raven 1.2.1 software (Cornell Laboratories 2003-2005). I scored the time of first aggressive response after playback initiation, total number of advertisement and aggressive calls produced, type of aggressive response (aggressive calls, approaching the speaker), and calculated the proportion of advertisement and aggressive calls produced before, during and after playback. After each playback, I measured the intensity and distance of up to five of the closest neighbors, counted the number of calling males within a $5 \mathrm{~m}$ radius and the intensity of chorus noise at the site of the focal male.

\section{Data analysis}

A One-Factor Analysis of Variance for repeated measures with a multicomparison significance level at 5\% was used to analyze the effect of playbacks on male calling behavior because I measured call parameters of the same male before, during and after treatment. A Friedman test for related samples was used to test for significant of treatment effects on the chorus formation and male spacing playbacks. I computed 95\% -exact confidence limits (binomial distribution) on the proportion of males that reacted with aggressive calls or physical aggression (approaching speaker) to playbacks and only show the lower or upper confidence limits for significant results of a two-tailed binomial test $(P<0.05)$. Results were analyzed using StatView SE+Graphics (Abacus Concepts 1988) and JMP IN 5.1 (SAS Institute Inc. 1989-2003) software. The Animal Care and Use Committee of the University of Missouri approved all experimental procedures. 


\section{Results}

\section{Arrival times and settling patterns.}

Males were calling from the canopy during the pre-chorus activity period when I began observations; the founder male started calling on average about 12.8 minutes $( \pm 2.3)$ after sunset in the 18 choruses sampled. The chorus formation period ended about 28.6 minutes $( \pm 10.3)$ after sunset, around the end of civil twilight. The first females arrived on average at the chorus around 64.3 minutes $( \pm 12.3)$ after sunset.

Average chorus size was $8.89 \pm 2.81$ (range: 6 -14) males per chorus with a mean intermale distance of $3.17 \pm 1.2 \mathrm{~m}$ (range $5.6-1.8$ ). Male movement within the chorus was minimal after males started to call $(10.3 \pm 2.4 \mathrm{~cm}$ from original calling perch on average). Males moved mainly when engaged in aggressive calling or in a fight. I observed 23 fighting events during the sampling period (average of 1.27 fights per night). These fights, however, were not used in the analysis of fighting behavior presented below.

\section{Calling behavior.}

Aggressive calls were common during pre-chorus calling activity, during chorus formation and during the first 40 minutes of chorus activity. Males produced $10.3( \pm 2.7)$ aggressive calls every 3-minutes on average before descending from the canopy during the pre-chorus calling activity $(\mathrm{n}=2$ sampling periods per night) and an average of $17.8( \pm 3.2)$ aggressive calls per minute $(n=3$ sampling periods per night) during chorus formation. Chorusing males produced a maximum of $26( \pm 4.6)$ aggressive calls during the first 30 minutes of chorus 
activity and gradually reduced the number of aggressive calls produced.

Production of aggressive calls dropped significantly after 60 minutes of chorusing when compared to aggressive-call production during chorus formation (16.4 \pm 3.7 calls for the group; Repeated Measures ANOVA $F_{1,19}=93.71$,

$P<0.001$, Fig. 3). I found no significant correlation between number of aggressive calls produced by the focal male and the number and proximity of males that settled subsequently within the chorus $\left(\mathrm{f}^{2}=0.13 ; \mathrm{p}=0.23\right.$; average aggressive calls of settlers in three minutes was $24.3 \pm 8.5$; average number of neighbors was $2.7 \pm 0.8)$.

\section{Aggressive calling.}

A summary of the measurements of the temporal properties of aggressive calls is given in Table 1. Males produced bouts of aggressive calls interspersed between bouts of advertisement calls. Advertisement calls produced during bouts of aggressive call were longer than advertisement calls produced between bouts of aggressive calls (mean difference of about 3.6 \pm 2.3 pulses). Advertisement call rate dropped sharply during bouts of aggressive calls.

Solitary males produced an average of $10.55 \pm 3.2$ aggressive calls per minute with an average of $3.8( \pm 2.1)$ aggressive calls per bout; such males produced about $2.3( \pm 1.8)$ advertisement calls between bouts of aggressive calls. Males calling from groups produced $18.5 \pm 3.9$ aggressive calls per minute with an average of $8.6( \pm 3.2)$ calls per bouts; males calling in pairs or groups produced an average of $1.2( \pm 0.7)$ advertisement calls between bouts of aggressive calls. Aggressive call rate varied greatly among and between individuals with one or 


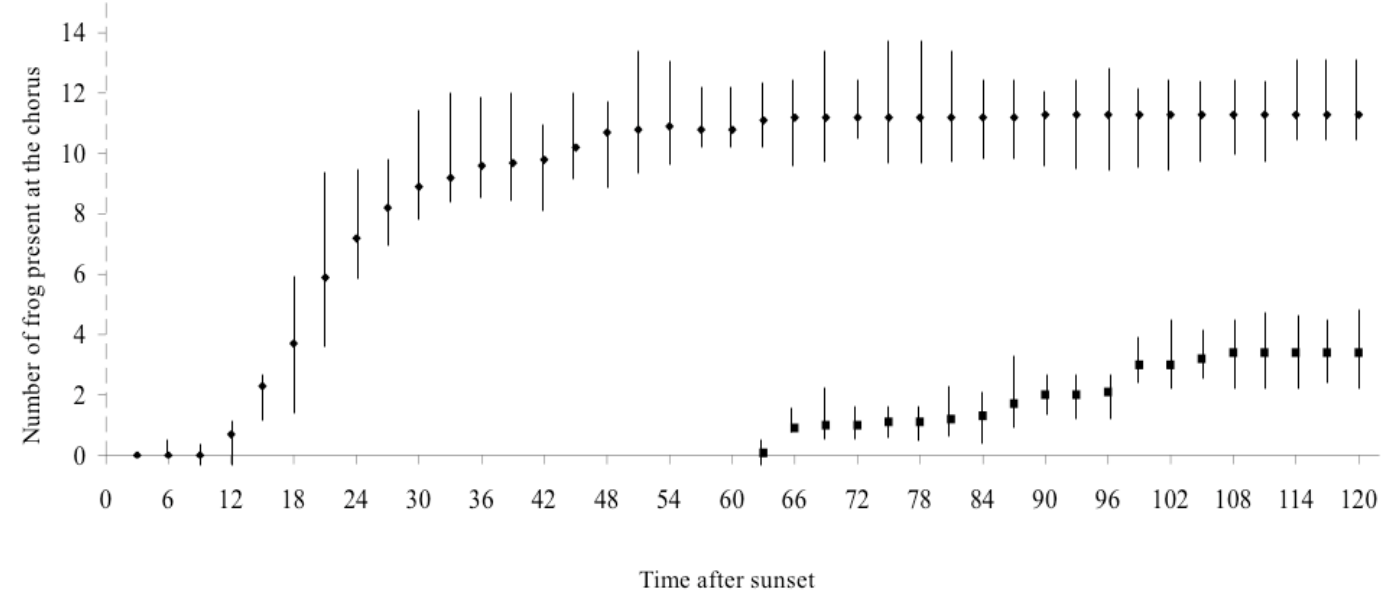

Figure 2. Arrival time of males and females in choruses of up to 14 males (Average $=10.3$ ). First male (founder male) arrives about 6 minutes after sunset. By 26 minutes, $90 \%$ of males are already at the chorus site. Females arrive about an hour after sunset.

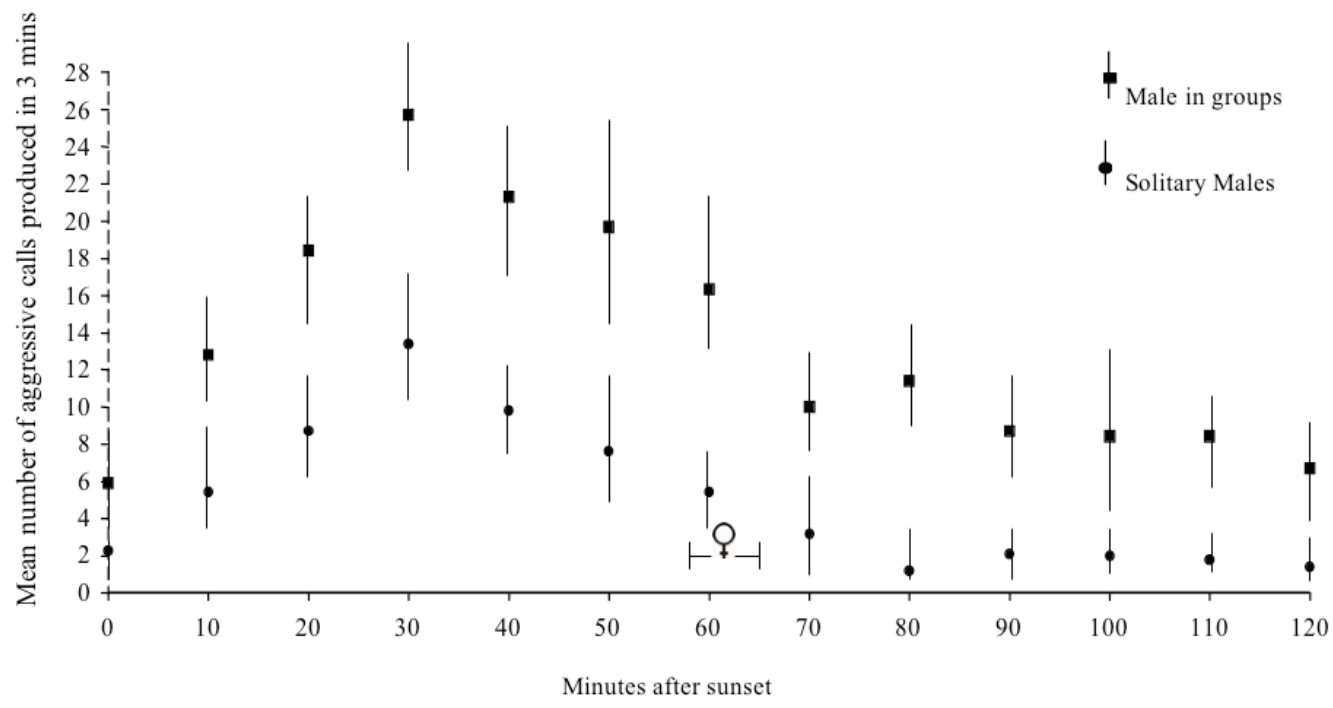

Figure 3. Peak production of aggressive calls during the first 120 minutes of chorus formation for 18 choruses of the bird-voiced treefrog. Solitary males (circles) produced significantly fewer aggressive calls when compared to individual males calling in pairs (squares) during peak activity 18-minutes after chorus initiation (MANOVA, F-test $=48.5 ; \mathrm{P}<0.01$ ) and 60 minutes after chorus initiation (MANOVA, F-test $=36.1 ; \mathrm{P}<0.01$ ). Arrival of first female coincided with a drop in aggressive activity $(68.4 \pm 2.8$ minutes after chorus formation; female symbol; $\mathrm{N}=18$ ) in the chorus. Lines represent the standard deviations for each average point. 
Table 1. Mean values for gross-temporal parameters of Hyla avivoca aggressive calls under three different types of aggregations.

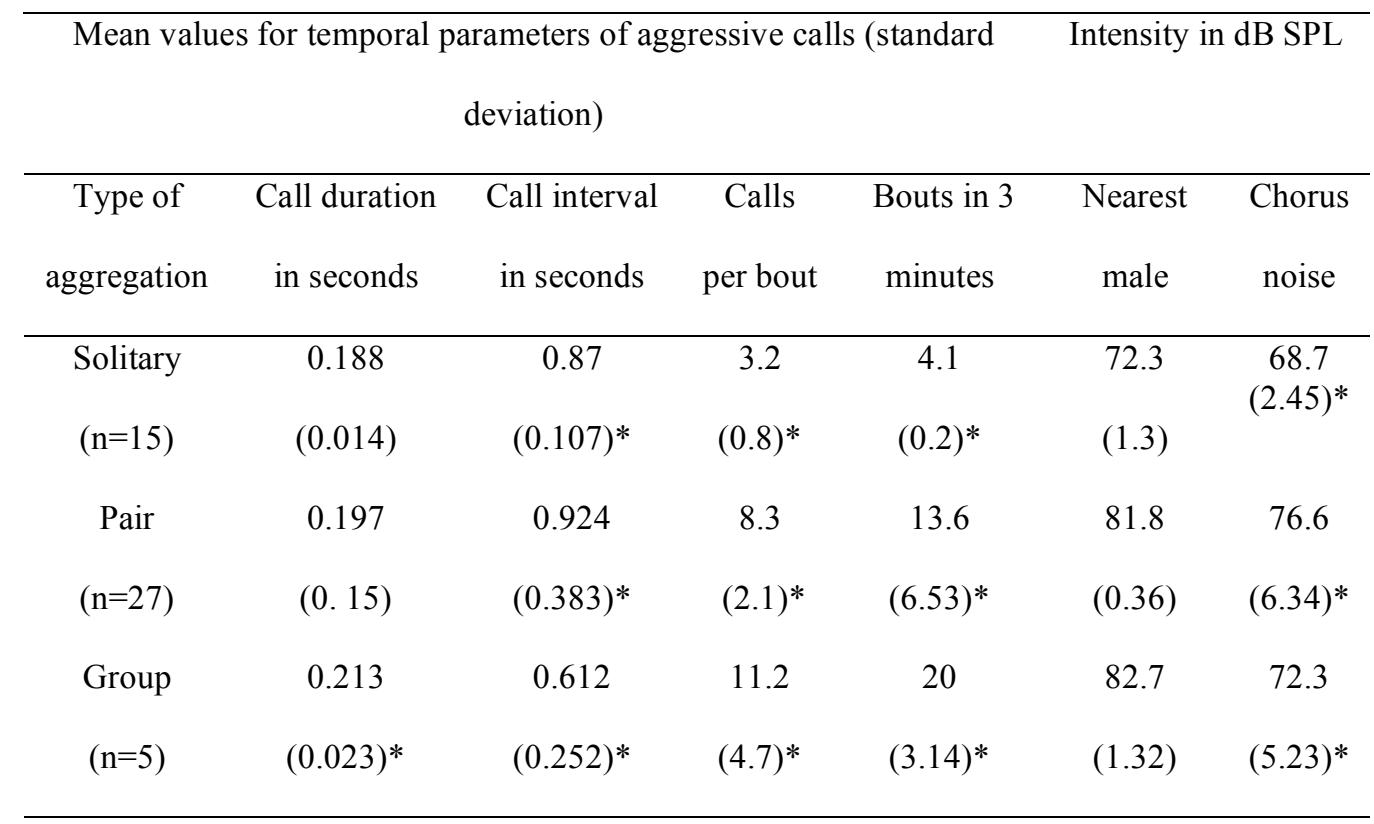

*Significance of $\mathrm{P}<0.05$ for a One-factor Repeated Measures ANOVA. 
more calling neighbors (Table 1). Aggressive call production did not correlate with intermale distance, $5.4 \mathrm{~m} \pm 3.2\left(\mathrm{r}^{2}=0.43 ; P=0.32\right)$, meaning that proximity to nearest caller did not predict the intensity of aggressive calling by a focal male. The intensity at which males responded with aggressive calls for males calling in denser aggregations correlated with the overall intensity of the chorus and not with the intensity of the nearest neighbor $\left(\mathrm{r}^{2}=0.012 ; \mathrm{n}=23 ; P<0.001\right)$. However, there was no relationship between proximity of nearest neighbor and frequency of aggressive calling between males calling in pairs or in groups $\left(\mathrm{r}^{2}=0.22 ; \mathrm{n}=45 ; P\right.$ $=0.18)$. Aggressive call production for males calling in pairs $(\mathrm{N}=22)$ or in groups $(\mathrm{N}=23)$ was not statistically different from each other (Repeated Measures ANOVA F 1,$44 ; P=0.67)$.

\section{Agonistic interactions and fights.}

Agonistic interactions, in which two or more males exchanged aggressive calls between bouts of advertisements calling but without escalating into a fight, were the most common type of interaction. However, I observed 46 agonistic interactions that progressed to a fight or were first observed as a fight. Of these, 14 interactions occurred between multiple males that interchanged aggressive calls with the initial challenger (first male to produce aggressive calls); these data were not used in the following analysis. Of the 32 fights recorded between two males, 22 were observed before physical contact occurred, and enough data are available to obtain statistically relevant information in order to make generalizations about the sequence of events and the escalation of aggressive behaviors resulting in fighting. 
Prior to a fight, one male increased the rate of aggressive call production up to 4 times and often approached a close neighbor or moved as if actively seeking another male. These type of aggressive calls, termed fast-rate aggressive calls, are temporally distinct and more ritualized than regular aggressive calls and probably constitute a threat display that elicits a fight or a flight response from a neighboring male. In 17 of the 22 encounters, a neighbor responded to the challenger by exchanging fast-rate aggressive calls with the challenger from its calling position. In the other five encounters, the challenger approached the neighbor and displaced him from the calling perch, without any observable response from the challenged male. In the 17 events where a challenger was confronted with fast-rate aggressive calls from the other male, one or both males approached and started to joust and grapple each other while emitting shorter fastrate aggressive calls. The calls emitted during combat were shorter (similar to release calls: Halliday and Adler 1987) and repeated at an irregular rate $(27.3 \pm$ 7.5 calls per minute). A significant number of fights (14 of 17), ended with a male being evicted from the calling perch ( 8 males retreated, 6 males were thrown away). Roughly, half of the 19 evicted males were later seen calling in a nearby perch, away from the site of the interaction. Fast-rate aggressive calls were given in response to regular aggressive calls; a resident caller or an approaching male were as likely to initiate a bout of fast-rate aggressive calls ( 8 resident, 7 intruder). There was no significant difference in weight or body condition among fighting males (Body weight: T-test; $P=0.23$; body condition T-test; $P=0.17$ ). 


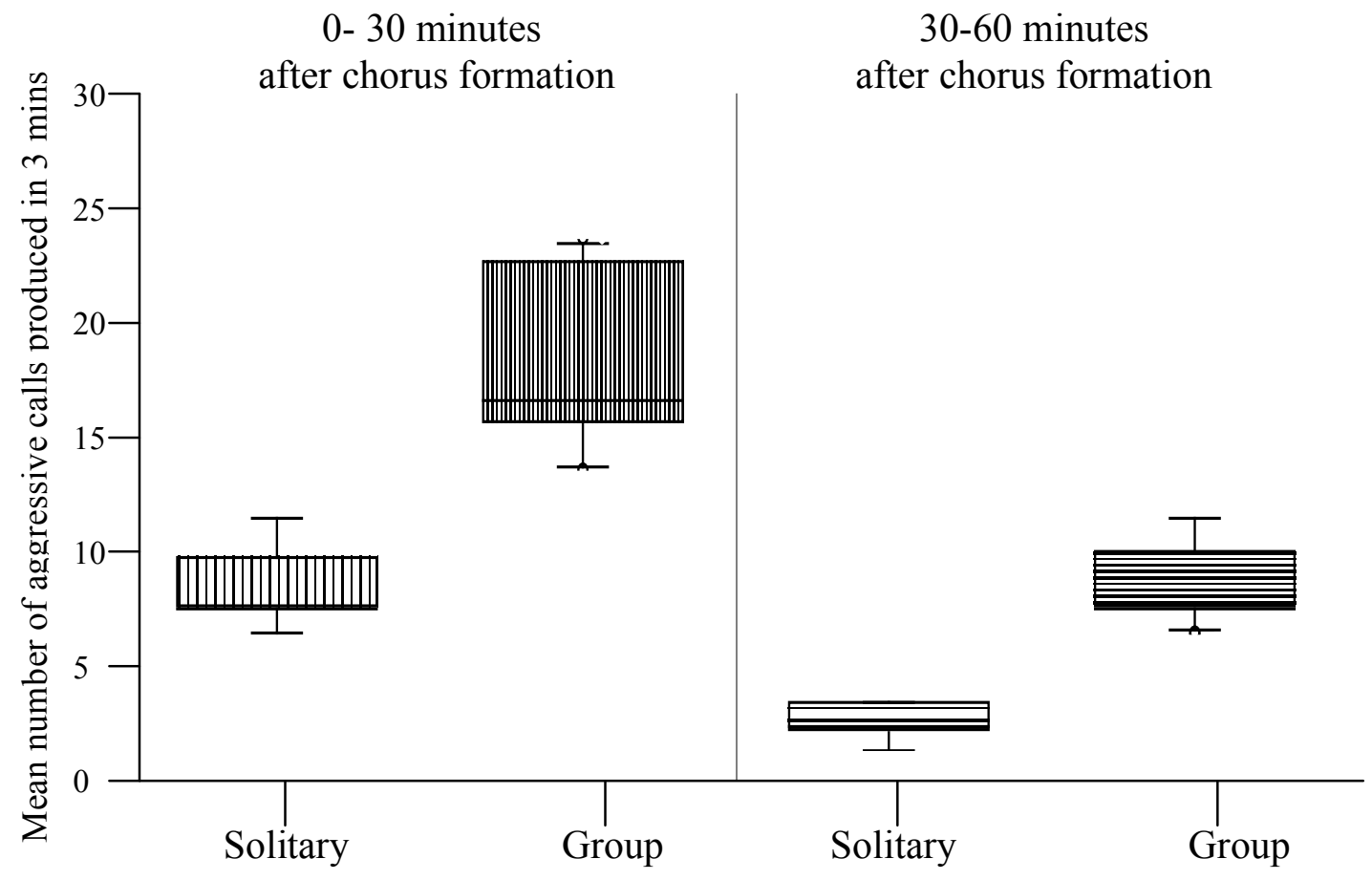

Figure 4. Highest number of aggressive calls produced by individual males during chorus formation and after chorus formation. (0-30 minutes, $\mathrm{F}=128.06, \mathrm{P}<$ 0.01; 30-60 $\mathrm{F}=0.096 \mathrm{P}<0.01$ ). 


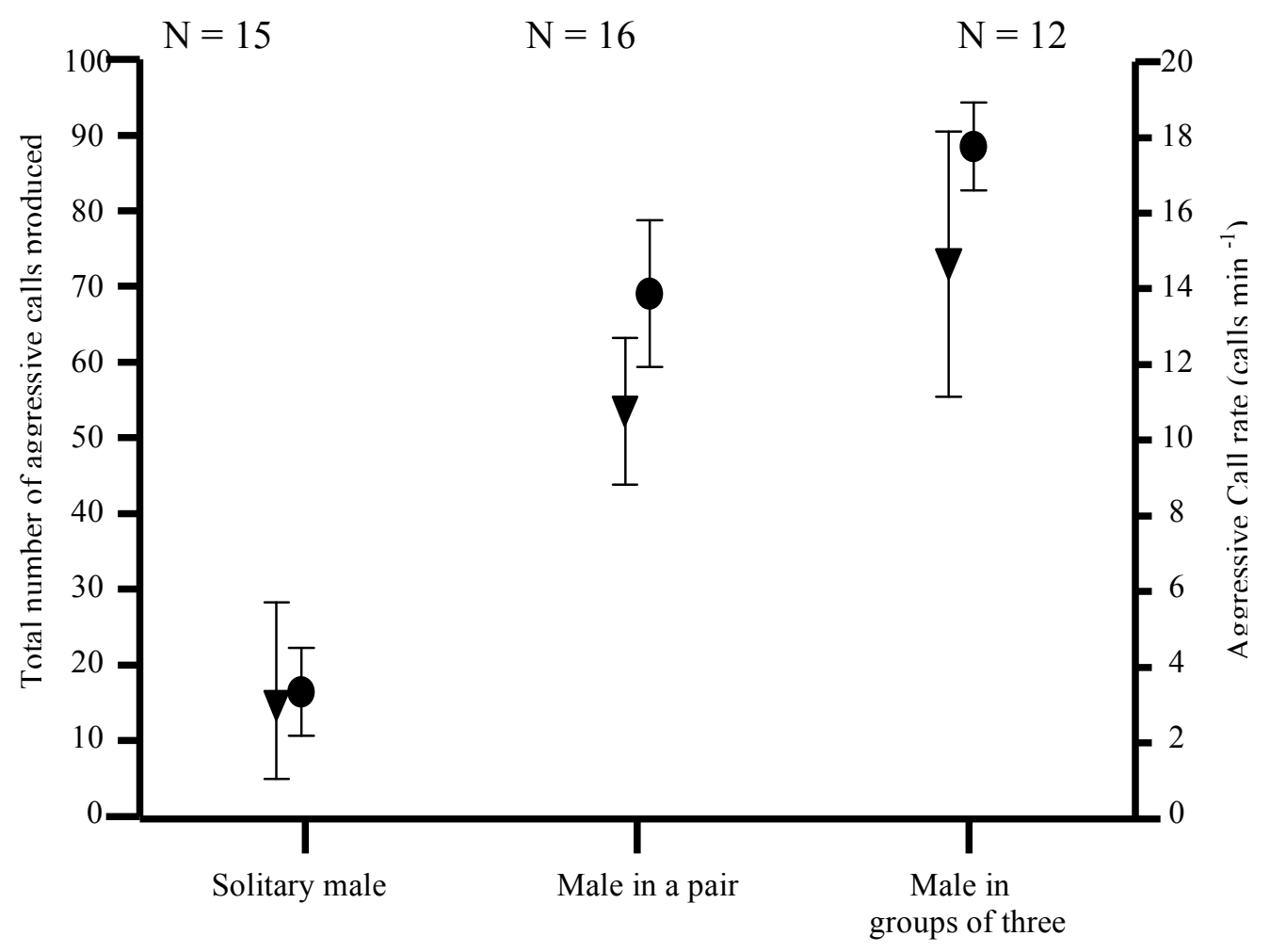

Figure 5. Aggressive calls produced during a 10-minute period, 30 minutes after the onset of chorus activity. ( $\sim 30$ minutes after sundown). Filled circles show the total number of aggressive calls produced by males calling under three different acoustic environments. Filled triangles show the aggressive call rate for each group. $\mathrm{P}=0.001$. Friedman's test for unrelated samples. 


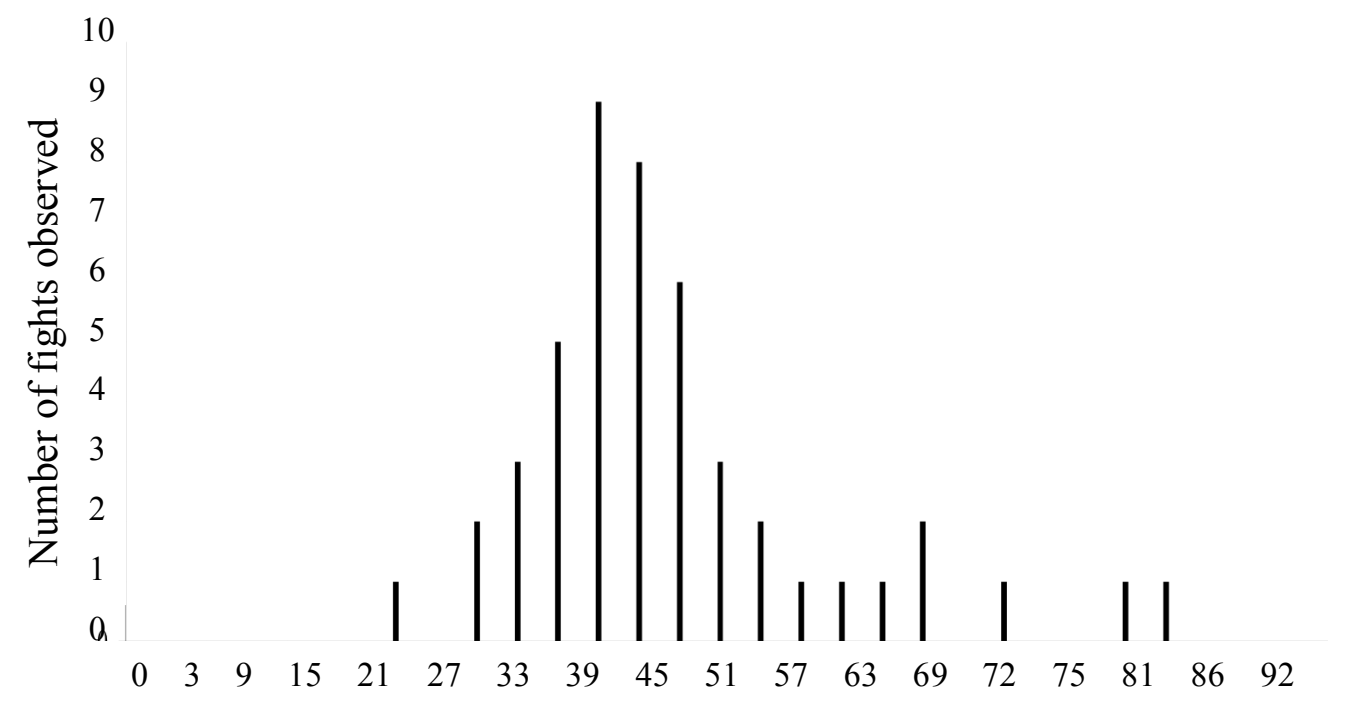

Minutes after sunset
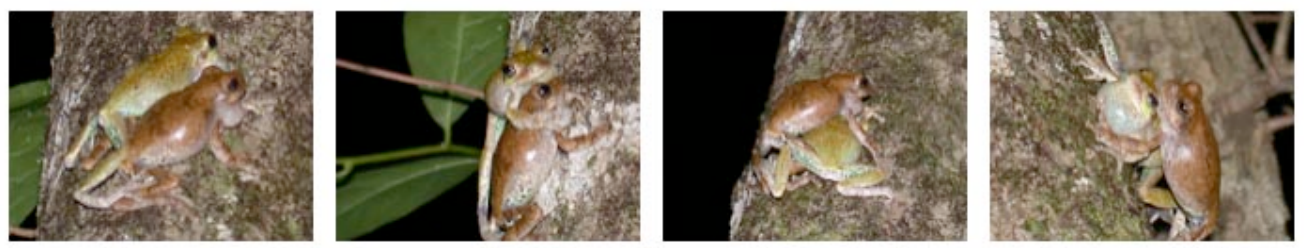

Figure 6. Top panel shows the frequency of fights during the first 90 minutes of chorus formation. Peak fighting activity occurs from approximately 10 to 20 minutes after chorus formation when $90 \%$ of males arrive to the chorus. Bottom panel shows a fighting sequence of a pair of $H$. avivoca males. 


\section{Playback Experiment 1 - Effect of advertisement and aggressive calls on}

chorus formation and male spacing: More males settled next to either of the active speakers and arrived sooner near these speakers than to the mute speaker. Males were as likely to settle next to a speaker broadcasting aggressive calls $(\mathrm{n}=$ $2.3 \pm 0.56)$ than to a speaker broadcasting advertisement calls $(\mathrm{n}=2.1 \pm 0.74, \mathrm{p}=$ 0.36, two-tailed binomial test). Males settled on average closer to the speaker broadcasting advertisement calls than to the speaker broadcasting aggressive calls or the mute speaker $(2.3 \pm 0.2 ; \mathrm{p}<0.05$ Friedman's test; Table 2$)$.

\section{Playback Experiment 2 - Male response to playbacks of advertisement calls}

and aggressive calls: The proportions of males responding to the various

playback tests are summarized in Table 3. Before reacting with aggressive calls in response to playbacks of advertisement calls, males increasing advertisement call length $(\mathrm{F}-$ Test $=53.9, \mathrm{P}<0.01 \mathrm{df}=39)$ and call rate $(\mathrm{F}-$ Test $=113.6, \mathrm{P}<0.01$ $\mathrm{df}=39$ ). They also overlapped calls and interdigitated pulses with the advertisement-call stimulus. Males presented with playbacks of advertisement call at $78 \mathrm{~dB}$ SPL increased advertisement call length and rate. A significant number of males presented with advertisement call playback at $86 \mathrm{~dB}$ interrupted the playbacks with aggressive calls (Fig.1B; 15/16 males). A significant proportion of males presented with playbacks of aggressive calls at low intensity (78 dB) reacted with a delayed response aggressive (13/16), and 14/16 males presented with an aggressive playback, gave a delayed aggressive response. A significant number of males $(12 / 16)$ followed the aggressive call response with a display of fast-rate aggressive calls and lunged at the speaker. 
Table 2. Number of males that settled next to each speaker. $\mathrm{N}=15$ males per trial

\begin{tabular}{ccccc}
\hline $\begin{array}{c}\text { Type of } \\
\text { playback }\end{array}$ & $\begin{array}{c}\text { Number of } \\
\text { males in } 3 \mathrm{~m}^{2} \\
\text { radius }\end{array}$ & $\begin{array}{c}\text { Closest } \\
\text { distance to } \\
\text { speaker }\end{array}$ & $\begin{array}{c}\text { Avg male } \\
\text { distance }\end{array}$ & $\begin{array}{c}\text { Bouts in 3 } \\
\text { minutes }\end{array}$ \\
\hline Aggressive & $6.5(1.2)^{*}$ & $2.3(0.2)^{*}$ & $2.1(1.2)^{*}$ & $24(6.19)^{*}$ \\
Advertisement & $6.8(1.27)^{*}$ & $1.7(1.2)$ & $1.9(0.9)^{*}$ & $18(2.57)^{*}$ \\
Mute control & $4.7(1.03)$ & $1.7(0.3)$ & $2.8(0.4)$ & $14(5.14)$ \\
\hline
\end{tabular}

* Statistical significance of $\mathrm{P}<0.05$ for a Friedman test for related samples when compared to the values of the mute speaker, which served as control.

Table 3. Proportion of the responses of males to playbacks of aggressive and advertisement calls at different intensities. (16 males per treatment; $\mathrm{N}=96$ ).

\begin{tabular}{ccccccc}
\hline \multirow{2}{*}{ Type of response } & \multicolumn{3}{c}{$\begin{array}{c}\text { Advertisement call playback } \\
\text { in db }\end{array}$} & \multicolumn{3}{c}{$\begin{array}{c}\text { Aggressive call playback in } \\
\mathrm{dB}\end{array}$} \\
\cline { 2 - 7 } & Low 78 & Med 82 & Hi 88 & Low 78 & Med 82 & Hi 88 \\
\hline $\begin{array}{c}\text { Increased call } \\
\text { length }\end{array}$ & 0.937 & 0.937 & 0 & 0.937 & 0 & 0 \\
$\begin{array}{c}\text { Delayed } \\
\text { aggressive } \\
\text { response }\end{array}$ & 0.812 & 0.437 & 0.125 & 0.812 & 0.125 & 0.063 \\
$\begin{array}{c}\text { Aggressive call } \\
\text { interruption } \\
\text { Fast rate }\end{array}$ & 0.125 & 0.875 & 0 & 0.812 & 0.812 & 0.937 \\
aggressive calls & 0 & 0 & 0.125 & 0 & 0.187 & 0.685 \\
\hline
\end{tabular}

Table 4. Temporal call parameters of aggressive calls given under different social interactions.

\begin{tabular}{|c|c|c|c|c|c|}
\hline $\begin{array}{c}\text { Type of } \\
\text { Aggressive call }\end{array}$ & $\mathrm{N}$ & $\begin{array}{l}\text { Call length in } \\
\text { second }\end{array}$ & $\begin{array}{c}\text { Pulse } \\
\text { number }\end{array}$ & $\begin{array}{l}\text { Bouts per } \\
\text { minute }\end{array}$ & $\begin{array}{l}\text { Calls per } \\
\text { bout }\end{array}$ \\
\hline Solitary males & 20 & $0.188(0.014)$ & 5.2 & $1.2(0.2)^{*}$ & $3.2(0.8)^{*}$ \\
\hline Pairs of males & 20 & $0.197(0.015)$ & 6.1 & $4.6(2.43)^{*}$ & $8.3(2.1)^{*}$ \\
\hline $\begin{array}{c}\text { Fast-rate } \\
\text { aggressive } \\
\text { calls }\end{array}$ & 20 & $0.120(0.010)$ & $3.8(0.6)$ & $3.4(1.2)$ & $12.2(1.1)$ \\
\hline $\begin{array}{c}\text { Combat } \\
\text { aggressive } \\
\text { calls }\end{array}$ & 20 & $0.121(0.012)$ & $3.4(0.8$ & $4.1(2.4)$ & $26(12.4)$ \\
\hline Release calls* & 20 & $0.109(0.027)$ & $3.7(1.2)$ & $\mathrm{N} / \mathrm{A}$ & $\mathrm{N} / \mathrm{A}$ \\
\hline
\end{tabular}




\section{Discussion}

Early research in anuran communication proposed that advertisement calls serve the dual purpose of attracting females and maintaining male-male spacing (Emlen 1968; Wiewandt 1969; Whitney and Krebs 1975; Reviewed in: Wells 1988). Various studies demonstrate that the spatial organization of calling males in choruses can be mediated by the acoustic intensity of a neighbor's advertisement call (i.e. male proximity) without the need for a distinctive aggressive call (Eleutherodactylus diastema Wilczynski and Brenowitz 1988; Hyla gratiosa Murphy and Floyd 2005; Panacanthus pallicornis Chamorro-R et al. 2007; reviewed in Gerhardt and Huber 2002). Furthermore, the data gathered in my experiments demonstrate that aggressive calls in $H$. avivoca specifically, elicit an aggressive response from males but do not prevent new individuals from settling next to established callers. What then, is the evolutionary advantage for aggressive calls?

\section{The role of aggressive calling during the early stages of chorus formation.}

Aggressive call production increases significantly as males descend from the canopy and settle at the chorus site to call. The number of aggressive calls that males produced dropped substantially after chorus formation, before female arrival. These patterns suggest that males produce aggressive calls in order to compete for a calling space and when approached by other calling males during the chorus formation. The response of males to playbacks of advertisement and aggressive calls also provides support to the hypothesis that males produce aggressive calls when approached by other calling males. 
Playbacks broadcasting aggressive calls during chorus formation attracted the about the same numbers of males to a $3 \mathrm{~m}^{2}$ calling area within the chorus than did playbacks of advertisement calls. The experiment does not provide evidence that aggressive calls alone repel males from a calling area, but both aggressive and advertisement calls did mediate spacing in H. avivoca.

Regardless of the stimulus used, males were attracted to speakers and to one another, causing a general clumping of calling males next to the speaker. The average male-male distances observed in the chorus results in lower overall densities, even in larger choruses and should increase the clear broadcasting area of individual males. I found little correlation between number of aggressive calls produced by a male and number and proximity of neighbors that settled next to it, suggesting that aggressive calls in $H$. avivoca are not more effective than advertisement calls in mediating inter-male distance during chorus formation.

Producing aggressive calls during chorus formation may benefit males indirectly by limiting the number of males that settle in the immediate calling area within the chorus. In addition, males engage in potentially non-attractive behavior, i.e. fights, before females arrive to the chorus. However, the data show aggressive calling alone does not increase male spacing nor result in the eviction of an intruder. Instead, aggressive calls may arise as a competitive behavior that disrupts the calling patterns of rival male (Halliday and Adler 1987).

\section{The cost and benefits of aggressive calls and fighting.}

Most of the studies on agonistic interactions and the evolution of fighting behavior focus on the rules of rival assessment prior to a fight (Jakobsson et al. 
1995; Gardner and Morris 1989) and utilize variants of Game Theory to explain fighting and other ritualized aggressive behaviors (Maynard Smith 1982). Aggressive signals provide information about the behavior and intent of the signaler, presumably demonstrating its readiness to fight. Game theory predicts that if aggressive signals are not limited by any physiological factor of the signaler, then aggressive calls are under no reliable constraint (Maynard Smith 1982). In other words, animals are able to bluff other contestants and engage in displays of aggressive behavior even when the chances of losing are greater than the chances of winning a fight (Dawkins and Krebs 1978). Maynard Smith (1982) predicted that even when a signaler can announce its intent to fight via aggressive calls, animals engaging in aggressive signaling can only reliably announce their ability to win.

Agonistic interactions among calling males can be expected to be advantageous if males receive an immediate (i.e. indirect) benefit by expelling a competing neighbor from the calling site. In the bird-voiced treefrog, as in other lekking anurans, call rate and not body size or any of its correlates determines the outcome of male mating success via female choice (Sullivan 1982 a, b; Gerhardt 2005). The quality of the calling territory plays little or no role in mate selection. Thus a male might gain little by revealing its RHP and might show its intent to engage in aggressive calling and fights with a male that calls too close to its calling site within the chorus (Robertson 1984; 1986; Wagner 1989b). The usual assumption is that males defend an acoustic space, which allows a relatively clear broadcast of its calls to attract females (Burmeister et al. 1999). Under these 
circumstances, males should fight to fend off a competitor whether or not he will be the winner. The graded aggressive calls of $H$. avivoca, may signal readiness to fight or might serve as a threat display employed prior to a fight. I was not able to measure any extrinsic variable (number of neighbors, time of night, body condition, site tenure, threat initiation) that reliably predicts which male will win a fight, nor did I measure any cost of fighting to males other than eviction from the calling arena and time spent fighting. A possible explanation is that rival males may show that they are likely to fight but may not provide rivals with an honest signal of fighting ability, suggesting there is no assessment of RHP in H. avivoca.

All of the observed physical interactions occurred prior to female arrival. By engaging in aggressive behavior prior to female arrival, males almost certainly reduced the risk of being unattractive to females. Additionally, most of the males evicted from a calling territory resumed calling elsewhere within the same night. If losers are able to resume calling, albeit at a different calling site within the chorus, fighting in $H$. avivoca might not be as evolutionary costly as theory suggests (Zahavi 1977, Grafen 1990).

\section{Literature Cited}

Alcock J .2005. Animal Behavior: An Evolutionary Approach. 8th ed. Sunderland, MA: Sinauer Assoc

Bee MA, Perrill SA, Owen PC. 1999. Size assessment in simulated territorial encounters between male green frogs (Rana clamitans). Behav Ecol Sociobiol $45: 177-84$ 
Bourne GR. 1992. Lekking behavior in the Neotropical Frog Ololygon rubra. Behav Ecol Sociobiol 31:173-180

Bourne GR. 1993. Proximate costs and benefits of mate acquisition at leks of the frog Ololygon rubra. Anim Behav 45:1051-1056

Brenowitz EA. 1989. Neighbor call amplitude influences aggressive behavior and intermale spacing in choruses of the Pacific Treefrog Hyla regilla. Ethol 83:69-79

Burmeister SS Konieczka J, Wilczynski W. 1999. Agonistic interactions in a cricket frog (Acris crepitans) chorus: behavioral outcomes vary with local competition and within the breeding season. Ethol 105: 335-347

Burmeister SS, Ophir AG, Ryan MJ, Wilczynski W. 2002. Information transfer during cricket frog contests. Anim Behav 64:215-225

Chamorro-R J, Montealegre-Z F, González-O R. 2007. Determinants of male spacing behaviour in Panacanthus pallicornis (Orthoptera: Tettigoniidae). Ethology (113): 1158-1172

Crouch WB III, Patton PWC. 2002. Assessing the Use of Call Surveys to Monitor Breeding Anurans in Rhode Island. J Herpetol 36:2, pp. 185-192 
Dawkins R, Krebs JR. 1978. Animal signals: information or manipulation? In: Krebs JR, Davies NB (eds) Behavioural ecology: an evolutionary approach. Blackwell Scientific Publications, Oxford, pp 282-309

de Solla SR, Shirose LJ, Fernie KJ, Barrett GC, Brousseau CS, Bishop CA. 2005. Effect of sampling effort and species detectability on volunteer based anuran monitoring programs. Biol Conserv. 121: 585-594

de Solla SR, Fernie KJ, Barrett GC, Bishop CA. 2006. Population trends and calling phenology of anuran populations surveyed in Ontario estimated using acoustic surveys. Biodiv. and Conserv. 15: 3481-3497

Emlen ST. 1968. Territoriality in the bullfrog, Rana catesbeiana. Copeia (2)240243

Forsythe WC, Rykiel Jr. EJ, Stahl RS, Wu H-I, Robert M. Schoolfield RM. 1995. A model comparison for day length as a function of latitude and day of year. Ecological Modelling. 80(1): 87-95

Friedl TW, Klump GM. 2005. Sexual selection in the lek-breeding European treefrog: body size, chorus attendance, random mating and good genes. Anim Behav. 70:1141-1154 
Gardner R, Morris MR. 1989. The evolution of bluffing in animal contests: an ESS approach. J Theor Bio 1137: 235-243

Gerhardt HC. 1975. Sound pressure levels and radiation patterns of the vocalizations of some North American frogs and toads. J Comp Physiol 102, 1-12

Gerhardt HC. 2005. Advertisement-call preferences in diploid-tetraploid treefrogs (Hyla chrysoscelis and Hyla versicolor): implications for mate choice and the evolution of communication systems. Evolution 59(2) 395-408

Gerhardt HC, Klump GM. 1988. Masking of acoustic signals by the chorus background noise in the green treefrog: A limitation on mate choice. Anim Behav 36:1247-49.

Gerhardt HC, Huber F. 2002. Acoustic Communication in Insects and Frogs: Common Problems and Diverse Solutions. Chicago: University of Chicago Press

Gerhardt HC, Daniel RE, Perrill SA, Schramm S. 1987. Mating behaviour and male mating success in the green treefrog. Anim Behav 35:1490-1503

Grafe TU. 1997. Costs and benefits of mate choice in the lek-breeding reed frog, Hyperolius marmoratus Anim Behav 53:1103-1117 
Grafen A. 1990. Biological signals as handicaps. Anim Behav 46, 759-64

Halliday TR, Adler K. 1987. The Encyclopedia of Reptiles and Amphibians. Equinox, Oxford

Hammerstein P, Reichert SE. 1988. Payoffs and strategies in territorial contests:

ESS analyses of two ecotypes of the spider Agelenopsis aperta. Evol Ecol 2:115138

Höbel G. 2000. Reproductive ecology of Hyla rosenbergi in Costa Rica. Herpetologica 56 (4) 446-54

Huntingford F, Turner A. 1987. Animal Conflict. London: Chapman and Hall

Jakob EM, Marshall SD, Uetz GW. 1996. Estimating fitness: a comparison of body condition indices. Oikos 77:61-67

Jakobsson S, Brick O, Kullberg C. 1995. Escalated fighting behaviour incurs increased predation risk. Anim Behav 49:235-239

Kluge AG. 1981. The life history, social organization and parental behavior of Hyla rosenbergi Boulenger, a nest-building gladiator frog. Misc Publ Mus Zool 
Univ Michigan 160:1-170

Lutz B. 1960. Fighting and an incipient notion of territory in male treefrogs. Copeia 1960: 61-63

Maynard Smith J. 1982. Evolution and the Theory of Games. Cambridge: Cambridge University Press

Murphy CG. 1999. Nightly timing of chorusing by male barking treefrogs (Hyla gratiosa): The influence of female arrival and energy. Copeia 1999: 333-47

_. 2003. The cause of correlations between nightly numbers of male and female barking treefrogs (Hyla gratiosa) attending choruses. Behav Ecol 14:274-281

Murphy CG, Floyd SB. 2005. The effect of call amplitude on male spacing in choruses of barking treefrogs, Hyla gratiosa. Anim Behav 69:419-426

Narins PM, Hödl W, Grabul DS. 2003. Bimodal signal requisite for agonistic behavior in a dart-poison frog, Epipedobates femoralis. PNAS 100(2): 577-580

Owen PC, Gordon NM. 2005. The effect of perceived intruder proximity and resident body size on the aggressive responses of male green frogs, Rana clamitans (Anura: Ranidae). Behav Ecol Sociobiol 58:446-455 
Pröhl H. 1997. Territorial behavior of the strawberry poison-dart frog, Dendrobates pumilio. Amphibia-Reptilia 18:437-442

_. 2003. Variation in Male Calling Behaviour and Relation to Male Mating Success in the Strawberry Poison Frog (Dendrobates pumilio. Ethology 109:273 290

Pröhl H, Berke O. 2001. Spatial distributions of male and female strawberry poison frogs and their relation to female reproductive resources. Oecologia 129:534-542

Reyes Campos NB. 1971. Observaciones sobre la conducta del coquí, Eleutherodactylus coqui. Carib J Sci 11:209-210

Rheinlaender J, Gerhardt HC, Yager D, Capranica RR. 1979. Accuracy of phonotaxis in the green treefrog (Hyla cinerea). J Com Physiol 133:247-55

Robertson JGM. 1984. Acoustic spacing by breeding males of Uperoleia rugosa (Anura: Leptodactylidae). Z Tierpsychol. 64:283-297

. 1986. Male territoriality, fighting and assess merit of fighting ability in the Australian frog Uperoleia rugosa. Anim Behav 34:763-772 
Shackleton, MA, Jennions, MD, Hunt J. 2005. Fighting success and attractiveness as predictors of male mating success in the black field cricket, Teleogryllus commodus: the effectiveness of no-choice tests. Behav Ecol Sociobiol 58:1-8

Stevens CE, Paszkowski CA. 2004. Using chorus-size ranks from call surveys to estimate reproductive activity of the wood frog (Rana sylvatica). J Herpetol $38(3) 404-410$

Sullivan BK. 1982a. Sexual selection in Woodhouse's toad (Bufo woodhousei) I. Chorus organization. Anim Behav 30(3)680-686

_. 1982b. Sexual selection in Woodhouse's toad (Bufo woodhousei). II. Female choice. Anim Behav 31(4) 1011-1017

Thorpe KE, Taylor AC, Huntingford FA. 1995. How costly is fighting? Physiological effects of sustained exercise and fighting in swimming crabs, Necora pubes (L.) (Brachyura, Portunidae) Anim Behav (50) 1657-1666

Wagner I Jr.. 1989a. Graded aggressive signals in Blanchard's cricket frog: vocal responses to opponent proximity and size. Anim Behav 38:1025-1038

Wagner I Jr.. 1989b. Fighting, assessment, and frequency alteration in Blanchard's 
cricket frog. Behav Ecol Sociobiol 25:429-436

Wells KD. 1977. The social behaviour of anuran amphibians. Anim Behav, 25, 666-693.

_. 1978. Territoriality in the green frog (Rana clamitans): Vocalizations and agonistic behaviour. Anim Behav 26:1051-63

_. 1988. The effect of social interactions on anuran vocal behavior, p. 433-454.

In: The evolution of the amphibian auditory system. Fritzsch B, Ryan MJ, Wilczynski W, Hetherington TE, Walkowiak W (eds.) John Wiley and Sons, NY

Wells KD, Taigen TL. 1986. The effects of social interactions on the calling energetics in the gray treefrog (Hyla versicolor). Behav Ecol Sociobiol. 19:9-18.

Whitney CL, Krebs JR. 1975. Mate selection in Pacific tree frogs. Nature $255: 325-326$

Wiewandt TA. 1969. Vocalization, aggressive behavior and territoriality in the bullfrog, Rana catesbeiana. Copeia (2) 276-285

Wilczynski W, Brenowitz EA. 1988. Acoustic cues mediate inter-male spacing in a neotropical frog. Anim Behav 36: 1054-63 
Wollerman L, Wiley RH. 2001. Background noise from a natural chorus alters female discrimination of male calls in a Neotropical frog. Anim Behav 63:15-22

Zahavi, A. 1977. The cost of honesty (further remarks on the handicap principle).

J. Theor. Biol. 67, 603-5 


\title{
Chapter 4.
}

\section{Agonistic interactions in treefrogs II:}

\section{Evolution and behavioral relevance of aggressive calling and fighting}

\begin{abstract}
I studied the aggressive behavior of Hyla avivoca to determine if the type of interaction predicts the aggressiveness of a male's response and if males loose attractiveness to females by engaging in agonistic interactions, thus incurring in potential loss of fitness. Males presented with advertisement call playbacks responded first by increasing advertisement call length. Males reacted with aggressive calls to playbacks of: (1) advertisement calls and aggressive calls at intensities higher than the closest neighbor (2) aggressive calls that interrupted their advertisement calls, and (3) aggressive calls simulate an attacker. Females showed no phonotaxis towards aggressive calls alone, but approached advertisement calls followed or overlapped by aggressive calls, and showed no preference between advertisement calls alone and advertisement calls with aggressive calls, but preferred the longer of two advertisement calls even when followed by aggressive calls. Females preferred short advertisement calls followed by aggressive calls in favor of longer advertisement calls overlapped by aggressive calls. Males are under pressure to increase call attractiveness during aggressive interactions and avoid overlap by aggressive calls to avoid reducing their fitness. I discuss the evolution of agonistic interaction in light of various models of game theory and male mating success as expressed by female choice.
\end{abstract}




\section{Introduction}

Agonistic interactions, whether physical or not, arise when individuals seek dominion over limited resources like food, shelter, or mates (Huntingford and Turner 1987). Animals that display to potential mates and advertise via acoustic signals are limited by the number of places available from which to display within an aggregation and by the number of clear signals they can produce. Moreover, displaying from large, loud aggregations might negatively impact male mating success (Wollerman 1999). Hence, a display site in a chorus becomes a limited resource that is worth defending (Höglund and Alatalo 1995).

Males engaging in aggressive behavior might increase metabolic energy loss, especially if costly displays or fights (Thorpe et al.1995) are involved and risk predation or injury during a physical interaction (frogs: Lutz 1960, Kluge 1981; other vertebrates: Jakobsson 1988; Jakobsson et al. 1995; Hammerstein and Reichert 1988). Additionally, males might have a reduced opportunity to attract females (Shackleton et al. 2005) and risk being removed or expelled from the calling site (Blackwell 1988; Restrepo-Toro 1996; Reyes-Campos 1971).

In most lekking anurans, various advertisement call parameters, such as call rate and call length typically correlate with male mating success (Sullivan 1982a, b; Gerhardt et al. 1987; Arak 1988; Bourne 1993; Smith and Roberts 2003). Males might engage in aggressive calling and fights with males that call nearby and whose calls interfere with their acoustic display. Hence, as seen in Chapter 3, males should defend the acoustic space needed for attracting females, regardless of the likelihood of winning a fight. 
In this chapter, I explored how the social environment and the calling behavior of calling bird-voiced treefrogs, Hyla avivoca, affected the aggressive response of males by broadcasting playbacks of advertisement calls and aggressive calls that interrupted calling males, and by testing how playbacks of aggressive calls simulating fight threats affected male aggressive response. Specifically, I tested the hypothesis that males respond differently to playbacks of aggressive calls depending on the perceived threat presented to them and depending on the type and intensity of call interruption.

I also performed call-recognition and call-preference experiments with females using aggressive and advertisement calls to assess how the aggressive responses by males affect their chances of attracting females. Specifically, I tested the hypothesis that if males are to attract females while engaging in aggressive interactions they should also produce attractive advertisement calls.

\section{Methods}

\section{Playback set-up for aggressive response experiments.}

Synthetic aggressive calls of $H$. avivoca were generated using SoundEdit 2.0.7 Software (Shockwave Macromedia 1990-1996) on a MacIntosh PowerBook G4 (Apple Computer Inc., Cupertino, CA, USA) as described in chapter 2. I connected the computer to a Virtual Reality Sound Laboratories 200 -watt VR ${ }^{3}$ car amplifier and broadcast calls from a 4" x 10" midrange horn speaker (Parts Express W-46-02-104) mounted on a Velbon 5000 tripod. The sound pressure level (SPL) of the speaker output was adjusted away from the experimental males using a CEL-254 digital impulse sound level meter (Bedford, UK). 
I recorded calling males with a TasCam DAP1 Digital Audio Tape Recorder using Audio-Technica ATR-55 line cardioid condenser microphones. Calls were digitized and analyzed for each male using Raven 1.2.1 software (Cornell Laboratories 2003-2005). I recorded at least five advertisement calls of every focal male before initiating treatment to obtain a pre-stimulus measurement of calling performance, recorded the male throughout the length of the treatment and recorded five advertisement calls after the experiments to determine if males return to pre-treatment baseline calling behavior. I measured advertisement call length and scored time of first aggressive response and type of response (change in advertisement call length, number of aggressive calls, fast-rate aggressive calls, approach speaker). A response was considered a fast agonistic response if the experimental frog switched to aggressive calls, approached or attacked the speaker during the first playback. The response was considered a delayed agonistic interaction if the male reacted with aggressive calls after the second call of the playback. The response was considered graded if males increased advertisement-call length or rate prior to responding with aggressive calls, if the male increased the number and rate of aggressive calls after each call on the playback, or if a male progressed to attack the speaker after giving aggressive calls. These responses are not mutually exclusive and could be given sequentially.

\section{Experiment 1. Response to call interruptions:}

A stimulus consisting of four aggressive calls repeated at a rate of 0.5 calls per sec (200 msec long call and $1.8 \mathrm{sec}$ long interval $\sim 8 \mathrm{sec}$ total duration) was used to overlap the advertisement calls of 36 focal males. The playback was 
operated manually to start when the focal male gave an advertisement call, and this procedure was repeated for every advertisement call until the male responded with aggressive calls. A group of 18 males was assigned to a high intensity treatment ( $88 \mathrm{~dB}$ SPL at $1 \mathrm{~m}$ ) and another group of 18 to a low intensity treatment ( $78 \mathrm{~dB}$ SPL at $1 \mathrm{~m}$ ).

A stimulus consisting of a 23-pulse advertisement call was used to overlap every other advertisement call of the focal male until the focal male gave an aggressive response. The playback was started manually and broadcast at an intensity of $88 \mathrm{~dB}$ SPL at $1 \mathrm{~m}$ to 18 males.

\section{Experiment 2- Aggressive response to agonistic threats (fast-rate aggressive} calls):

I presented 20 solitary males with a sequence of aggressive calls simulating an intruder approaching the calling area of a focal male. The sequence consisted of two bouts of aggressive calls and a train of fast-rate aggressive calls. Each bout was composed of a group of four aggressive calls repeated at a rate of 0.5 calls per sec $(200 \mathrm{msec}$ long call and $1.8 \mathrm{sec}$ long interval $\sim 8 \mathrm{sec}$ total duration); the second group followed after a 15 second gap and consisted of a train of 12 fast-rate aggressive calls that also lasted 8 seconds. Each train of fastrate aggressive calls was separated by an interval of 20 seconds. The sequence was repeated until the focal male either approached the speaker or ceased calling.

I analyzed treatment effects using a One Factor Analysis of Variance for repeated measures with a multi-comparison significance level at $95 \%$ because I measured call parameters of the same male before, during and after treatment. I 
analyzed between- treatment effects using a Paired T-test. The aggressive responses of males were analyzed in terms of response functions by computing the $95 \%$-exact confidence limits (binomial distribution) of the proportion of males responding aggressively. Only the lower or upper confidence limits are shown in the figures when a two-tailed binomial test was significant $(P<0.05)$. I used StatView SE+Graphics (Abacus Concepts 1988) and JMP IN 5.1 (SAS Institute Inc. 1989-2003) software for the analyses.

\section{Female responses to aggressive calls.}

I tested females in no-choice, single-speaker experiments and preference trials to determine the effects of aggressive calls on female phonotaxis. Females were tested either on the night of capture at least two hours after being collected in the same choruses where the male playbacks took place, or on the following night. Females tested on the second night were held on individual containers inside a cooler with icy water (about $4^{\circ} \mathrm{C}$ ) to inhibit oviposition and were acclimatized to ambient temperature prior to testing.

All females were tested in the field at least $800 \mathrm{~m}$ away from the nearest frog chorus using a portable testing arena measuring $1 \mathrm{~m} \times 2 \mathrm{~m} \times 0.5 \mathrm{~m}$ with an open top and placed on a flat surface (Chapter 2 for details); speakers were placed $2 \mathrm{~m}$ apart from each other on opposite ends of the arena. Sound pressure level was adjusted to $86 \mathrm{~dB}$ SPL at the female release point $1 \mathrm{~m}$ away from each speaker using a CEL-254 sound level meter. The same set up was used for single speaker tests with only one active speaker. The playback system described in Chapter 2 was used to broadcast synthetic calls generated with SoundEdit software on a 
PowerBook G4 computer. Five calls were broadcast from each speaker being used before releasing the female from an acoustically transparent container at the center of the arena. I observed the behavior of each female for up to 10 minutes. A positive response was recorded when a female approached an active speaker to within $10 \mathrm{~cm}$ or closer and showed the appropriate phonotactic behavior (Rheinlaender et al. 1979).

Females were tested once with any particular playback (pair of alternative stimuli, or single speaker stimulus), but many were tested in additional playbacks with a time $/ 5$ minutes between playbacks. I presented all tests in random order and switched stimuli between speakers, recalibrating the sound pressure level of the speakers after each trial. This procedure minimized the possibility of side biases within the portable arena or caused by an outside source (i.e. light, grade, ambient noise, etc.). I conducted all trials at ambient temperature (from $22^{\circ} \mathrm{C}$ to $\left.26^{\circ} \mathrm{C}\right)$ and used stimuli with values of call properties that were close $\left( \pm 2^{\circ} \mathrm{C}\right)$ to those of males calling at the corresponding temperature. Most females were released at the site of capture within two days of being collected.

(1) No-choice playback experiments - I presented 10 females with three separate, no-choice tests in random order to determine if females recognize and orient to aggressive calls and combinations of advertisement and aggressive calls. In one test four aggressive calls repeated at a rate of 0.5 calls per sec $(200 \mathrm{msec}$ long call and $1.8 \mathrm{sec}$ long interval $\sim 8 \mathrm{sec}$ total duration); the call group was repeated every 15 seconds. In another test, a 23-pulse advertisement call was followed by two aggressive calls of $200 \mathrm{msec}$ with a $600 \mathrm{msec}$ interval between 
aggressive calls. The first aggressive call occurred $200 \mathrm{~ms}$ after each

advertisement call, simulating a calling male incorporating aggressive calls into its calling bout. In a third test, I used two adjacent speakers to create a no-choice test in which one broadcasted a 23-pulse advertisement call while the other broadcasted two aggressive calls overlapping each advertisement call. The playback simulated an interaction between two neighboring males. A playback of a 23-pulse advertisement call served as a control to compare the times females took to approach the speaker.

In the first two tests, I tallied the number of females that approached within $5 \mathrm{~cm}$ of the speaker. No response was scored if the female stayed in or around the release cage or moved away from the speaker. In the third test, I computed phonotaxis scores as the ratio of the time to respond to the experimental stimulus and the time to respond to the control.

(2) Preference tests for aggressive calls - Females were presented with a series of playbacks in a two-speaker paradigm simulating males engaged in agonistic interactions. The tests were designed to determine how aggressive calling by a focal male and how aggressive calls produced by a pair of neighbors might affect male mating success through female choice. First, to test the effect of aggressive call production on females I tested the standard stimulus of a 23-pulse advertisement call repeated every five seconds against an alternative stimulus consisting of a group of four aggressive calls ( $\sim 1.5 \mathrm{sec}$ total duration) repeated every 15 seconds (Fig. 4 stimulus A v. aggressive calls of stimulus C). A second test consisted of the standard 23-pulse advertisement call tested against one of 
three alternatives of advertisement calls followed by two aggressive calls: an 18pulse advertisement call (Fig. 4 stimulus F), an advertisement call of 23-pulses (Fig. 4 stimulus B), or an advertisement of 27-pulses (Fig. 4 stimulus F). These stimuli simulate a male producing various combinations of advertisement and aggressive calls. The timing relationship between calls emitted from each speaker was adjusted so that there was no overlap between alternative calls.

In two additional female preference tests, I sought to determine if the escalated aggressive responses of males during agonistic interactions reduce male mating success by negatively affecting female choice. First, a playback of a standard 23-pulse advertisement call followed by two aggressive calls was tested against an alternative stimulus consisting of a 23-pulse advertisement call followed by four aggressive calls. (Fig. 4, B v. C). Second, the 23-pulse advertisement call followed by 4 aggressive calls tested against an alternative consisting of a 23-pulse advertisement call followed by 8 aggressive calls repeated at a fast rate (200 msec call and a $350 \mathrm{msec}$ interval) (Fig. 4, C v. D). Fast-rate aggressive calls are often produced by males about to engage in a fight.

(3) Multiple speaker tests - Here I tested the hypothesis that aggressive calls produced by other neighbors reduce the attractiveness of a focal male's calls, especially when the aggressive calls overlap and interrupt its advertisement calls. First, I presented females with a 23-pulse advertisement call stimulus broadcast from a single speaker, while a set of adjacent speakers broadcast a combination of aggressive and advertisement calls. In one trial, a single speaker broadcast a 23pulse advertisement call while the pair of adjacent speaker broadcast a set of two 
aggressive calls that overlapped the advertisement playback (Fig. 5, A v. C). In a second trial, the single speaker broadcasted the 23-pulse advertisement call while the speaker set broadcasted a 27-pulse advertisement and the two-aggressive call playback that interrupted the long advertisement call (Fig. 5, A v. D).

Second, I used the same playback set-up in which the 23-pulse advertisement call with two aggressive calls served as the standard stimulus (Fig. 5 , stimulus B). The speaker pair emitted alternatives consisting of a combination of the 23-pulse advertisement call and a set of two aggressive calls that overlapped the advertisement call (Fig. 5, B v. C). I also used a 27-pulse advertisement call that was overlapped by two aggressive calls as the alternative stimulus (Fig. 5, B v. D).

Finally, I used a four-speaker set up, with two set of speaker pairs in which the 23-pulse advertisement call overlapped by the two aggressive calls served as the standard females, the alternative was the 27 pulse advertisement call overlapped by the two aggressive calls (Fig. 5, C v. D).

The results of the choice tests were analyzed in terms of preference functions showing the proportion of females choosing one of the alternatives an the $95 \%$-exact confidence limits of the binomial distribution. If the results were significant $(P<0.05)$, I show only the lower or upper confidence limit.

\section{Results}

All of the 36 males that had their advertisement calls overlapped with playbacks of aggressive calls responded by giving aggressive calls during the trials, but the response varied according to the intensity of the playback used. 
Eighty-three percent $(15 / 18)$ of the males exposed to the high intensity playbacks stopped calling immediately during the first aggressive call playback that overlapped their advertisement call and responded right after the playback by producing an aggressive bout of $($ mean $=8.2 \pm 1.25)$ aggressive calls (Fig. 1A). Eighty-nine percent (16/18) of males presented with aggressive call playbacks at $78 \mathrm{~dB}$ SPL first reacted by increasing advertisement call length. Males continued calling while the aggressive call playback overlapped their first two advertisement calls and showed a delayed aggressive response by producing bouts of aggressive calls $($ mean $=4.2 \pm 1.3)$ on or after the third call interruption (Fig. 1B).

The 18 males presented with playbacks of advertisement calls that overlapped their calls responded initially by producing longer-than-average calls and interdigitating their pulses with the pulses in the playback stimulus. Males showed a delayed aggressive response by initially producing a short bout of aggressive calls (Fig. 2A) and then escalating by producing longer bouts of aggressive calls in their subsequent responses (Fig. 2A).

All of the 20 males presented with the train of fast-rate aggressive calls that represented a fight threat responded initially with aggressive calls. However, three of the males ceased calling after the fast-rate aggressive call playback, deflated the vocal sac and pressed their body to the perch. The remaining 17 males responded by giving fast-rate aggressive calls and approaching the speaker while actively searching for the simulated calling male. 

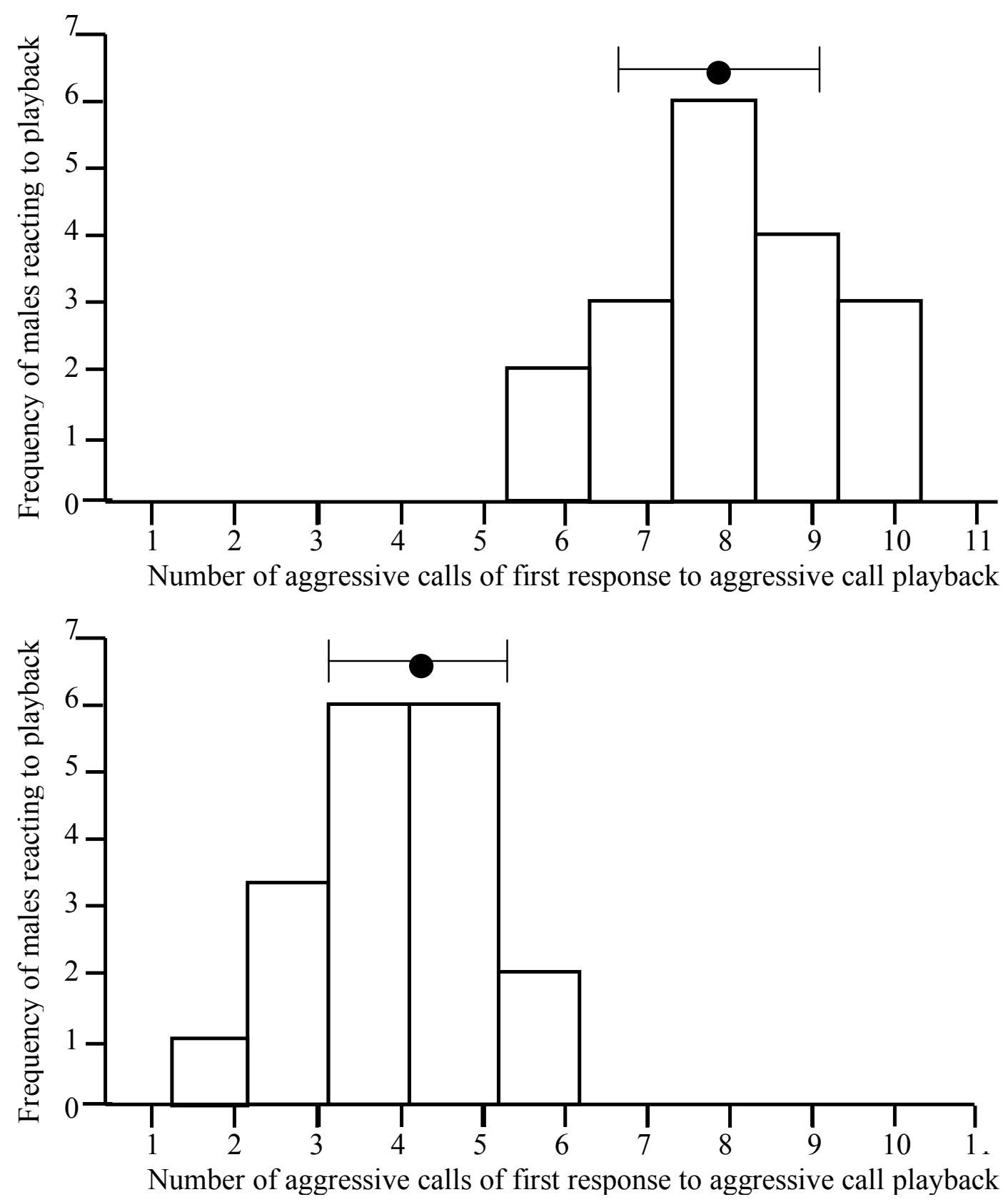

Figure 1. Histograms showing the response of males in number of calls produced in the first bout of the aggressive response of males to playback. Filled circles above histograms show average number of calls per bout; whiskers indicate the standard deviation for each group of males. (A) $88 \mathrm{~dB}$ SPL at $1 \mathrm{~m}$ and (B) $78 \mathrm{~dB}$ SPL at $1 \mathrm{~m}$. 


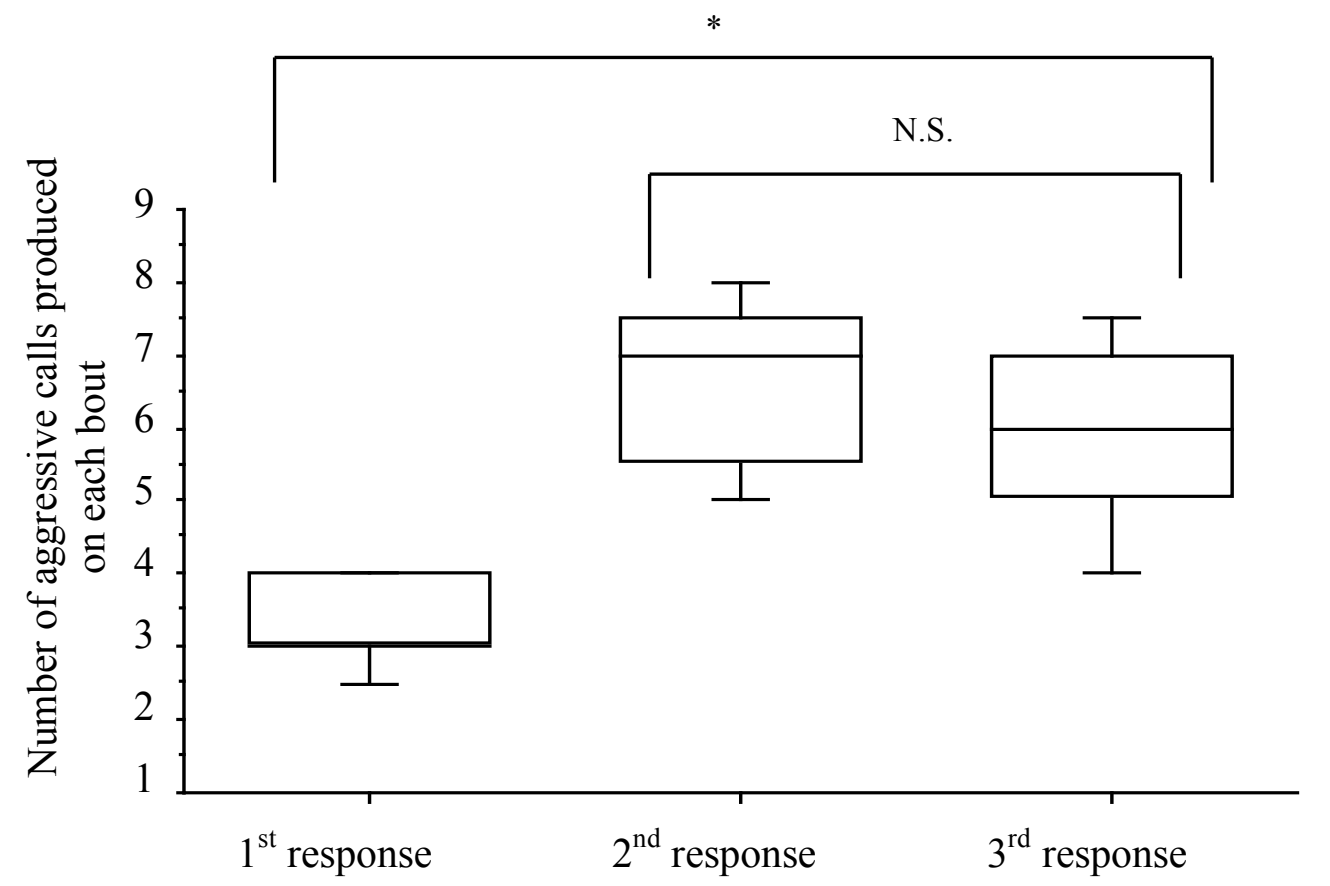

a.
. 
Figure 2. a. Escalated aggressive behavior in response to playbacks of aggressive calls simulating a distant neighbor (78 dB SPL at $1 \mathrm{~m})$. Males responded initially by increasing advertisement call length and call rate (not shown). In the first aggressive response males produce a mean of 3.7 aggressive calls per bout; on the second and third response, males produced a significantly higher number of aggressive calls (Repeated Measures ANOVA, F-test $=145.472 ; P=0.001)$. b. Number of aggressive calls produced during the first bout of aggressive response to the different playbacks used in the tests. Boxes and whiskers show $1 \mathrm{SE}$ and 1 $\mathrm{SD}$ around the mean respectively (Repeated Measures ANOVA F-test $=56.468 ; P$ $=0.001) .{ }^{*}$ Denotes a significance of $P=0.01$ in a Repeated Measures ANOVA. 


\section{Female response to aggressive calls.}

(1) No-choice playback experiments - None of the ten females tested approached the playback broadcasting aggressive calls alone; nine of 10 females approached the advertisement-call. Eight/10 females approached playbacks that contained a combination of advertisement and aggressive calls, and nine of 10 approached the interrupted advertisement calls. There was no difference in the time it took females to approach the advertisement-call playback or advertisement calls with aggressive calls playback (Paired t-test $P=0.081$ ), but females took a significantly longer amount of time to approach the speaker when the advertisement call was interrupted by the playbacks of aggressive calls (Paired ttest $\mathrm{p}<0.01$; Fig. 3$)$.

(2) Preference tests for aggressive calls - Females strongly preferred the 27-pulse advertisement call that was followed by aggressive calls in favor of the standard 23-pulse advertisement call (16/19 approached stimulus E; Fig. 4 A v. E). Females preferred the 23-pulse advertisement call in favor of 18-pulse advertisement calls followed by two aggressive calls (15/19 approached stimulus F; Fig. 4 A v. F).

Females were as likely to approach the 23-pulse advertisement call followed by two aggressive as they were to approach the alternative stimulus of a 23-pulse advertisement call followed by four aggressive calls (8/18 approached stimulus B; Fig. 4 A v. B). Similarly, females showed no preference between a playback that simulated a male about to engage in a fight (fast-rate aggressive 
calls) and the 23-pulse advertisement call followed by four aggressive calls (7/18 approached stimulus D; Fig. 4, C v. D).

(3) Multiple speaker tests - Females preferred advertisement calls that were not overlapped by aggressive calls (Fig. 5, A v. C and A v. D) even when the interrupted advertisement call was longer than the clear call $(P=0.001 ; \mathrm{AD}$ on Fig. 5). Females also preferred advertisement calls followed by aggressive calls in favor of advertisement calls overlapped by aggressive calls (Fig. 5, B v. C and B v. D). When offered a choice between pairs of advertisement calls that were both overlapped by aggressive calls, females preferred the longer call $(\mathrm{P}=0.003$; Fig. 5, C v. D). 


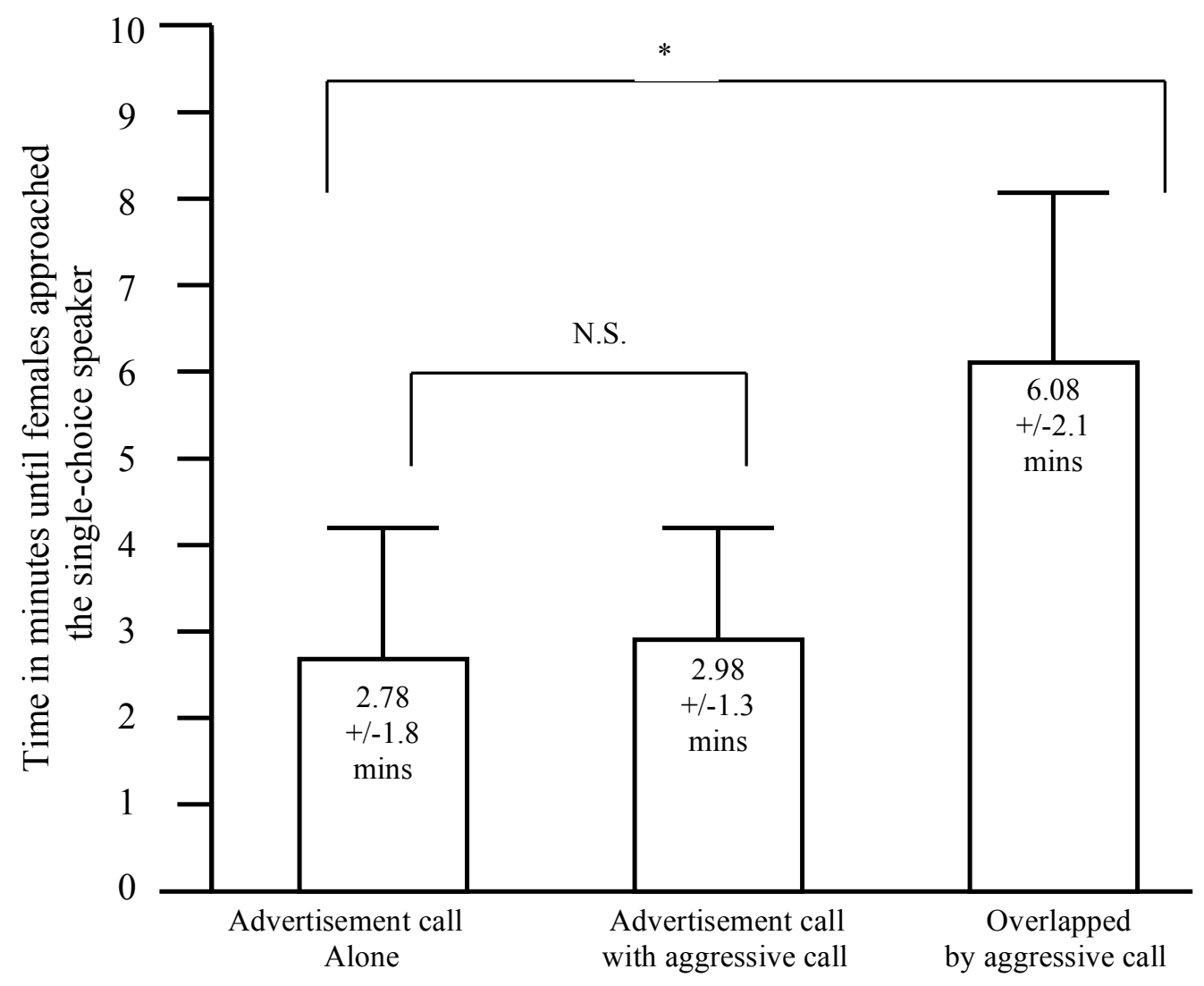

Figure 3. Bar graphs showing the amount of time it took females to approach a speaker in a single-choice speaker test. There was no difference in the time it took females to approach advertisement calls alone or with a following bout of two aggressive calls. It took significantly longer to females to approach the speaker when the advertisement call was overlapped by a bout of 2 aggressive calls from an adjacent speaker. ${ }^{*}$ Significance of $P=0.05$ in a one-tailed paired t-test. 

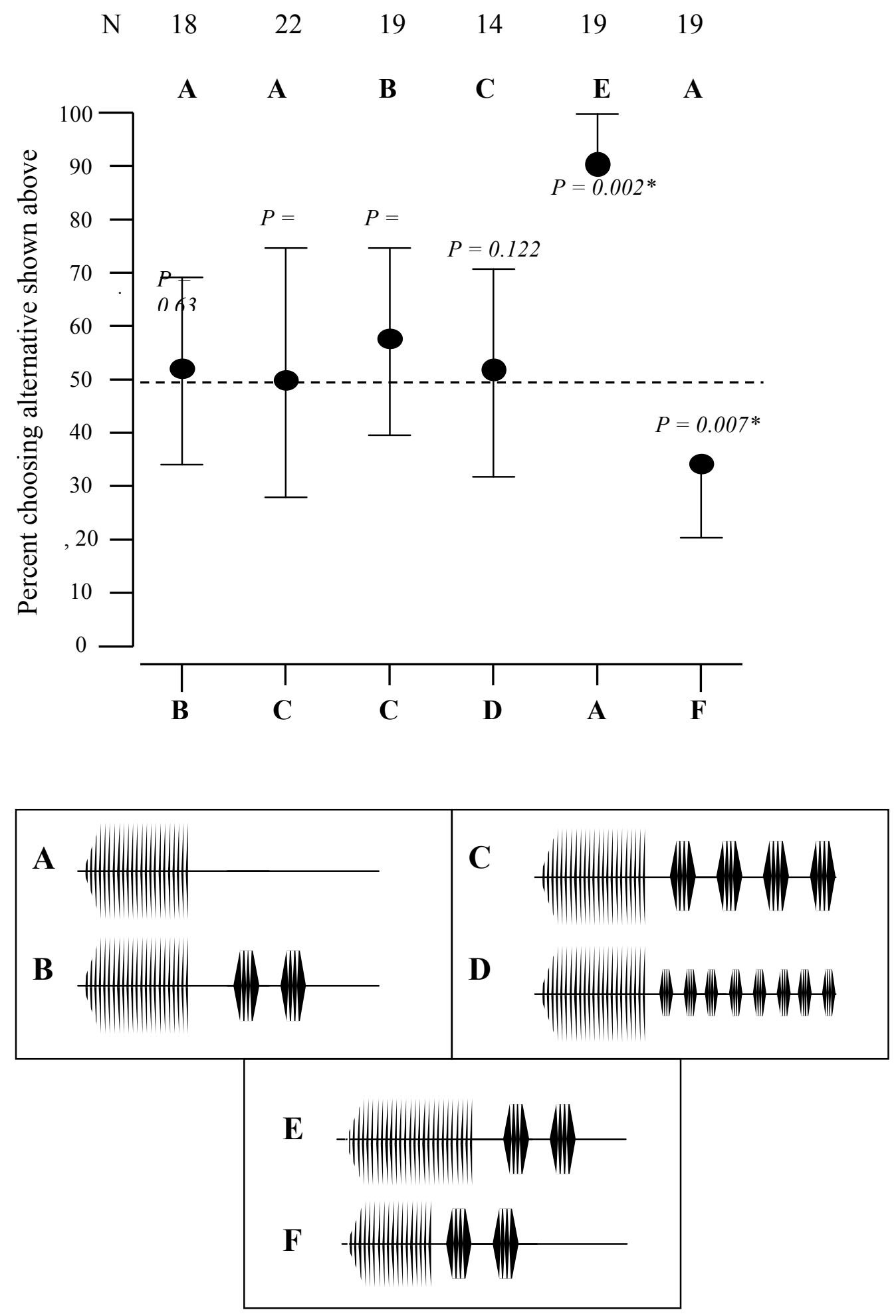
Figure 4. Proportions of females choosing the alternative stimulus on a series two-choice speaker stimulus test. The letter codes on the x-axis correspond to the combination of stimuli tested on each trial, each stimulus is represented on the right-hand panel. The top letter of the code corresponds to the stimulus used as the standard and the second letter to the alternative, for which the proportion of females choosing the stimulus in each trial is presented. The graph shows the preference of females for combinations of advertisement and aggressive calls representing various levels of aggression. Bottom panel shows cartoons of the stimuli. Significant at $\mathrm{P}<0.05$ for a Two-tailed binomial test. 
$\begin{array}{llllll}\mathrm{N} & 17 & 13 & 14 & 18 & 18\end{array}$

$\begin{array}{lllll}\text { A } & \mathbf{A} & \text { B } & \text { B } & \text { C }\end{array}$
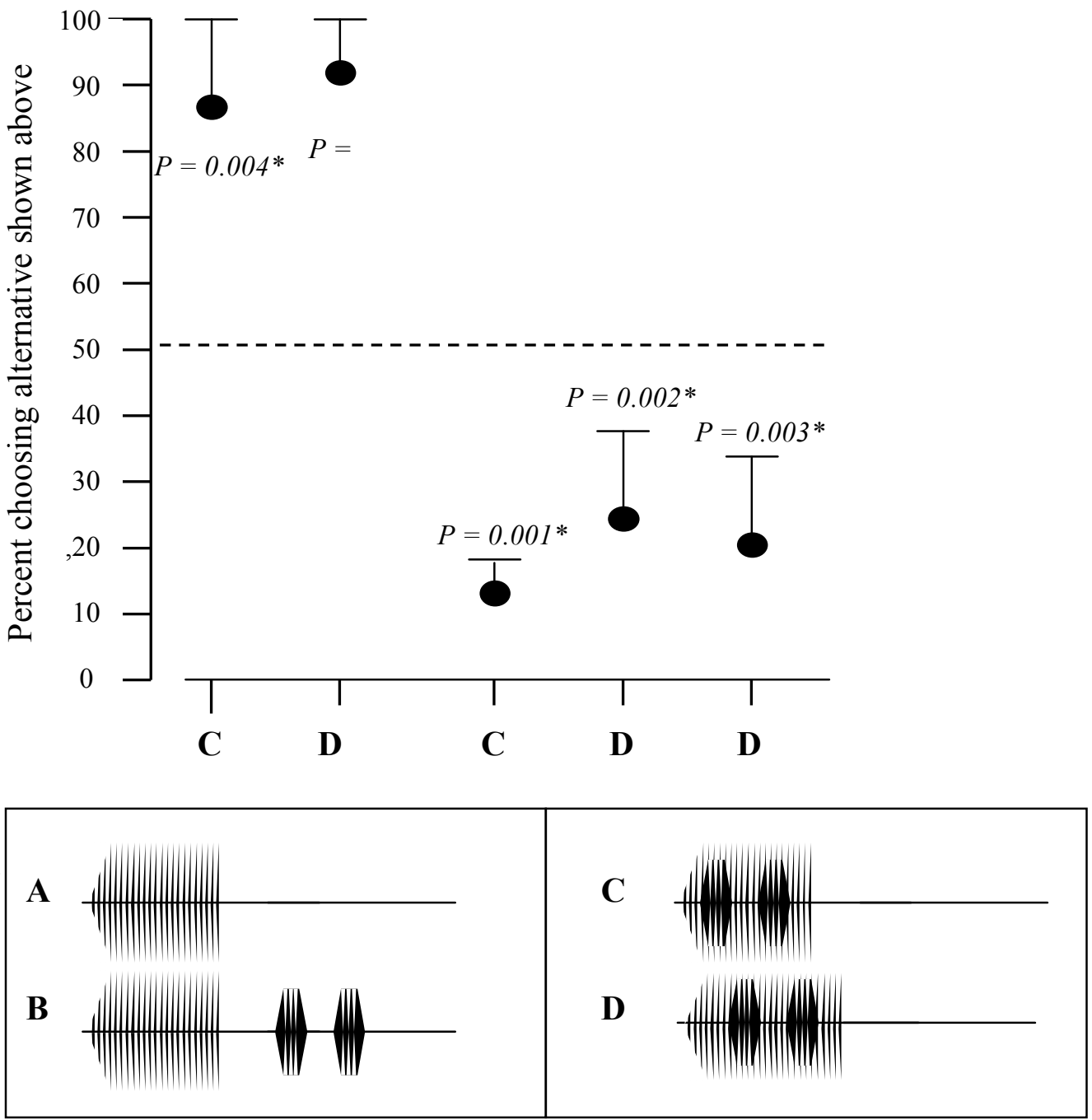

Figure 5. The graph shows the preference of females for advertisement calls overlapped by aggressive calls. The top letter of the code corresponds to the stimulus used as the standard and the second letter to the alternative. The first letter of the code corresponds to the stimulus used as the standard and the second letter to the alternative, for which the proportion of females choosing the stimulus in each trial is presented. Bottom panel shows cartoons of the stimuli Significant at $\mathrm{P}<0.05$ for a Two-tailed binomial test. 


\section{Discussion}

\section{Aggressive response experiments}

I tested the hypothesis that males respond differently to playbacks of aggressive calls depending on the type and intensity of call interruption. Males presented with a stimulus of aggressive calls at high intensity reacted by producing aggressive calls faster than did males presented with aggressive calls at lower intensities or with advertisement calls. The different responses of males suggest they assess the potential threat of the intruder and use a graded response increasing advertisement call attractiveness, and then respond with an aggressive call. Males escalate the aggressiveness of their response by producing fast-rate aggressive calls when a rival fails to retreat or increase its aggressiveness.

Aggressive calls alone were not attractive to females, and advertisement calls overlapped by aggressive calls (Fig 4B. stimuli C and D) were less attractive than uninterrupted advertisement calls, even when the interrupted advertisement call was longer than the uninterrupted advertisement call. Thus, males would be more likely to attract females if they produce advertisement calls during aggressive interactions and if they actively avoid overlap of their advertisement calls by the aggressive calls of other males. Males increase the attractiveness of their calls by increasing advertisement call length and call rate and by interdigitating the pulses of calls with playbacks (chapter 2).

In addition, males can adopt another tactic by overlapping their aggressive calls with the advertisement calls of other males to reduce the attractiveness of rivals. There are immediate direct and indirect benefits of escalated responses. 
Males may enhance their attractiveness by increasing call length prior to producing aggressive calls; and by interspersing aggressive calls between longer advertisement calls. This strategy would allow a male to attract a female while still responding to a threat from a neighboring male. In addition, a male might successfully evict a male from the calling arena by producing fast-rate aggressive calls without the necessity of a fight If all else fails, a fight between rival males will ensure that one of the males is evicted from the immediate calling area, and the evicted male has a chance to find a calling site somewhere else.

\section{Female response to aggressive calls}

Aggressive calling during male-male interactions can be costly if males spend too much energy producing aggressive calls or engaging in fights, or if aggressive calls are unattractive to females. I tested the hypothesis that males incur a potential loss of fitness while engaging in agonistic interactions by reducing the attractiveness of their signals to females and predicted that any aggressive component incorporated within a bout of advertisement calls would reduce or eliminate the attractiveness of advertisement calls.

Single-choice experiments demonstrated that females do not orient to aggressive calls alone. However, females oriented towards combinations of advertisement and aggressive calls. They showed no preference in tests in which two identical advertisement calls were presented but varied in the number of aggressive calls that followed the advertisement calls. Furthermore, females always preferred the longer of two advertisement calls whether it was followed by aggressive calls or not. Aggressive calls produced by neighbors can reduce the 
attractiveness of a focal male if these overlap its advertisement calls.

Many anurans also produce aggressive calls $(H$. cinerea: Oldham and Gerhardt 1975; H. versicolor: Pierce and Ralin ; H. microcephala: Wells 1988) or add acoustic components to their display. Aggressive calls are usually evoked by calls of one or more neighboring males (E. coqui: Narins and Capranica 1978; $H$. microcephala Wells 1988; Physalaemus pustulosus: Rand and Ryan 1981). In some cases, like Geocrinia victoriana (Littlejohn and Harrison 1985) and E. coqui (Narins and Capranica 1978), the added component has been demonstrated to be more effective in eliciting and aggressive response from males than in increasing call attractiveness (reviewed in Gerhardt and Huber 2002). In other cases, like in H. microcephala (Schwartz and Wells) and P. pustulosus, the added component increases male attractiveness as well as functioning in male-male competition. The gray treefrogs (H. versicolor) engage in aggressive behavior with calling neighbors but produce longer advertisement calls, interspersed between bouts of aggressive calls (Gerhardt 2005). Similarly, H avivoca also increase advertisement call length when engaging in competitive interactions and aggressive calling with other males. Calls are made longer by adding more pulses (Chapter 2), a behavior that potentially allows males to remain attractive, or increase attractiveness to females, while engaging in an aggressive interaction.

My results demonstrate that males do not necessarily reduce their chances of mating success by producing aggressive calls. Males engaged in aggressive calling have a reduced overall advertisement call rate but increased pulse number (i.e. call length) when compared to males calling in isolation. They have a 
reduced call rate and equal or lower call length when compared to males engaging in non-aggressive interactions with other calling males. Thus, males may offset the time spent producing aggressive calls by producing longer-than-average advertisement calls between bouts of aggressive calls, but they still produce calls at a lower call rate than non-aggressive interacting males.

\section{Agonistic interactions in $\boldsymbol{H}$. avivoca as an Evolutionary Stable Strategy}

The social context of a calling male and the aggressiveness of the signal presented to a male (loud advertisement call, short aggressive bout, long aggressive bout or fast-rate aggressive call) predicted the outcome of an aggressive interaction. Males responded first by modifying their advertisement call when presented with advertisement call playbacks at a moderate intensity, but responded with aggressive calls when the advertisement call playback was presented at a high intensity or when an aggressive-call playback was used. Males responded with fast-rate aggressive calls to playbacks of fast-rate aggressive calls.

The evolution of fighting and other agonistic interactions in animals has been traditionally explained as Evolutionary Stable Strategies (ESS) using models of Game Theory (Maynard Smith 1982). One model predicts that an animal should accurately display its intent to engage in a fight and announce its resource holding potential (RHP; Parker 1974). Males, however, can also engage in bluffing and produce a dishonest signal that may show intent to fight but where rivals can not assess the fighting abilities of potential rivals (Dawkins and Krebs 1978). The War of Attrition model of Maynard Smith and Parker (1976) predicts that an ESS for animal conflicts will arise whenever disputes are settled by 
conventional displays with no assessment of the opponent's fighting ability or its risk of injury when in engaging in a fight (Manyard-Smith 1982). The hawk-dove model assumes that a ritualized threat display should provide enough information to assess the fighting ability of each male prior to a fight (Manyard-Smith 1982). Both models assume that for these agonistic interactions to be evolutionary stable, the contestants most produce costly displays that serve as estimates of an opponent's fighting ability (Zahavi 1977, Dawkins and Krebs 1978). A third model however, the sequential assessment game (Enquist and Leimar 1983), proposes that contestants do not have to engage in costly behaviors to demonstrate intent to fight or the capacity to win such a fight. Hurd and Ydenberg (1996) used this approach to study aggressive communication constructing a model that demonstrates the use of ESS on threat displays that may not infer any information about status or ability but that more important are not costlier than other displays.

\section{Literature Cited}

Alcock J. 2005. Animal Behavior: An Evolutionary Approach. 8th ed. Sunderland, MA: Sinauer Assoc

Arak A. 1988. Female mate selection in the natterjack toad: active choice or passive attraction? Behav Ecol Sociobiol 22:317-27

Bee MA, Perrill SA, Owen PC. 1999. Size assessment in simulated territorial encounters between male green frogs (Rana clamitans). Behav Ecol Sociobiol 
45:177-84

Bourne GR. 1992. Lekking behavior in the Neotropical Frog Ololygon rubra. Behav Ecol Sociobiol 31:173-180

Bourne GR. 1993. Proximate costs and benefits of mate acquisition at leks of the frog Ololygon rubra. Anim Behav 45:1051-1056

Brenowitz EA. 1989. Neighbor call amplitude influences aggressive behavior and intermale spacing in choruses of the Pacific Treefrog (Hyla regilla). Ethology $83: 69-79$

Burmeister SS, Ophir AG, Ryan MJ, Wilczynski W. 2002. Information transfer during cricket frog contests. Anim Behav 64:215-225

Chamorro-R J, Montealegre-Z F, González-O R. 2007. Determinants of male spacing behaviour in Panacanthus pallicornis (Orthoptera: Tettigoniidae). Ethology (113): 1158-1172

Crouch WB III, Patton PWC. 2002. Assessing the Use of Call Surveys to Monitor Breeding Anurans in Rhode Island. J Herpetol 36:2, pp. 185-192

Dawkins R, Krebs JR. 1978. Animal signals: information or manipulation? In: 
Krebs JR, Davies NB (eds) Behavioural ecology: an evolutionary approach.

Blackwell Scientific Publications, Oxford, pp 282-309

de Solla SR, Shirose LJ, Fernie KJ, Barrett GC, Brousseau CS, Bishop CA. 2005. Effect of sampling effort and species detectability on volunteer based anuran monitoring programs. Biol Conserv. 121: 585-594

de Solla SR, Fernie KJ, Barrett GC, Bishop CA. 2006. Population trends and calling phenology of anuran populations surveyed in Ontario estimated using acoustic surveys. Biodiv. and Conserv. 15: 3481-3497

Emlen ST. 1968. Territoriality in the bullfrog, Rana catesbeiana. Copeia (2)240243

Forsythe WC, Rykiel Jr. EJ, Stahl RS, Wu H-I, Robert M. Schoolfield RM. 1995. A model comparison for day length as a function of latitude and day of year. Ecological Modelling. 80(1): 87-95

Friedl TW, Klump GM. 2005. Sexual selection in the lek-breeding European treefrog: body size, chorus attendance, random mating and good genes. Anim Behav. 70:1141-1154

Gardner R, Morris MR. 1989. The evolution of bluffing in animal contests: an 
ESS approach. J Theor Bio 1137: 235-243

Gerhardt HC. 1975. Sound pressure levels and radiation patterns of the vocalizations of some North American frogs and toads. J Comp Physiol 102, 1-12

Gerhardt HC. 2005. Advertisement-call preferences in diploid-tetraploid treefrogs (Hyla chrysoscelis and Hyla versicolor): implications for mate choice and the evolution of communication systems. Evolution 59(2) 395-408

Gerhardt HC, Klump GM. 1988. Masking of acoustic signals by the chorus background noise in the green treefrog: A limitation on mate choice. Anim Behav $36: 1247-49$.

Gerhardt HC, Huber F. 2002. Acoustic Communication in Insects and Frogs: Common Problems and Diverse Solutions. Chicago: University of Chicago Press

Gerhardt HC, Daniel RE, Perrill SA, Schramm S. 1987. Mating behaviour and male mating success in the green treefrog. Anim Behav 35:1490-1503

Grafe TU. 1997. Costs and benefits of mate choice in the lek-breeding reed frog, Hyperolius marmoratus Anim Behav 53:1103-1117

Grafen A. 1990. Biological signals as handicaps. Anim Behav 46, 759-64 
Guayasamín JM, Barrio-Amorós C. 2005. Combat behaviour in Centrolene andinum (Rivero 1968) (Anura: Centrolenidae). Salamandra 41(3): 153-155

Halliday TR, Adler K. 1987. The Encyclopedia of Reptiles and Amphibians. Equinox, Oxford

Halliday TR, Tejedo M. 1995. Intrasexual selection and alternative mating behaviour. In: Heatwole H, Sullivan BK (eds) Amphibian Biology: Vol 2. Social behaviour, Surrey Beatty, Chipping Norton, pp 419-68

Hammerstein P, Reichert SE. 1988. Payoffs and strategies in territorial contests: ESS analyses of two ecotypes of the spider Agelenopsis aperta. Evol Ecol 2:115138

Höbel G. 2000. Reproductive ecology of Hyla rosenbergi in Costa Rica. Herpetologica 56 (4) 446-54

Hoglünd J, Alatalo RV. 1995. Leks: Princeton. Princeton University press

Huntingford F, Turner A. 1987. Animal Conflict. London: Chapman and Hall

Jakob EM, Marshall SD, Uetz GW. 1996. Estimating fitness: a comparison of 
body condition indices. Oikos 77:61-67

Jakobsson, S. 1988. Territorial fidelity of willow warbler (Phylloscopus trochilus) males and success in competition over territories. Behav Ecol Sociobiol 22: 79-84

Jakobsson S, Brick O, Kullberg C. 1995. Escalated fighting behaviour incurs increased predation risk. Anim Behav 49:235-239

Kluge AG. 1981. The life history, social organization and parental behavior of Hyla rosenbergi Boulenger, a nest-building gladiator frog. Misc Publ Mus Zool Univ Michigan 160:1-170

Lutz B. 1960. Fighting and an incipient notion of territory in male treefrogs. Copeia 1960: 61-63

Maynard Smith J. 1982. Evolution and the Theory of Games. Cambridge: Cambridge University Press

Marshall VT, Humfeld SC, Bee MA. 2003. Plasticity of aggressive signalling and its evolution in male spring peepers, Pseudacris crucifer. Anim Behav 65:122334

Marshall VT, Schwartz JJ, Gerhardt HC. 2006. Effects of heterospecific call 
overlap on the phonotactic behaviour of grey treefrogs. Anim Behav 72:449-559

Murphy CG. 2003. The cause of correlations between nightly numbers of male and female barking treefrogs (Hyla gratiosa) attending choruses. Behav Ecol $14: 274-281$

Murphy CG, Floyd SB. 2005. The effect of call amplitude on male spacing in choruses of barking treefrogs, Hyla gratiosa. Anim Behav 69:419-426

Narins PM, Capranica RR. 1978. Communicative significance of the two-note call of the treefrog Eleutherodactylus coqui. J Comp Physiol 127:1-9

Narins PM, Hödl W, Grabul DS. 2003. Bimodal signal requisite for agonistic behavior in a dart-poison frog, Epipedobates femoralis. PNAS 100(2): 577-580

Owen PC, Gordon NM. 2005. The effect of perceived intruder proximity and resident body size on the aggressive responses of male green frogs, Rana clamitans (Anura: Ranidae). Behav Ecol Sociobiol 58:446-455

Pröhl H. 1997. Territorial behavior of the strawberry poison-dart frog, Dendrobates pumilio. Amphibia-Reptilia 18:437-442

Pröhl H. 2003. Variation in male calling behaviour and relation to male mating 
success in the strawberry poison frog (Dendrobates pumilio) Ethol 109:273-290

Pröhl H, Berke O. 2001. Spatial distributions of male and female strawberry poison frogs and their relation to female reproductive resources. Oecologia $129: 534-542$

Restrepo-Toro JH. 1996. Ecología conductual de una rana arbórea Neotropical. Licenciatura, Universidad del Valle, Cali

Reyes Campos NB. 1971. Observaciones sobre la conducta del coquí, Eleutherodactylus coqui. Carib J Sci 11:209-210

Rheinlaender J, Gerhardt HC, Yager D, Capranica RR. 1979. Accuracy of phonotaxis in the green treefrog (Hyla cinerea). J Com Physiol 133:247-55

Riechert SE. 1978. Games spiders play: behavioral variability in territorial disputes. Behav Ecol Sociobiol 3:135-162

Robertson JGM. 1984. Acoustic spacing by breeding males of Uperoleia rugosa (Anura: Leptodactylidae). Z Tierpsychol. 64:283-297

Robertson JGM. 1986. Male territoriality, fighting and assess merit of fighting ability in the Australian frog Uperoleia rugosa. Anim Behav 34:763-772 
Shackleton, MA, Jennions, MD, Hunt J. 2005. Fighting success and attractiveness as predictors of male mating success in the black field cricket, Teleogryllus commodus: the effectiveness of no-choice tests. Behav Ecol Sociobiol 58:1-8

Stevens CE, Paszkowski CA. 2004. Using chorus-size ranks from call surveys to estimate reproductive activity of the wood frog (Rana sylvatica). J Herpetol 38(3) $404-410$

Stewart MM, Rand AS. 1992. Diel variation in the use of aggressive calls by the frog Eleutherodactylus coqui. Herpetologica 48(1)49-56

Sullivan BK. 1982a. Sexual selection in Woodhouse's toad (Bufo woodhousei) I. Chorus organization. Anim Behav 30(3)680-686

Sullivan BK.. 1982b. Sexual selection in Woodhouse's toad (Bufo woodhousei). II. Female choice. Anim Behav 31(4) 1011-1017

Sullivan BK, Ryan MJ, Verrell PA. 1995. Female choice and mating system structure. In: Heatwole H, Sullivan BK (eds) Amphibian biology, vol 2. Social behavior. Surrey Beatty, Chipping Norton, pp 469-517

Thorpe KE, Taylor AC, Huntingford FA. 1995. How costly is fighting? 
Physiological effects of sustained exercise and fighting in swimming crabs, Necora pubes (L.) (Brachyura, Portunidae) Anim Behav (50) 1657-1666

Tsuji H, Lue KY. 1998. Temporal aspects of the amplexus and oviposition behavior of the fanged frog Rana kuhlii from Taiwan. Copeia 1998: 769-773

Tsuji H, Matsui M. 2002. Male-Male Combat and Head Morphology in a Fanged Frog (Rana kuhlii) from Taiwan. J Herpetol, 36(3): 520-526

Wagner I Jr.. 1989a. Graded aggressive signals in Blanchard's cricket frog: vocal responses to opponent proximity and size. Anim Behav 38:1025-1038

Wagner I Jr.. 1989b. Fighting, assessment, and frequency alteration in Blanchard's cricket frog. Behav Ecol Sociobiol 25:429-436

Wells KD. 1977. The social behaviour of anuran amphibians. Anim Behav, 25, 666-693.

_. 1978. Territoriality in the green frog (Rana clamitans): Vocalizations and agonistic behaviour. Anim Behav 26:1051-63

_. 1988. The effect of social interactions on anuran vocal behavior, p. 433-454. In: The evolution of the amphibian auditory system. . Fritzsch B, Ryan MJ, 
Wilczynski W, Hetherington TE, Walkowiak W (eds.) John Wiley and Sons, NY

Wells KD, Taigen TL. 1986. The effects of social interactions on the calling energetics in the gray treefrog (Hyla versicolor). Behav Ecol Sociobiol. 19:9-18.

Whitney CL, Krebs JR. 1975. Mate selection in Pacific tree frogs. Nature $255: 325-326$

Wiewandt TA. 1969. Vocalization, aggressive behavior and territoriality in the bullfrog, Rana catesbeiana. Copeia (2) 276-285

Wilczynski W, Brenowitz EA. 1988. Acoustic cues mediate inter-male spacing in a neotropical frog. Anim Behav 36: 1054-63

Wiley RH. 1983. The evolution of communication: information and manipulation. In: Halliday TR, Slater PJB (Eds) Animal Behavior Vol 2 Communication. NY WH. Freeman.

Wollerman L, Wiley RH. 2001. Background noise from a natural chorus alters female discrimination of male calls in a Neotropical frog. Anim Behav 63:15-22

Zahavi, A.. 1977. The cost of honesty (further remarks on the handicap principle). J. Theor. Biol. 67, 603-5. 


\title{
Chapter 5:
}

\section{Role of acoustic signals in chorus formation in treefrogs}

\begin{abstract}
Choruses are focal points for sexual selection where males compete for calling sites from where to attract a mate. Females, in turn, locate and choose mates mainly on the bases of acoustic signals. Surprisingly, the factors influencing the onset and location of choruses and the individual positions of males within the general chorusing area have been studied very little. I tested the hypothesis that acoustic cues affect the timing and location of choruses of anurans. I used three different playback arrays simulating choruses that formed: (1) before the seasonal onset of reproduction; (2) before the daily onset of reproduction: and (3) in ecologically similar novel areas adjacent to the traditionally occupied chorus sites. Males exposed to playbacks before the onset of the breeding season and before the daily onset of chorusing behavior moved to the area of the active speakers and formed a chorus, whereas males in control sites, failed to form a chorus earlier than expected. I also set speakers with different call parameters to learn if acoustic cues influence where males calling in a chorus might settle. Specifically I tested the hypothesis that males will associate with males of high quality and will produce calls of similar to or of greater quality (i.e. call duration) than those of its immediate neighbor. I set out speakers broadcasting either short or long calls and observed the numbers and calling patterns of males that settled next to each speaker. More males settled and called near the long-caller speaker than near the
\end{abstract}


short-caller speaker; call performance in the first situation was variable, but males near the short-call speaker produced longer-than-average calls. I discuss my results in light of sexual selection and the evolution of chorus formation and lekking behavior in treefrogs,

\section{Introduction}

The social environment in which acoustic communication occurs is a significant factor shaping behavior. Even though most animals produce longrange signals that can be perceived by individuals other than the intended receiver, the complex social environment in which most long-range acoustic communication takes place remains largely unstudied. One such complex social environment is a chorus, the lek-like breeding aggregations of frogs and insects in which individuals use acoustic signals in their sexual displays (Bradbury and Vehrencamp 1998). In spite of the wealth of research on anuran and insect communication (reviewed in Ryan 2001, Gerhardt and Huber 2002, Greenfield 2001), we know very little about what effect acoustic signals may have on how these aggregations are shaped in time and space, or how and why a particular male settles in a chorus in response to his immediate neighbors.

Anuran choruses are generally located in or near suitable bodies of water that serve as oviposition sites for females (Wells 1977), and although they can occupy large areas, the distribution of such choruses and the callers in the chorus is not random (Sullivan 1983; Brenowitz 1989). Rather, two spatial patterns are usually evident within the chorus. First, males tend to form smaller aggregations of close neighbors (5-15 males for some species, pers. obs.), which may interact 
vocally mainly within the group (Brenowitz et al. 1994). Second, males tend to be spaced within these smaller aggregations. This kind of spacing results from interactions with immediate neighbors (Gerhardt et al. 1989; Brenowitz 1989).

What attracts displaying males to the breeding area? What influences the formation of smaller aggregations within the general breeding site? Several hypotheses have been proposed for the evolution of this aggregative behavior. If males of a particular species defend specific oviposition sites (territories), then their mating system has been characterized as a resource-defense polygyny (Emlen and Oring 1977; Wells 1977). If males defend a calling site and females pick an oviposition site somewhere else, the mating system has been characterized as a resource-based lek polygyny (Alexander 1975; Emlen and Oring 1977).

At a gross level of analysis, the general chorusing area of such a lek is best explained as a hotspot (Bradbury 1985). A lek is an aggregation of breeding animals where: (1) males display and may compete for access to females; (2) there is no resource for females other than the displaying males themselves; (3) males provide no parental care for the next generation (Bradbury 1981). However, the hotspot model suggests that males increase the chance of attracting females if they display near these sites, since females must come to this area for breeding (Höglund and Alatalo 1995), like oviposition sites which in most cases lie within the general chorusing area, if not within an individual males calling space. This model, however, does not explain why males aggregate non-randomly in smaller groups within the breeding site (hotshot model, see below). Whereas males in resource-defense systems may often be spaced relatively uniformly and at 
relatively large distances, calling males in resource-based leks often form aggregations of 5-20 males within the general chorusing area. Males usually space themselves out within these aggregations but the distance between callers is typically far less than the distance between males of territorial species (Gerhardt pers. com.). Accordingly, other models have been proposed to explain the evolution of this behavior. The chorus-attraction model suggests that males might benefit from the greater acoustic output of an aggregation compared to that of solitary individuals such that more females might be attracted to larger choruses, or larger groups within choruses (Gerhardt and Huber 2002). However, there is little evidence for this idea, and at least one experimental study provides strong negative evidence (Murphy 2004). Alternatively, the hotshot model predicts that females prefer to mate with attractive individuals and actively search a breeding area for them (sexual selection theory). Consequently, aggregations of displaying males might result as more males join the group, attracted by 'hotshot' males and might explain why sometimes males form smaller groups within the larger breeding aggregation. Lower quality males may benefit from associating with these attractive males and thus may be attracted to their vicinity within the chorus (Höglund and Alatalo 1995). If males are strongly competing to attract females, then we might expect them to join attractive males and to be stimulated to call earlier than usual if rival males begin calling early. I will present preliminary data that supports the latter hypothesis, suggesting additional evidence of the hotshot model for one species. 
The chorus attraction and hotshot models suggest that acoustic signals might play a key role in the decisions made by lek-breeding animals in terms of where, when and how to associate with other displaying males, whereas the hotspot model suggests that displaying males associate in areas where females are most likely to be attracted or encountered.

The focus of this chapter is to investigate the role of acoustic signals in influencing: (1) the onset of calling in aggregations of lek-breeding species (i.e. frog choruses); (2) the choice of the location of the aggregation; (3) the choice of a calling site within the aggregation; and (4) the assessment of a calling strategy by males.

\section{Methods}

\section{STUDY SYSTEMS}

I studied the chorusing behavior of the bird-voiced treefrog, Hyla avivoca, and the canyon treefrog, H. arenicolor; North American hylids grouped within the subfamily Hylinae (Barber 1999; Duellman 2001; Faivovich et al. 2004; Halloway et al. 2005). More importantly, males of both species produce a stereotyped pulsed call repeated at regular intervals from small lek-like aggregations where male clump in smaller groups within the larger breeding site. Males increase call length but reduce call rate in response to a greater number of calling neighbors. Females showed a similar preference patterns for gross temporal parameters of a male's calls and preferred higher call rates and call length (Chapter 2 for H. avivoca; H. arenicolor: pers. obs., Gerhardt et al. in prep). This pattern of calling appears to be more energetically costly compared to 
producing short calls at long time interval in a close relative, H. versicolor (Wells et al. 1998). The species differ in the shape and location of their choruses, and in the inter-male interactions that arise in the chorus, providing an excellent setting for comparing male reproductive behavior under different ecological environments in related species.

Bird-voiced treefrogs, H. avivoca, descend from the canopy during the breeding season and form choruses along the lower branches of flooded forests in Southeastern USA. Males aggregate in small groups within the chorus and often overlap calls with neighbors, increasing call length and altering the length of the inter-pulse interval both within and between calls when overlapped by close neighbors (Chapter 2 and 3). Canyon treefrogs, H. arenicolor, emerge from rocky outcrops and canyons near streams and form small linear aggregations of calling males ( $4.7 \pm 3$ males) along the shoreline of permanent to semi-permanent streams in the arid Southwestern USA.

I conducted acoustic playbacks at the beginning and during the breeding season from 2004 to 2006 to test the hypothesis that acoustic signals influence chorus formation in Hyla avivoca and H. arenicolor. The specific goals were: (1) to test the effect of acoustic signals on the seasonal and daily onset of chorus formation; and (2) to test the role of acoustic signals in the choice of the location of the aggregation in an effort to test the hotshot model of chorus formation. Playback set-up - I used a set a group of GS 10 (T-Sound) omnidirectional speakers (TIC corporation) to broadcast synthetic calls simulating a conspecific chorus that formed earlier in the season (H. avivoca) or earlier in the day during 
the breeding season (H. avivoca and H. arenicolor). Four speakers strapped to trees at various heights were used to simulate choruses of $H$. avivoca, whereas two speakers placed along the shoreline of the creeks were used for $H$. arenicolor. There was no need to use four speakers for $H$. arenicolor since males typically form sparse choruses in clusters of $4.7 \pm 3$ males (see above), stretched out linearly along creeks.

The speakers were connected to two Virtual Reality Sound Laboratories 200watt $\mathrm{VR}^{3}$ car amplifiers that controlled the gain of the stimulus playing from a MacIntosh PowerBook G4 (Apple Computer Inc., Cupertino, CA, USA) computer. The SPL was set to $86 \mathrm{~dB}$ SPL (sound pressure level in decibels [dB] re $20 \mu \mathrm{Pa}$, "fast" RMS [root-mean-square] meter constant) at a distance of $0.5 \mathrm{~m}$ for $H$. avivoca and $88 \mathrm{~dB}$ SPL for $H$. arenicolor. Speakers were placed before any chorus activity in a known chorusing site. SPL was adjusted (CEL-254 sound level meter) early in the day before testing. Inter-speaker distance varied between sites and species and was similar to the distance observed at each specific population. A set of mute omnidirectional speakers, placed at least 50 meters away from the active speakers at an ecologically similar site within the chorus, served as visual control for each trial. Playbacks started one hour before sunset; sunset schedules were obtained from the US Naval Observatory database (http://aa.usno.navy.mil/data/docs/RS_OneYear.php).

\section{Experiment 1: Do acoustic signals affect the onset of chorus formation in} treefrogs? 
1a. Seasonal onset of chorus formation in H. avivoca - I selected paired

locations of choruses of similar size at three different localities within the range of H. avivoca (18 choruses; see Table 1) before the beginning of the breeding season during the month of April in 2004, 2005, and 2006. At this stage, some males called sporadically from the canopy but did not descend to regular chorus height (Chapter 3). I assigned the aggregations in each paired location to either active speaker (experimental) or mute speaker treatment (control), alternating treatments between each aggregation randomly using a number generator from Research Randomizer (www.Randomizer.org; C1997-2008, Urbaniak and Plous). The experimental treatment consisted of playbacks of synthetic advertisement calls with realistic timing relationships broadcast from four omni directional speakers, which simulated a small aggregation of calling frogs. Two speakers were placed at the average height of calling males at $1.82 \mathrm{~m}$, another was placed at $1.4 \mathrm{~m}$ and the forth speaker at a height of $1.9 \mathrm{~m}$, the last two values representing the lower and upper standard deviations, respectively. The speakers broadcasted calls for two hours, starting one hour before sunset, at $88 \mathrm{~dB}$ SPL at $50 \mathrm{~cm}$. Before starting the playback, I counted males using one of two Bioear 10 parabolic acoustic receivers (Information Unlimited - Amhrest, NH) from the ground. This equipment made it possible to accurately detect the calls of different individual males from the canopy during the pre-chorus calling period.

I recorded the arrival times of all males within a $3 \mathrm{~m}^{2}$ radius of each speaker and measured the distance between males after the playback ended. I used the parabolic acoustic receivers from the ground to detect the calls of any 
individuals still calling from the canopy and measured the average perch height of males that descended to call at the chorus site. I compared the values obtained for the males during the experimental treatment to the same group of males after the season breeding began (Fig. 2).

\section{1b. Daily onset of chorus formation in H. avivoca and H. arenicolor - A}

similar experimental procedure was repeated during the breeding season to test the hypothesis that acoustic cues may stimulate males to join and call at the chorus site before the usual time of chorus formation. I performed playback trials during the breeding season (May-July) with 16 paired-aggregations of H. avivoca from Mississippi (average number of males $=19.4, \pm 5.3$ ) and 16-paired aggregations of $H$. arenicolor from Arizona, (average number of males $=9.4, \pm$ 3.3). Each night, one of the aggregations was randomly selected for a similar playback treatment (see above).

The speakers were set in paired locations and the active speaker-set broadcast synthetic advertisement calls for two hours, starting one hour before sunset for both species. Before starting the playback, I counted any calling $H$. avivoca using a Bioear 10 parabolic acoustic receivers (Information Unlimited Amhrest, NH) to obtain an accurate estimate of males present in the canopy directly above the chorusing area. Males of $H$. arenicolor call only sporadically prior to chorus formation, usually from crevices or from under rocks Such calling was much less predictable than pre-chorus activity in H. avivoca and the secretive nature of the frogs were the two factors leading to the decision to not attempt to estimate pre-chorusing numbers or activity in $H$. arenicolor. 
Table 1. Localities of the paired choruses used for the early season and daily onset chorus formation trials for Hyla avivoca. Each chorus in the chorus pair was at least $600 \mathrm{~m}$ apart from each other and each was tested once with the active speaker and once with the mute speaker. Distance was estimated using data from trail markers.

\begin{tabular}{|c|c|c|c|c|}
\hline Location & $\begin{array}{l}\text { Num. of } \\
\text { choruses }\end{array}$ & Date & $\begin{array}{l}\text { Minimum distance } \\
\text { between chorus pairs }\end{array}$ & Chorus size \\
\hline \multirow[t]{2}{*}{ Mississippi } & 8 & $\begin{array}{l}\text { April } \\
2004\end{array}$ & $600 \mathrm{~m}$ & $7.8 \pm 1.6$ \\
\hline & 2 & $\begin{array}{l}\text { April } \\
2006\end{array}$ & $800 \mathrm{~m}$ & $7.5 \pm 0.9$ \\
\hline South & 4 & April & More than $1 \mathrm{~km}$ & $9.2 \pm 1.3$ \\
\hline Carolina & & 2005 & & \\
\hline Tennessee & 4 & $\begin{array}{l}\text { April } \\
2006\end{array}$ & More than $1 \mathrm{~km}$ & $6.7 \pm 0.9$ \\
\hline
\end{tabular}


I recorded the arrival times of all males within a $3 \mathrm{~m}^{2}$ radius of each speaker and measured the position of males every 15 minutes until the end of the 120 -minute playback. I also recorded perch height, intermale distance and distance to speaker for settling males. I used a Bioear 10 parabolic acoustic receiver from the ground to detect the calls of any individuals of $H$. avivoca calling from the canopy. I compared the number of males that responded to the different chorus-onset treatments with a Wilcoxon signed-rank test with a significant set at $P<0.05$. I used StatView SE+Graphics (Abacus Concepts 1988) and JMP IN 5.1 (SAS Institute Inc. 1989-2003) software for my analyses.

\section{Experiment 2: Do acoustic signals aid in chorus localization by $\boldsymbol{H}$. avivoca}

\section{and $\boldsymbol{H}$. arenicolor?}

I broadcast conspecific synthetic calls using the same playback system described above for each species to determine if frogs use acoustic signals as cues to locate a new breeding site during the breeding season. The speakers were placed in unoccupied areas that were adjacent and ecologically similar to the sites where a chorus usually formed. In contrast to the chorus-onset experiments, the active speakers broadcast calls from the new unoccupied sites while the mute speakers were placed as control at the traditional chorus sites, where males had been observed forming choruses during the breeding season of 2005 and 2007. I broadcast advertisement calls daily for two hours, starting at sunset, when normal calling activity begins for both species. Each trial ran for six consecutive days at 10 different locations for both species. I observed chorus attendance for 11 days (from day 0 to day 10), the playback started on day one and continued until day 6 , 
By playing calls on consecutive days, I allowed frogs in the periphery of the testing area to receive the nightly stimulus from the speakers, hence simulating an established chorus. By choosing multiple sites, I also account for unmeasured variation in environmental variables, such as temperature, humidity, and time of season. I monitored both areas (traditional chorus site and artificial chorus site) after the two-hour period for presence or absence of male and female frogs within a $3 \mathrm{~m}^{2}$ area around each speaker. I scored the first day of arrival and any observed reproductive activity at the active speaker sites by counting calling males, gravid females and egg masses; I then compared average values for number of males present at the new sites. (Table 3)

\section{Experiment 3: Do males of $\boldsymbol{H}$. avivoca assess the attractiveness of calling neighbors?}

I tested the prediction that males arriving at a calling area are more likely to associate with a male that produces calls that are more attractive to females (long calls) than with a male producing relatively unattractive calls (of shorter duration). I therefore broadcast both long and short synthetic advertisement calls, each from a separate speaker for one hour, starting at sunset before males start to call. A third, mute speaker was also placed at the chorus site and served as a visual control. I conducted 30 trials with $H$. avivoca at various localities in Louisiana, Mississippi, and Tennessee. Each speaker was placed $3 \mathrm{~m}$ from each other at the calling site, one broadcasting a short call (Table 4), a second broadcasting a long call (Table 4) and a mute speaker used as a control. The order 
of the speaker was assigned randomly using a number generator (www.Randomizer.org; $@ 1997-2008$, Urbaniak and Plous).

I recorded the calling behavior of the first male that arrived next to each speaker using a TasCam DAP1 Digital Audio Tape Recorder. An audio-Technica ATR-55 Line Cardioid Condenser Microphone placed $2 \mathrm{~m}$ above the speaker was used to record the calls of the first male. The microphone recorded the playback and any frog calling at a distance of up to $4 \mathrm{~m}$. I stopped recording the calls of the focal male once a second male arrived and started to call, hence I am certain that the first male that arrived next to the speaker was the only male recorded. The speakers continued to broadcast calls for the complete two hour period. I then counted the number of males that approached and settled next to the speakers within a $2 \mathrm{~m}^{2}$ radius and measured the distance to speaker, snout-vent length, tibial length and mass of the focal male. I analyzed call length and call rate of the focal male to assess possible correlations between phenotype and call properties of the focal male and to compare these values to those of the playback stimulus. Relative calling effort was determined by comparing the calling activity of the focal male with the corresponding playback. Calls were digitized using SoundEdit 2.0.7 Software (Shockwave Macromedia 1990-1996) on a MacIntosh PowerBook G4 (Apple Computer Inc., Cupertino, CA, USA), and analyzed calls using Raven 1.2.1 software (Cornell Laboratories 2003-2005). I analyzed treatment effects between groups using a Friedman test for related samples. I used StatView SE+Graphics (Abacus Concepts 1988) and JMP IN 5.1 (SAS Institute Inc. 19892003) software for the analyses. 


\section{Results}

Experiment 1a: Seasonal onset of chorus formation in $\boldsymbol{H}$. avivoca - Males exposed to playbacks of advertisement calls descended to chorus level $(n=18$ nights; Fig.1) before the onset of the breeding season and called. Males in the control treatment were not exposed to acoustic stimuli remained in the canopy. Four males were observed at chorus level in a control area on three nights but none of them where observed or heard calling. (Fig 1, tables 2 and 3).

\section{1b: Daily onset of chorus formation in $H$. avivoca and $H$. arenicolor -} Males of $H$. avivoca from all of the chorus sites where frogs were calling sporadically from the canopy descended earlier during the breeding season when presented with playbacks that simulated a chorus of calling males. Males arrived at the chorus an average of 19.3 minutes earlier in the presence of speakers ( $\mathrm{t}$-test $=6.46 ; \mathrm{p}<0.01 ; \mathrm{n}=16$ nights). Males of $H$. avivoca called from perches at a similar height and similar inter-male distance as the males that descended during regular times (Fig. 2). In $H$. arenicolor males arrived 23.6 minutes earlier (t-test $=$ 9.78; $\mathrm{p}<0.01 ; \mathrm{n}=16$ nights) than control groups where there was a mute speaker.

\section{Experiment 2: Do acoustic signals aid in chorus localization by $\boldsymbol{H}$. avivoca}

and $\boldsymbol{H}$. arenicolor? $-H$. avivoca did not approach or settle in the new chorus sites created by simulating a chorus of conspecific frogs. Males of $H$. arenicolor, on the other hand, settled and called from eight of the 10 new calling sites on or around the third day of sampling (see figure $4 b$ ). No females were seen on either chorus, but egg masses were observed at two of the new $H$. arenicolor chorus sites, showing evidence of reproduction at the new sites. 


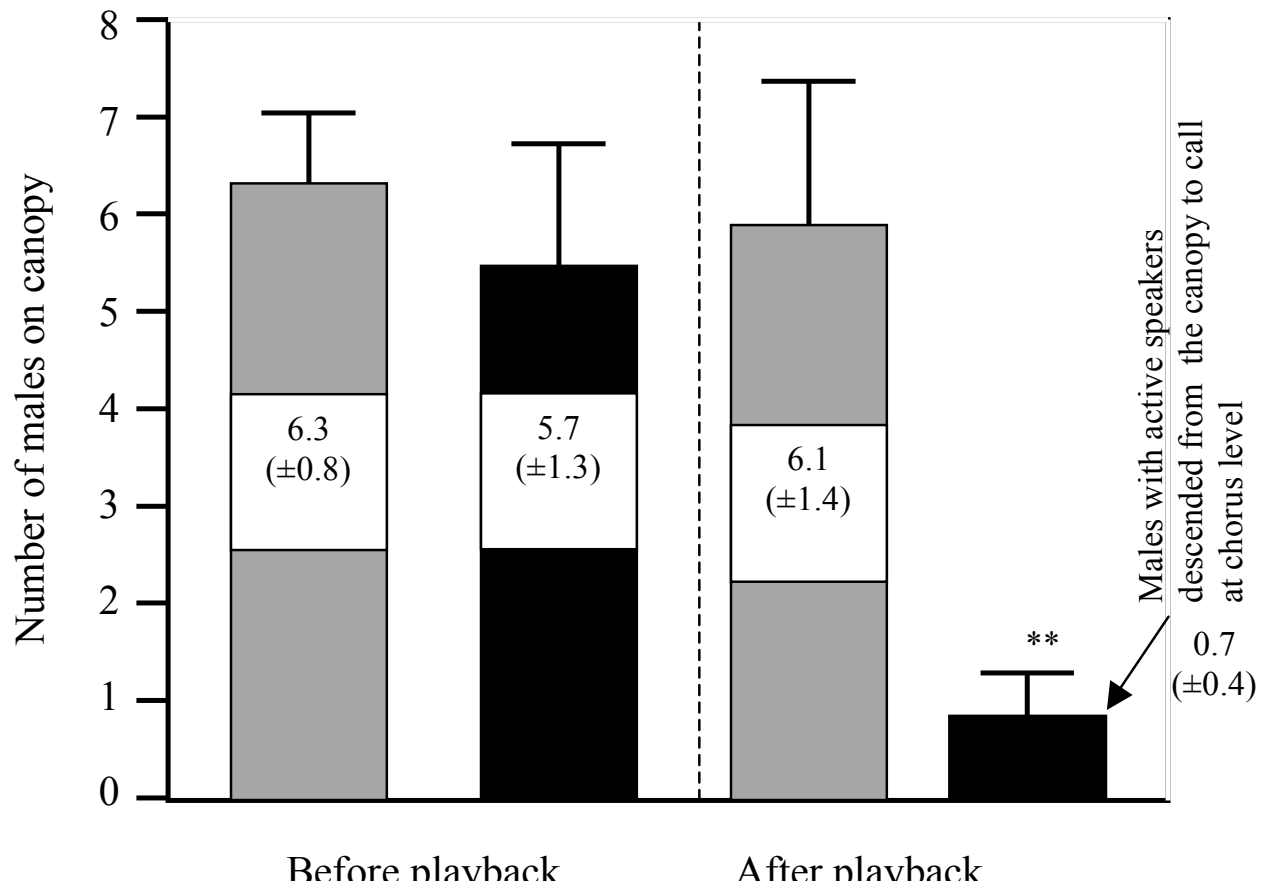

Figure 1. Effect of acoustic stimuli on the seasonal onset of chorus formation in treefrogs. Gray bars represent the mean numbers of males on the plots with speakers; black bars represent the mean number of males on the plots without speakers; error bars represent one standard deviation. Only males exposed to the playback (black bars) descended to chorus level ( $\mathrm{n}=20$ nights; Binomial test $\mathrm{p}<$ 0.01 . see table 2 for details), males not exposed to the speakers did form choruses at the regular sites, but remained in the canopy during the trials.

** Denotes a significance of $\mathrm{P}<0.01$ for a Binomial Test. 
Table 2. Effect of acoustic signals on chorus formation before the onset of the breeding season. I tested 9 pairs of choruses on separate nights, each chorus was tested once with active speakers and once with mute speakers. Males from the active speakers descended to call, males found at chorus level in the control trials (mute speakers) were not calling.

\begin{tabular}{|c|c|c|c|c|c|c|c|c|c|c|}
\hline \multirow[t]{2}{*}{ Time } & \multirow[b]{2}{*}{ 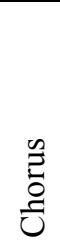 } & \multicolumn{2}{|c|}{ Mute speaker } & \multicolumn{2}{|c|}{ Active speaker } & \multirow{2}{*}{ 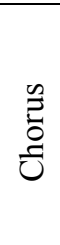 } & \multicolumn{2}{|c|}{ Mute speaker } & \multicolumn{2}{|c|}{$\begin{array}{c}\text { Active } \\
\text { speaker }\end{array}$} \\
\hline & & $\Xi \frac{\overrightarrow{0}}{\mathrm{c}}$ & 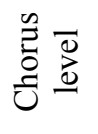 & $\Xi \frac{\grave{0}}{\tilde{\Xi}}$ & 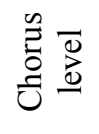 & & $\Xi \frac{\hat{े}}{\stackrel{\Xi}{\tilde{~}}}$ & 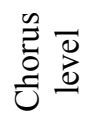 & $\Xi \underset{\tilde{\Xi}}{\overparen{\Xi}}$ & 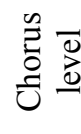 \\
\hline Before & $1 \mathrm{a}$ & 6 & 0 & 6 & 0 & $1 \mathrm{~b}$ & 7 & 0 & 7 & 0 \\
\hline After & & 5 & 0 & 0 & 7 & & 5 & 1 & 0 & 7 \\
\hline Before & $2 a$ & 6 & 0 & 7 & 0 & $2 b$ & 7 & 0 & 8 & 0 \\
\hline After & & 6 & 0 & 1 & 8 & & 6 & 0 & 0 & 8 \\
\hline Before & & 7 & 0 & 8 & 0 & $3 b$ & 6 & 0 & 8 & 0 \\
\hline After & $3 a$ & 4 & 0 & 0 & 8 & & 6 & 0 & 0 & 7 \\
\hline Before & & 5 & 0 & 5 & 0 & $4 b$ & 4 & 0 & 6 & 0 \\
\hline After & $4 a$ & 7 & 1 & 1 & 7 & & 6 & 0 & 0 & 6 \\
\hline Before & & 8 & 0 & 5 & 0 & $5 b$ & 7 & 0 & 5 & 0 \\
\hline After & $5 a$ & 5 & 2 & 0 & 5 & & 6 & 0 & 1 & 5 \\
\hline Before & & 6 & 0 & 6 & 0 & $6 b$ & 5 & 0 & 6 & 0 \\
\hline After & $6 a$ & 6 & 0 & 0 & 8 & & 6 & 0 & 0 & 7 \\
\hline Before & & 8 & 0 & 6 & 0 & $7 b$ & 8 & 0 & 5 & 0 \\
\hline After & $7 a$ & 7 & 0 & 0 & 6 & & 7 & 1 & 0 & 5 \\
\hline Before & & 5 & 0 & 5 & 0 & $\mathbf{8 b}$ & 5 & 0 & 5 & 0 \\
\hline After & $8 a$ & 7 & 0 & 0 & 6 & & 7 & 0 & 0 & 6 \\
\hline Before & & 6 & 0 & 7 & 0 & $9 b$ & 5 & 0 & 7 & 0 \\
\hline After & $9 a$ & 4 & 0 & 0 & 6 & & 5 & 0 & 0 & 6 \\
\hline
\end{tabular}


Table 3. Effect of acoustic signals on the selection of a new chorusing area. Active speakers broadcasting conspecific advertisement calls were set out for six consecutive days in novel areas where males do not form chorus. 10 pairs of choruses on 10 consecutive nights.

Day

Average number of males present each day

\section{Hyla avivoca}

Hyla arenicolor

Chorus site with New site with mute speaker

$$
\begin{aligned}
& 14.3 \pm 0.9 \\
& 12.7 \pm 0.1 \\
& 12.3 \pm 0.5 \\
& 18.6 \pm 1.2 \\
& 15.8 \pm 0.6 \\
& 12.1 \pm 0.5 \\
& 17.1 \pm 0.3 \\
& 15.9 \pm 1.1 \\
& 17.4 \pm 0.7 \\
& 13.7 \pm 0.4 \\
& 10.4 \pm 1.1
\end{aligned}
$$

active speaker

0

0

0

0

0

0

0

0

0

0

0
Chorus site with mute speaker

$$
\begin{gathered}
12.1 \pm 3.4 \\
13.3 \pm 2.8 \\
18.6 \pm 3.1 \\
12.4 \pm 1.2 \\
9.2 \pm 2.6 \\
8.7 \pm 1.8 \\
12.7 \pm 2.3 \\
14.4 \pm 2.4 \\
9.2 \pm 1.7 \\
8.9 \pm 0.6 \\
8.1 \pm 1.8
\end{gathered}
$$

New site with active speaker 


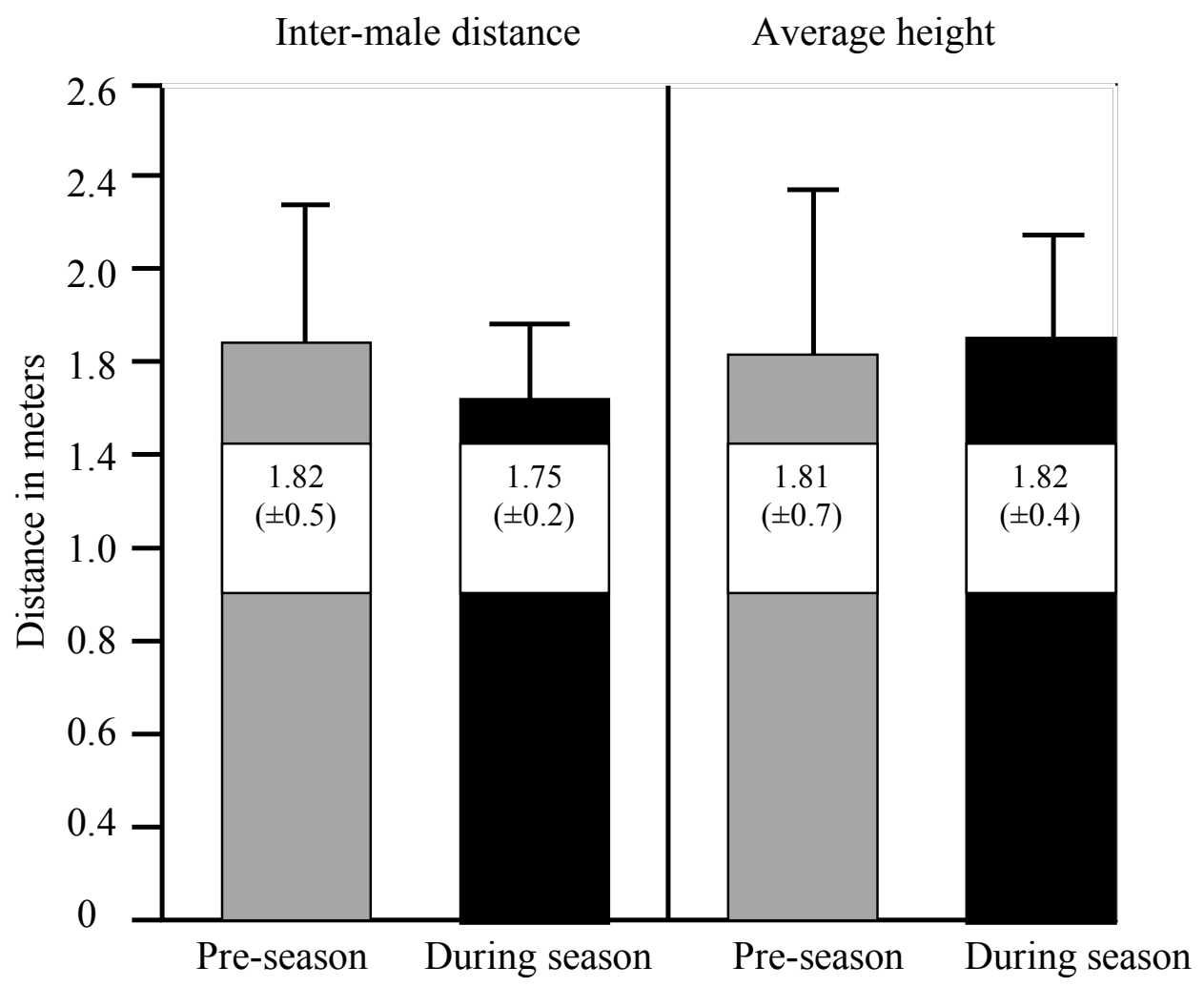

Figure 2. Chorusing parameters for perch height and inter-male distance for choruses of male $H$. avivoca during the pre-season playback experiments and during the regular chorus season without speakers. There was no difference in the chorusing behavior (inter-male distance and perch height) of males that descended earlier in the season with the speakers (represented by gray bars) before the breeding season when compared to the behavior of males from the same site during the regular breeding season (represented by black bars). 


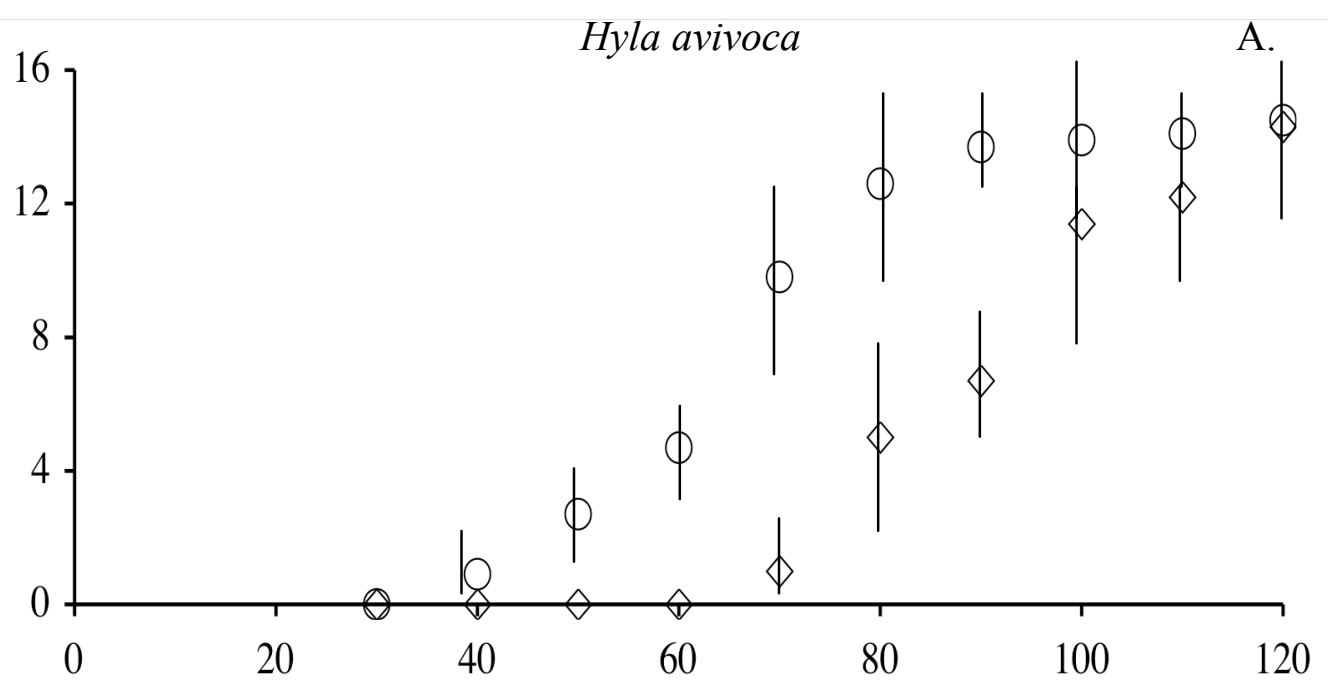

Time since initiation of playback in minutes

Hyla arenicolor

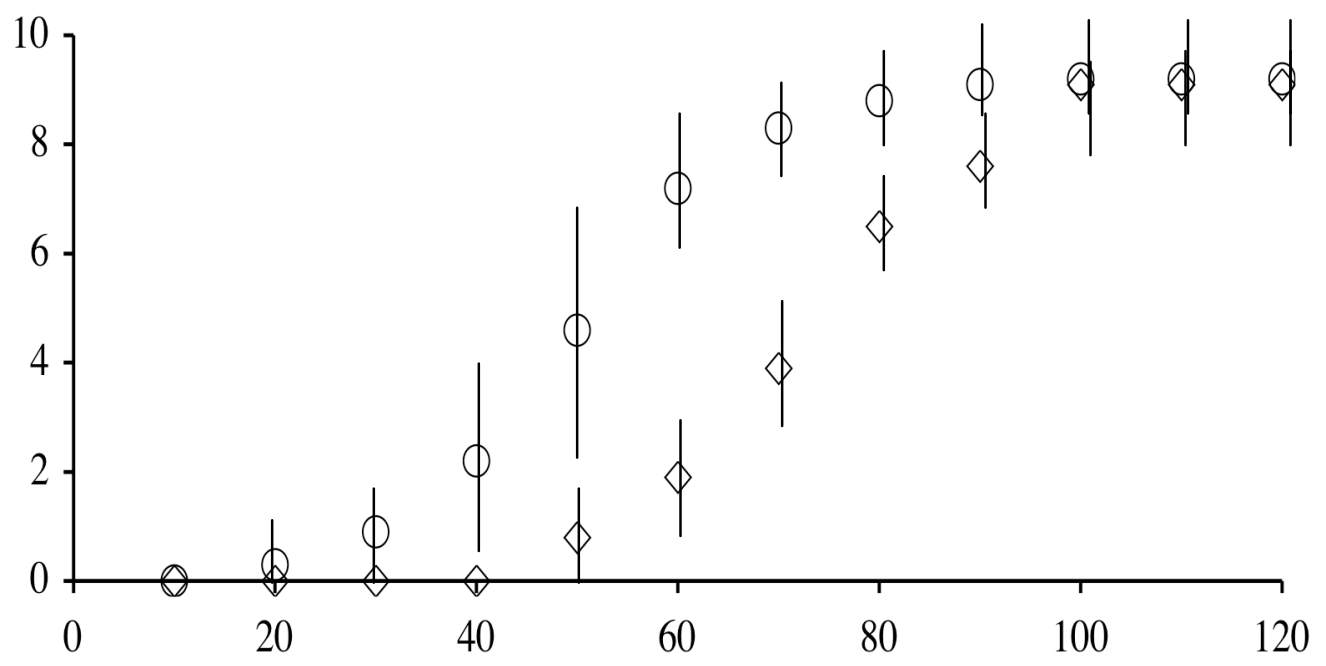

Time since initiation of playback in minutes

Chorus sites with active speakers

$\diamond$ Chorus sites with mute speakers 
Figure 3. Effect of acoustic stimuli on the daily onset of chorus formation in treefrogs. Playback started one hour before sunset (time 0), males calling from choruses with active speakers descended earlier to the chorus. Data were pulled together and averaged for all days for each species. Sixteen paired localities were sampled for both species for a total of $\mathrm{N}=32$ nights. Circles represent frogs calling from chorus sites with active speakers; rhomboids represent frogs calling from choruses with mute speakers; lines represent error bars. 

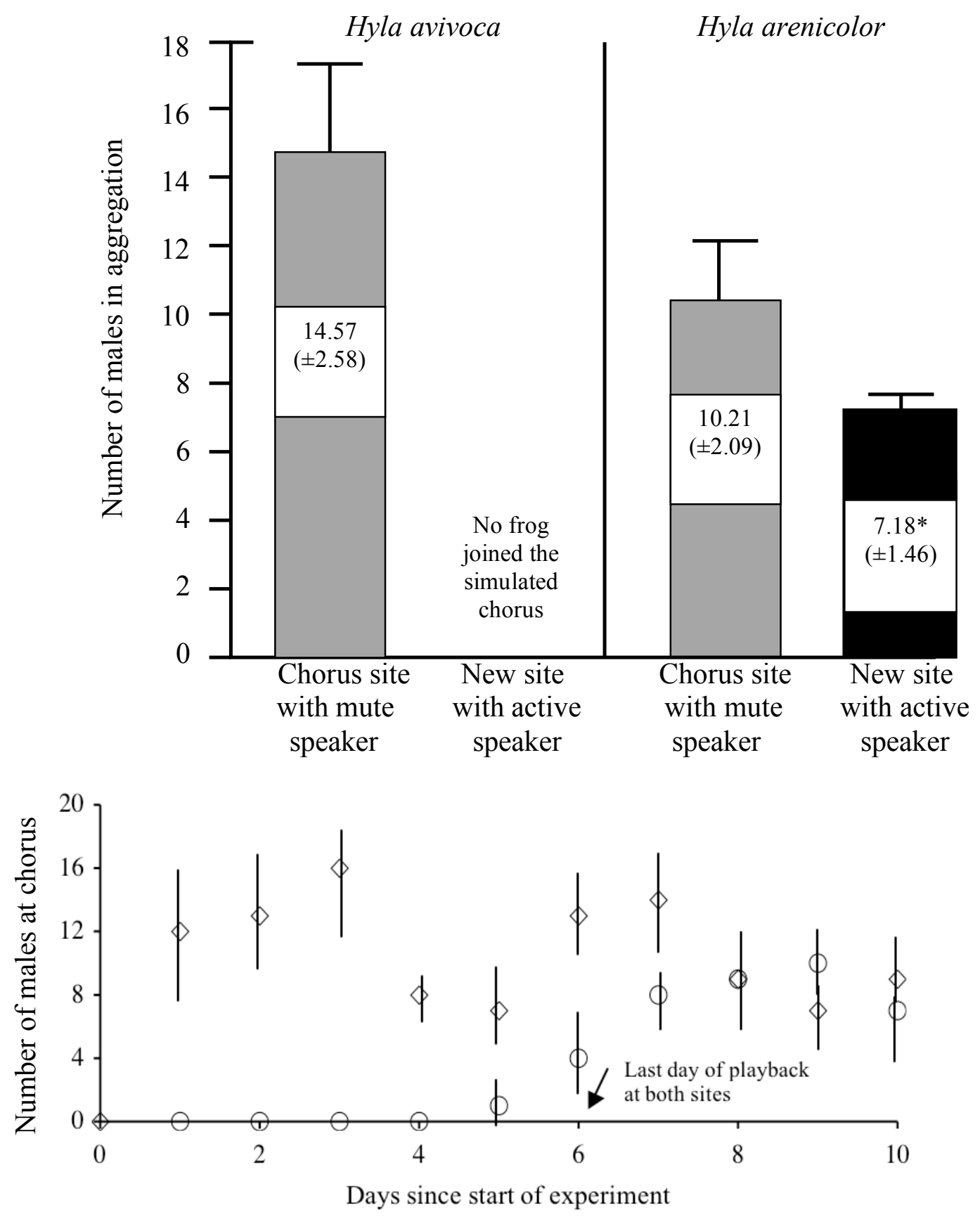

New sites with active speakers $\diamond$ Chorus sites with mute speakers

Figure 4. A. Average number of males present at the novel and occupied chorus sites) B. Average number of $H$. arenicolor males visiting aggregations $(n=10$ paired aggregations) each night. The speakers broadcast advertisement calls from novel, unoccupied sites for six consecutive nights. Circles represent the traditional chorus sites with mute speakers; rhomboids represent new sites with active speakers; lines represent error bars. 


\section{Experiment 3: Do male $\boldsymbol{H}$. avivoca assess the attractiveness of calling neighbors?}

A summary of the results can be found on Table 3. Significantly more males settled next to the speaker broadcasting longer calls than to the short call or the control treatment (binomial distribution, $P=0.014$ ). Males that settled next to the long-caller speaker produced longer calls than did males that settled next to the short calls and males calling in the control site (Repeated Measures ANOVA; FTest $=13.6 ; P=0.01, \mathrm{df}=7)$. There were no significant differences in call length, call rate and inter-male distance between males that settled near the short call treatment and control treatment. 
Table 4. The first three columns show the mean values (SD) for the temporal parameter and chorus environment of the focal $H$. avivoca males tested for the effect of neighbors calls on choice of calling site and acoustic performance. The last column shows the locality of the males that settled first in the chorus. The experiment was conducted on 30 nights, on five occasions males settled in places away from the active speakers. However in 18/25 males that settled next to an active speaker settled next to the speaker producing long advertisement call (binomial probability; $P=0.014$ ).

\begin{tabular}{ccccc}
\hline Type of playback & $\begin{array}{c}\text { Calls length in } \\
\text { seconds }\end{array}$ & $\begin{array}{c}\text { Calls per } \\
\text { minute }\end{array}$ & $\begin{array}{c}\text { Distance to } \\
\text { speaker in meters }\end{array}$ & $\begin{array}{c}\text { Number of } \\
\text { males }\end{array}$ \\
\hline Long call & $2.89( \pm 0.76)^{*}$ & $6.07( \pm 1.23)^{*}$ & $1.6( \pm 0.79)$ & $18^{*}$ \\
25 pulses, $2.4 \mathrm{sec}$ & & & & 7 \\
Short call & $2.4( \pm 0.45)$ & $5.04( \pm 0.72)$ & $1.8( \pm 0.91)$ & 7 \\
15 pulses, $1.8 \mathrm{sec}$ & & & & \\
Mute speaker & $2.3( \pm 0.37)$ & $5.13( \pm 1.02)$ & $1.9(0 \pm 0.83)$ & 5 \\
\hline
\end{tabular}




\section{Discussion}

\section{Role of acoustic cues on the onset and location of chorus formation.}

Empirical evidence suggests that males use environmental cues to return to a breeding site (Murphy 2004) or colonize a new one (Höbel 1999), but little is known about the role which acoustic signals play in attracting frogs to a new chorus site. Studies of the role of advertisement calls as acoustic cues used in orientation towards suitable breeding habitat suggest that some species, particularly those with a short reproductive window might benefit from doing so (Bee 2007). The wood frog, Rana sylvatica, has a short breeding season that may last only a few days and males need to find the breeding aggregation quickly in order to breed. Bee (2007) demonstrates that males show a positive phonotaxis towards playbacks of a conspecific chorus and suggest that acoustic calls help males localize these aggregations. Males displaying in a chorus are in close proximity to other males and call within the active space of the signals of many other individuals (Brenowitz 1982). Thus, it is possible that other frogs locate choruses by assessing the calls of other males.

The seasonal- and daily-onset experiments performed with $H$. avivoca and daily- onset experiments conducted with $H$. arenicolor clearly indicate that acoustic signals from the chorus influence calling behavior of males in aggregations. Males joining artificial choruses support the hotshot model for chorus formation, suggesting that males approach the signals of more competitive males that arrive earlier at a chorus site. These experiments demonstrate the importance and reliability of acoustic signals in attracting individuals to a chorus 
and help to explain the evolution of the aggregative behavior of males because of a communication network, in which all signaling individuals interact as senders and receivers (McGregor and Peake 2000).

The failure of the playbacks to move the location of calling bird-voiced treefrogs or to attract new callers to the simulated chorus provides evidence against the chorus attraction model in this species. Canyon treefrogs, however, readily formed new choruses in a new site after a few days of chorus playbacks. Both kinds of frogs call from small, dispersed choruses; nonetheless, the chorusing behavior of each species differs greatly. Bird-voiced treefrogs descend from the canopy to call during chorusing hours (Chapter 3), whereas $H$. arenicolor are more active during the day (Stebbins 2003). Field observations suggest that $H$. avivoca might be highly philopatric during the breeding season, with males returning nightly to the same calling perches (Martínez Rivera, unpublished). In addition, the calling habitat of $H$. avivoca is limited to flooded forest and swamps in and near wooded bottomlands. Hence, joining a new chorus might not be ecologically feasible for a species with potentially little movement and territorial behavior. $H$. arenicolor lives in riparian habitat on a patchy dry environment. Males typically call from swift flowing creeks and small streams, disperse loosely in groups along the quieter areas of the body of water, and call for a short nightly window of about three hours. Some males call from the same site on repeated nights while others can be seen moving about at night between groups of calling males (Martínez Rivera, unpublished). 
More research is needed to determine if males $H$. arenicolor engage in active mate searching like $R$. sylvatica. However, it seems more plausible that males are looking for new breeding areas. Some of the more localized calling areas within the creek can dry quickly, and males might need to search for new sites within a night. If they do so, then showing positive phonotaxis towards a group of calling males would be advantageous.

These findings highlight the need for more extensive and comparative data to test if males assess the quality of calling neighbors when settling in a chorus, and if the quality of neighbors influences the calling behavior and possible mating success of the focal male (both predictions of the hotshot model). My data show that males will approach a male producing attractive calls, but males might also be attracted in greater numbers to simulated choruses composed of attractive males than to simulated choruses of average or unattractive males. In addition, more data are needed to learn if the choice of the location of the aggregation and calling site within the aggregation is influenced by the calls of other males. If frogs were attracted to a new site regardless of the relative attractiveness of founding males, this would constitute evidence for the chorus attraction model. If frogs were attracted to the new site only when males producing attractive calls were founders, then this would be evidence for the hotshot model. These two hypotheses are not mutually exclusive because they both predict attraction of males by sound to a new location. Such results would constitute evidence against the hotspot model because males would be forming a chorus without a tradition of female attendance. 


\section{Effect of neighbors calls on choice of calling site and acoustic performance.}

Males were influenced by the calling behavior of neighbors. The majority of males settled next to a speaker that simulated a caller emitting long attractive calls. The hotshot theory of lek formation proposes that displaying males should actively search for attractive males and display near them (Beehler and Foster 1988). These results suggest a proximate explanation for the aggregative behavior males, since there are possible fitness benefits obtained by associating with a particular male. If a caller has a greater chance of attracting females, then a given male might benefit by calling in close proximity to this 'sexy' male. In $H$. versicolor, longer calls are known to be more attractive to females (Gerhardt 2005).

Alternatively, a male calling next to a male of lesser quality might benefit by spending less energy and still being more attractive. This scenario is highly unlikely because females of both species (H. avivoca, Chapter 2; H. arenicolor, unpublished data) prefer long calls (Chapter 2) and would be expected to select against males with short calls. In addition, I have shown that males preferentially associate with the more attractive of two signals and change their calling patterns in ways that make their calls more attractive to females when compared to males calling next to less attractive signals.

In general, the calling patterns of frogs and insects become increasingly complex as group size increases, presenting a difficult challenge for researchers trying to understand the evolutionary advantages of chorusing behavior and the effectiveness of mate choice in a chorus. However, treating each signaler (and 
receiver) in a chorus as part of a communication network would help uncover the patterns of these interactions. In a communication network (sensu McGregor and Peake 2000), any member (signaler or receiver) of the network (i.e. chorus) can gain information from an interaction among other signalers and influence its behavior accordingly and any receiver may use this information in order to gauge the qualities of possible rivals and mates. Males gain information from multiple calling neighbors that enable them to assess the quality of their rivals and adjust their calling accordingly. Females in a communication network obtain valuable information on male quality via male-male vocal interactions that could be used to assess the quality of potential mates (Mennill et al. 2002).

\section{Literature Cited}

Alexander RD. 1975. Natural selection and specialized chorusing in acoustical insects. In: Insects, science and society, ed. D. Pimentel, 35-77. NY: Academic Press

Andersson M. 1994. Sexual Selection. Princeton University Press, Princeton, NJ

Barber PH. 1999. Phylogeography of the canyon treefrog, Hyla arenicolor (Cope). Molecular Ecol. 8:563-76

Beehler BM, Foster MS. 1988. Hotshots, hotspots, and female preference in the organization of lek mating systems. Am. Nat, 131:203-219 
Bradbury JW. 1981. The evolution of leks. In: Natural Selection and Social Behavior. Chapter 9. R.D. Alexander and D. Tinkle, ed(s). Chiron Press, NY, Sunderland, Mass.: SinauerAssociates

Brenowitz EA. 1982. The active space of Red-winged black bird song. J. Comp Physiol. A. 147:511-522

_. 1989. Neighbor call amplitude influences aggressive behaviour and inter-male spacing in choruses of the Pacific treefrog (Hyla regilla). Ethology 83: 69-79

da Silva HR. 1997. Two character states new to hylines and the taxonomy of the genus Pseudacris. J Herp. 31: 609-613

Duellman WE. 2001. Hylid frogs of Middle America. St. Louis, MO. Society for the Study of Amphibians and Reptiles

Duellman WE, Trueb L. 1994. Biology of Amphibians. NY: McGraw-Hill

Dundee HA, Rossman DA. 1996. The Amphibians and Reptiles of Louisiana. 1996 Paperback Ed. Louisiana State University Press. P. 87-89 
Emlen ST, Oring LW. 1977. Ecology, sexual selection and the evolution of mating systems. Science 197: 185-93

Gerhardt HC. 1991. Female mate choice in treefrogs: Static and dynamic acoustic criteria. Anim. Behav. 42: 615-35

_. 1994. Reproductive character displacement of female mate choice in the grey treefrog Hyla chrysoscelis. Anim. Behav. 47: 959-69

_. 2001. Acoustic communication in two groups of closely related treefrogs. In Advances in behavioral biology, ed. Rosenblat PJB, Snowdon CT, Roper,TJ. 99167 NY: Academic Press

_. 2005a. Advertisement-call preferences in diploid-tetraploid treefrogs (Hyla chrysoscelis and Hyla versicolor): implications for mate choice and the evolution of communication systems. Evolution 59:395-408

Gerhardt HC, Huber F. 2002. Acoustic communication in insects and anurans. The University of Chicago Press, Chicago

Gerhardt HC, Diekamp B, Ptacek M. 1989. Inter-male spacing in choruses of the spring peeper, Pseudacris (Hyla) crucifer. Anim. Behav. 35:1490-503. 
Greenfield MD. 1992. The evening chorus of the desert clicker, Ligurotettix coquilletti (Orthoptera: Acrididae): mating investment with delayed returns. Ethology 91: 265-278

_. 1994. Synchronous and alternating choruses in insects and anurans: Common mechanisms and diverse functions. Am. Zool. 34:605-15

_. 2002. Signalers and receivers: Mechanisms and evolution of arthropod communication. Oxford: Oxford University Press

Greenfield MD, Rand S. 2000. Frogs have rules: Selective attention algorithms regulate chorusing in Physalaemus pustulosus (Leptodactylidae). Ethology 106: $331-47$

Höbel G. 1999. Facultative nest construction in the gladiator frog Hyla rosenbergii (Anura: Hylidae). Copeia 3: 797-801

Höglund J, Alatalo RV. 1995. Leks. Princeton: Princeton University Press

Klump GM, Gerhardt HC. 1992. Mechanisms and function of call-timing in malemale interactions in frogs. In Playback and studies of animal communication: Problems and Prospects. NATO Advanced Research Workshop (P. Mc Gregor ed.) pp 1-9, NY Plenum Press 
McGregor PK. 1993. Signalling in territorial systems: a context for individual identification, ranging and eavesdropping. Philos Trans R Soc B 340: 237-244

McGregor PK, Peake TM. 2000. Communication networks: social environments for receiving and signaling behaviour. Acta Ethol. 2: 71-81

McGregor PK, Otte KA, Peake TM. 2000. Communication networks: receiver and signaller perspectives. In. Espmark Y., Amundsen T., Rosenqvist G. (eds) Animal signals. Adaptive significance of signalling and signal design in animal communication. Tapir, Trondheim, pp 405-416

Murphy CG. 2003. The cause of correlations between nightly numbers of male and female barking treefrogs (Hyla gratiosa) attending choruses Behav. Ecol14: 274- 281

Redmer M, Brown LE, Brandon RA. 1999. Natural history of the bird-voiced treefrog (Hyla avivoca) and green treefrog (Hyla cinerea) in Southern Illinois. Illinois Natural History Survey Bulletin. 36:2: 67

Ryan MJ. Ed. 2001. Anuran Communication. London. Smithsonian Institution 
Ryan MJ, MD Tuttle, Taft, LK. 1981. The costs and benefits of frog chorusing behavior. Behav Ecol Sociobiol. 8:273-278

Schwartz JJ. 1993. Male calling behavior, female discrimination and acoustic interference in the Neotropical treefrog, Hyla microcephala under realistic conditions. Behav. Ecol. Sociobiol. 32: 401-414

Schwartz JJ, Buchanan BW, Gerhardt HC. 2001. Female mate choice in the gray treefrog (Hyla versicolor) in three experimental environments. Behav. Ecol. Sociobiol. 49: 443-55.

Sullivan BK. 1982. Male mating behavior in the Great Plains toad (Bufo cognatus). Anim. Behav. 30: 680-96

Welch AM, Semlitsch RD, Gerhardt HC. 1998. Call duration as an indicator of genetic quality in male gray treefrogs. Science. 280: 1928-30

Wells KD. 1977. The social behaviour of anuran amphibians. Anim. Behav. 25: $666-93$

Wells KD, Taigen TL. 1986. The effect of social interactions on calling energetics in the grey treefrog (Hyla versicolor). Behav. Ecol. Sociobiol. 19:9-18 


\section{Chapter 6 General Discussion}

Anuran choruses are great systems to study the evolution of acoustic communication and behavioral ecology. The main experiments of this dissertation demonstrate the conflicts that arise during male-male interactions and how such interactions may affect the calling behavior of males. By calling from dense aggregations, males are faced with competition among senders (Gerhardt and Klump 1988; Wollerman and Wiley 2001) and must alter their calling behavior in order to maintain the acoustic integrity of their calls and increase the chances of being heard and chosen by females (Gerhardt and Huber 2002). Thus males have evolved strategies of advertisement call modification that directly increase signal attractiveness and females have evolved mechanisms to discriminate among clear, uninterrupted calls in order to reduce the risk of mating with the wrong species or of mating with males of lower quality (Wiley 2006; Gerhardt 2005).

In this dissertation, I showed how changes in the calling patterns of males affect the relative attractiveness of signals to females. These changes include increased call duration during male-male interactions, call overlap, and pulse overlap. Males increased call length in response to playbacks of calling males, and females in turn, preferred longer calls. Longer calls increase detectability and attractiveness of calling males, thus a male that produces longer calls increases the chances of being detected in noisy environments (Schwartz et al. 2002). Calling, however, is energetically expensive to frogs (Wells and Taigen 1986); consequently, males increase call length and call rate only when other males are 
present. Moreover, the fact that males revert to producing fewer calls of normal duration suggests that costly, long calls are reliable indicators of male reproductive fitness, since males cannot sustain increased calling activity for long periods (Wells and Taigen 1986).

Call production and signal interference become more evident as more males join the chorus, each producing more calls of longer duration. One for of call interference, as seen in Chapter 2 is the overlap of calls from two or more neighboring males. Call overlap, however, reduces the attractive effect of increasing call duration; females preferred clear, uninterrupted calls (Chapter 2 and 4), even when these calls were shorter than overlapped calls. A secondary tactic, described for the first time in frogs, is adopted by bird-voiced treefrogs. Namely, males engaged in pulse interdigitation during call overlap by increasing the length of the silent interval between calls. Females preferred overlapped signals with interdigitated pulses to overlapped signals in which pulses overlapped partially or completely.

Aggressive calling between males was common, and its production increased significantly as males settled at the chorus site. Playbacks of aggressive calls broadcast during chorus formation attracted the comparable numbers of males as did advertisement calls, suggesting that aggressive calls do not repel males from sitting next to rivals producing such signals. In a classic review of the calling behavior of frogs, Wells (1977) suggested that aggressive calls might benefit males indirectly by limiting the number of males that settle in the immediate calling area within the chorus. The data presented here does not 
support this hypothesis. However, males may be able to settle aggressive disputes without reducing their chances of attracting females by engaging in potentially non-attractive behavior, such as fights, while females are not in the chorus.

Aggressive signals provide information about the current and future behavior of the signaler and presumably indicate its readiness to fight. Game theory predicts that if aggressive signals are not limited by any physiological factor of the signaler (i.e. they are not costly to produce), then aggressive calls are under no reliable constraint (Maynard Smith 1982). In other words, animals are able to effectively 'bluff' other contestants and engage in displays of aggressive behavior even when the chances of losing are greater than the chances of winning an actual fight (Dawkins and Krebs 1978). Maynard Smith (1982) predicted that a signaler could announce intent to fight via aggressive calling.

Most of the physical interactions observed in this study occurred prior to female arrival (Chapter 3 and 4). By engaging in aggressive behavior prior to female arrival, males might eliminate the risk of being unattractive to females unless they are monitoring such behavior from a distance and it influences their mating decisions. Additionally, most of the males evicted from a calling territory resumed calling elsewhere within the same night. If losers are able to resume calling, albeit at a different calling site within the chorus, fighting in $H$. avivoca might not be as evolutionary costly as theory suggests (Zahavi 1977, Grafen 1990). Female choice trials also show that females do not approach aggressive calls alone but do approach advertisement calls produced along with aggressive calls; they also prefer longer advertisement calls even when presented along with 
aggressive calls. Finally, females do not approach advertisement calls overlapped by aggressive calls (Chapter 4). Moreover, females join the chorus and choose between calling males later in the evening, when aggressive-call production is less. I propose that by producing aggressive calls earlier in the evening, males are able to settle aggressive disputes with little impact on their chance of being selected by a female. Nonetheless, the data do not show if females avoid males that produce mostly aggressive calls. To answer that question, a series of artificial choruses could be presented in which each artificial chorus broadcasts combinations of advertisement and aggressive calls in different proportions. I would predict that females will join artificial choruses without aggressive calls earlier than artificial choruses with aggressive calls and will possibly avoid choruses where only or mostly aggressive calls and fast-rate aggressive calls are being broadcast.

Males reacted aggressively to playbacks of advertisement and aggressive calls that simulated a close neighbor. In contrast, males presented with aggressive calls simulating a distant neighbor or together with advertisement calls showed a delayed aggressive response (Chapter 4); they increased advertisement call length and then produced aggressive call bouts. The different responses of males to different combination of aggressive calls suggest that males can assess the potential threat posed by the intruder. Males also escalate in the aggressiveness of their response by showing their intent to fight when playbacks continues to play after a male reacts with aggressive calls.

There are immediate direct and indirect benefits to an escalated response. 
First, males will increase the chance of being detected and enhance attractiveness to females by increasing call length prior to producing aggressive calls. Second, if an intruder does not cease to call, a male might be able to attract females while still responding to a threat from a neighboring male by interspersing aggressive calls between longer advertisement calls. Third, a male might successfully evict a male from the calling arena without the necessity of a fight by producing fast-rate aggressive calls in response to that male. Finally, if all else fails, a fighting encounter between the males will ensure that one of the males is evicted from the immediate calling area, with the loser is left to find a different calling site.

Lastly, the social context of a calling male and the aggressive intent of the signal presented to a male almost invariably predicted the outcome of an aggressive interaction. Males respond aggressively to a neighbor that demonstrates its intent to escalate in aggression and fight. Males responding to this threat will have to "decide" if they want to fight or not. Game Theory predicts that an animal should accurately display its intent to engage in a fight and announce its resource holding potential (RHP; Parker 1974). Males, however, can also engage in bluffing and produce a dishonest signal that may show intent to fight but provides do information whereby challengers can assess the fighting abilities of the signaler (Dawkins and Krebs 1978).

On the one hand, most of the research on agonistic interactions studies the evolution of fighting behavior (Jakobsson et al.1995) and the rules of rival assessment prior to a fight (Gardner and Morris 1989). Bird-voiced treefrogs, on the other hand, engage on ritualize bouts of aggressive calling. I propose that 
aggressive calling in lekking treefrogs evolved as an Evolutionarily Stable Strategy (ESS) for animal contests (Manyard-Smith and Price 1973; ManyardSmith 1982) that would allow males to behave agonistically without engaging in costly fights. As predicted by the War of Attrition model (Manyard-Smith 1982), an ESS will arise whenever disputes are settled by conventional displays with no assessment of the opponent's fighting ability.

My seasonal onset-of-chorus activity trials showed that acoustic signals serve as cues used to determine the onset of chorus formation. Male $H$. avivoca and H. arenicolor approach a chorus site earlier in the season and earlier in the evening during the breeding season if conspecific advertisement calls are broadcast from the site, even when no frogs are calling in these areas. The chorus attraction experiments showed that, whereas males of $H$. avivoca did not approach playbacks of conspecific calls from novel areas, males of $H$. arenicolor will form new breeding choruses if calls are broadcast from these new sites. Moreover, females were attracted to calling males at the new sites.

Separate playbacks of the calls of different species should be used to generalize the statement that acoustic signals serve as cues to determine the onset of chorus formation. Speakers broadcasting burst of white noise and speakers with broadcasting white noise with the correct temporal parameters of the species being tested can be used to determine what aspects of the calls frogs use as cues when approaching a chorus. Only if frogs approach such artificial choruses, then a stronger, more general statement could be made about the role of acoustic cues in attracting frogs to a chorus. Bee (2007) shows that more male wood frogs (Rana 
sylvatica) approached a speaker broadcasting a conspecific chorus than silent speakers in a multi speaker test on a testing arena. In the same set of experiments, more male wood frogs approached the speaker broadcasting the conspecific chorus than those of $R$. septentrionalis, a sympatric species with a call that has a similar spectral range (Bee 2007). My experiments were conducted in the field, under natural ambient conditions and where speakers would attract males from their natural environment. More controlled experiments, similar to those in Bee (2007), might yield a different result.

Preliminary data gathered in 2003 and 2004 suggest that males may preferentially approach a site with calling males instead of settling in a silent site at the time of chorus formation. In this experiment, different groups of $8 \mathrm{H}$. avivoca males, from a pool of 24 collected from Mississippi, were released into an enclosed, artificial pond with (internal diameter of 5.2m; see Schwartz et al. 2001 for a detailed description of the artificial pond). The frogs were left to form a chorus by calling from previously arranged perches that had active or mute speakers. Each side of the enclosure had two wooden $\mathrm{H}$ frames (each vertical pole measuring $2 \mathrm{~m}$ and the horizontal beam measuring $1.6 \mathrm{~m}$ ) as calling perches. Each of the four $\mathrm{H}$ frames was equipped with four PVC pipes that served as refugia for the frogs to settle before calling (each pipe was $2.5 \mathrm{~cm}$ in diameter and $10 \mathrm{~cm}$ long, pipes were placed at a height of 1.4 and $1.8 \mathrm{~m}$ on the vertical poles of each H frame). A pair of GS 10 (T-Sound) omnidirectional speaker (TIC corporation) was set on each side of the enclosure on at the base of each $\mathrm{H}$ frame. The eight frogs were released earlier in the day on the artificial pond (usually at $3 \mathrm{pm}$ ). 
Artificial rain was simulated by turning on a sprinkler above the pond enclosure at $6 \mathrm{pm}$ and let run for two hours, excess water drained the pond through an overflow system. A speaker set on one side of the arena broadcast calls for an hour from 8:30 until 9:30pm at an intensity of $86 \mathrm{~dB}$ SPL at $1 \mathrm{~m}$. An observer who was inside the enclosure before the playback started, noted the position and time of the first male that called. At the end of the experiment the total number and position of males was also counted. Each night the frogs were returned to the pool of 24 males and a new set of males was used every other day. The experiment ran for 6 days on each season. Not enough data were obtained to gather statistically relevant data, and concerns about independence of data points prevented me from using the result of this experiment on the data chapters. However, a larger proportion of males (average of $5.2(+/-1.6)$ males, the 8 used daily) called on or next to the $\mathrm{H}$-frames with the active speakers. These preliminary results suggest that when male $\mathrm{H}$ avivoca are prevented to join a chorus on a traditional site, they will preferentially select a site where speakers broadcast calls.

Females did not join choruses during the early season and early onset experiments. Moreover, as I showed in Chapter 3, female H. avivoca do join the chorus later in the evening after males have settled. So, given the time constrains of the experiments conducted in this dissertation, such data could not have been obtained. In order to determine if females use acoustic signals as cues to join a chorus, arriving males should be removed from the artificial chorus before they start to call. The arrival time of females joining these artificial choruses should be compared with the arrival times of females joining control choruses sites without 
speakers and experimental chorus sites without speakers where males have also being removed. Murphy (2003) found that females of $H$. gratiosa approached chorus sites in similar numbers when calling males where removed as they joined to call and when the chorus was left to form normally. However, by comparing arrival times to the different treatments and the density of females at each sites, and correcting these data for seasonal differences and possible differences due to weather, it would be possible to determine the strength of a response from the females that did approach an aggregation.

Lastly, I tested the prediction that males would call next to males producing longer calls preferred by females. This prediction, supports the hotshot model of lekking behavior, where a male would display next to an attractive male in an effort to increase its chances of encountering females by being next to an attractive male. Males did approach speakers broadcasting longer calls; however, these males produced longer calls than males calling in isolation or males that settled and called next to speakers that broadcast short calls. Hence, males that approached 'hotshot' speakers also produced more expensive, attractive calls.

An interactive playback system, in which the length of the calls broadcast from two speakers could be modified by the researcher, would be a way to overcome this problem. The researcher can reduce the length of the calls of the 'hotshot' speaker after the male settled and started to call or alternatively, the researcher can increase the length of the call of the short call speaker. By observing the behavior of the focal male after the switch in the call length of the speaker, a researcher could determine if a male prefers to display next to an 
attractive 'hotshot' male. A trend supporting the hotshot model for chorus formation could be determined if the focal male moves away from the 'hotshot' speaker and approaches the short call speaker after the researcher has manually increased the length of these calls. If males settle preferentially next to the 'hotshot' speakers and stay there after the call length has been reduced, it would provide partial support of the model.

\section{Literature Cited}

Bee MA. 2007. Selective phonotaxis by male wood frogs (Rana sylvatica) to the sound of a chorus Behav Ecol Sociobiol 61:955-966

Dawkins R, Krebs JR. 1978. Animal signals: information or manipulation? In Behavioural Ecology: Krebs JR, Davies NB(eds) Oxford: Blackwell. pp 282-309.

Gardner R, Morris MR. 1989. The evolution of bluffing in animal contests: An ESS approach. J of Theor Biol. 137:235-243

Gerhardt, HC. 2005. Advertisement-call preferences in diploid-tetraploid treefrogs (Hyla chrysoscelis and Hyla versicolor): implications for mate choice and the evolution of communication systems. Evolution 59, 395-408

Gerhardt HC, Huber F. 2002. Acoustic communication in insects and anurans: common problems and diverse solutions. University Press, Chicago 
Gerhardt HC, Klump GM. 1988. Masking of acoustic signals by the chorus background noise in the green treefrog: a limitation on mate choice. Anim Behav $36: 1247-1249$

Grafen A. 1990. Biological signals as handicaps. Anim. Behav. 46, 759-64.

Jakobsson S, Brick O, Kullberg C. 1995. Escalated fighting behaviour incurs increased predation risk. Anim. Behav. 49: 235-239

Maynard Smith J. 1982. Evolution and the Theory of Games. Cambridge University. Press, London.

Maynard Smith J, Price GR. 1973. The logic of animal conflict. Nature 246, 1518.

Murphy CG. 2003. The cause of correlations between nightly numbers of male and female barking treefrogs (Hyla gratiosa) attending choruses. Behav Ecol $14: 274-281$

Parker GA. 1974. Assessment strategy and the evolution of animal conflicts. J. Theor. Biol. 47, 223-40. 
Schwartz JJ, Buchanan BW, Gerhardt HC. 2001. Female mate choice in the gray treefrog (Hyla versicolor) in three experimental environments. Behav Ecol Sociobiol 49: 443-455

Schwartz JJ, Buchanan BW, Gerhardt HC. 2002. Acoustic interactions among male gray treefrogs Hyla versicolor, in a chorus setting. Behav Ecol Sociobiol 53:9-19

Wells KD. 1977. The social behaviour of anuran amphibians. Anim Behav 25:666-693

Wells KD, Taigen TL. 1986. The effect of social interactions on calling energetics in the gray treefrog (Hyla versicolor) Behav Ecol Sociobiol 19:9-18

Wiley RH. 2006. Signal Detection and Animal Communication. In: Advances in the study of behavior, vol. 36, Kumar SS ed. pp 217:247

Wollerman L, Wiley RH. 2002. Background noise from a natural chorus alters female discrimination of male calls in a Neotropical frog. Anim Behav 63: 15-22

Zahavi A. 1977. The cost of honesty (further remarks on the handicap principle).

J. Theor. Biol. 67, 603-5 


\section{VITA}

Carlos César Martínez Rivera was born on February 4, 1979 in Mayagüez

Puerto Rico. His family moved to San Juan early in his life and he graduated from Colegio del Espíritu Santo, Hato Rey Puerto Rico in 1996. He returned to Mayagüez to attend Universidad de Puerto Rico- Recinto Universitario de Mayagüez, and graduated in 2001 with a Bachelors in Biological Sciences with a minor in Botany and Zoology. As an undergraduate, Carlos participated in multiple aspects of research, specifically in habitat restoration, invasive species, and behavior of Caribbean land iguanas. Right after graduation, Carlos initiated his doctorate degree in the laboratory of Carl Gerhardt at the University of Missouri-Columbia in 2001. As a graduate student, he participated in numerous extracurricular activities, such an OTS Course, Herpetofaunal surveys in Ecuador and he help carry a tropical Ecology course with Tim Holtsford. He finished his doctorate studies in July, 2008.

Carlos is Curator of Reptiles and Amphibians and Amphibian Conservation Biologist at the Philadelphia Zoo. He oversees the live collection of reptiles and amphibians at the Zoo and executes the on-site and ex-situ conservation program for amphibians. The program focuses on the conservation and reintroduction of endangered amphibians from South America and the Caribbean through captive propagation, research and community-based monitoring programs to ensure the long-term survival of these species. 